\title{
Micro-CHP Systems for Residential Applications Final Report
}

\author{
June 2006 \\ Prepared by \\ United Technologies Research Center \\ 411 Silver Lane \\ East Hartford, CT 06108 \\ Prepared for \\ U.S. Department of Energy \\ National Energy Technology Laboratory \\ Contract No. DE-FC26-04NT42217 \\ 626 Cochrans Mill Road \\ P.O. Box 10940 \\ Pittsburgh, PA 15236-0940 \\ Technical Contact: \\ Timothy DeValve, Benoit Olsommer \\ UTRC Micro-CHP Project Leaders \\ (860) 610-7286, (860) 610-7463
}

devalvtd@utrc.utc.com,olsommbc@utrc.utc.com

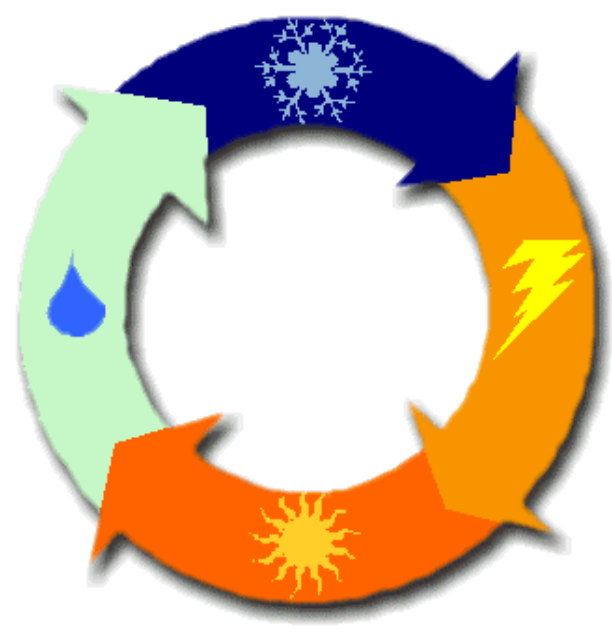




\section{DISCLAIMER}

This report was prepared as an account of work sponsored by an agency of the United States Government. Neither the United States Government nor any agency thereof, nor any of their employees, makes any warranty, express or implied, or assumes any legal liability or responsibility for the accuracy, completeness, or usefulness of any information, apparatus, product, or process disclosed, or represents that its use would not infringe privately owned rights. Reference herein to any specific commercial product, process, or service by trade name, trademark, manufacturer, or otherwise does not necessarily constitute or imply its endorsement, recommendation, or favoring by the United States Government or any agency thereof. The views and opinions of authors expressed herein do not necessarily state or reflect those of the United States Government or any agency thereof. 


\section{Table of Contents}

1 Executive Summary ........................................................................................................................1

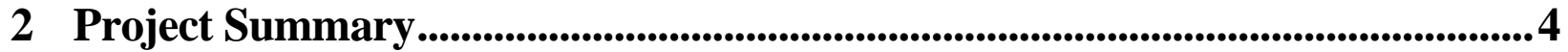

2.1 Project Approach .........................................................................................................................4

2.2 Report Organization............................................................................................................................6

3 Market Analysis..................................................................................................................8 8

3.1 World Market Characteristics........................................................................................................8

3.2 U.S. Market Characteristics .......................................................................................................9

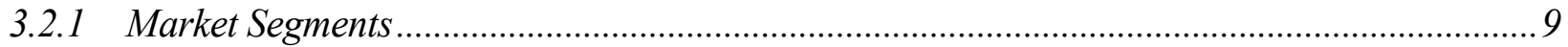

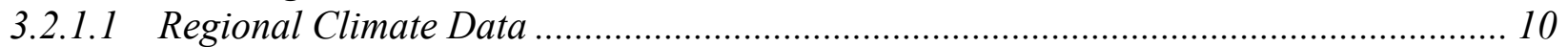

3.2.1.2 Regional Annual Energy Consumption \& Expenditure Data ...................................... 11

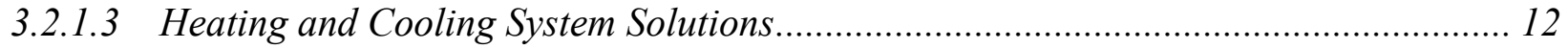

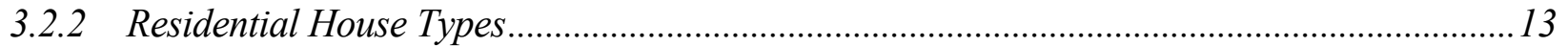

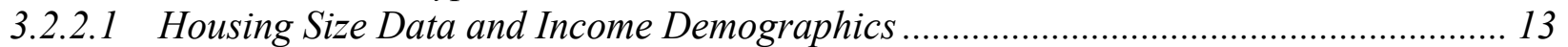

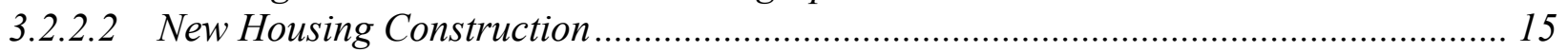

3.2.2.3 Energy Consumption and Expenditure in Target States........................................... 17

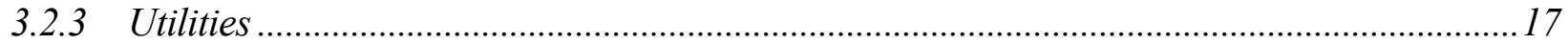

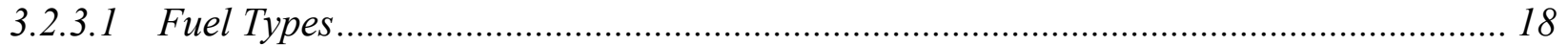

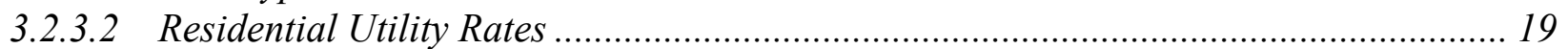

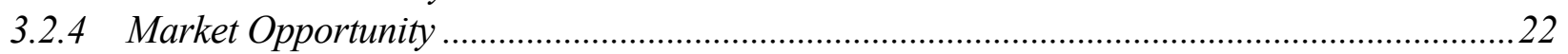

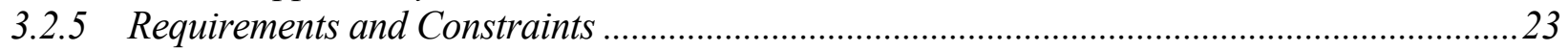

4 Technology Assessment ............................................................................................226

4.1 Technology Options ......................................................................................................................26

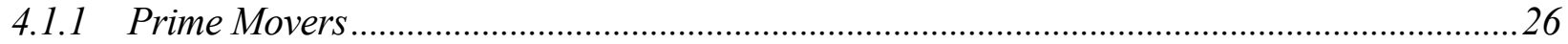

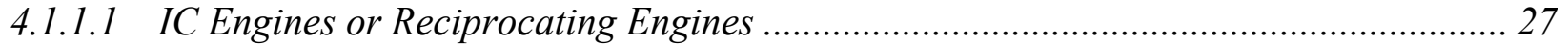

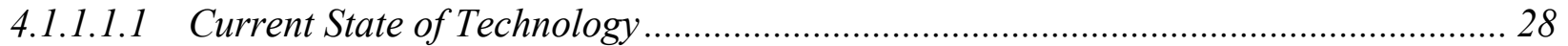

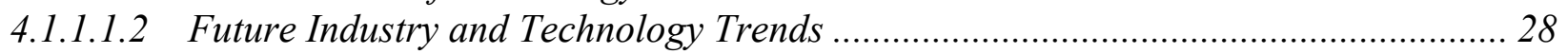

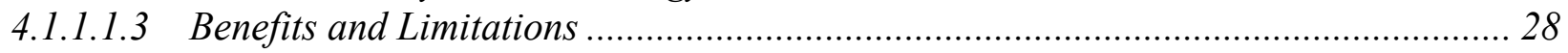

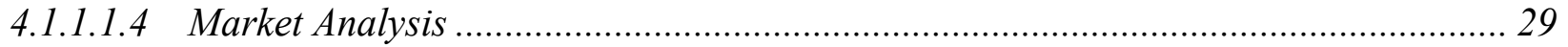

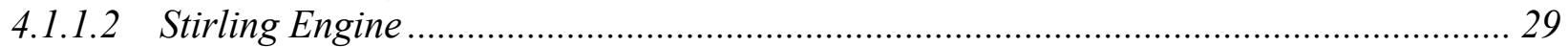

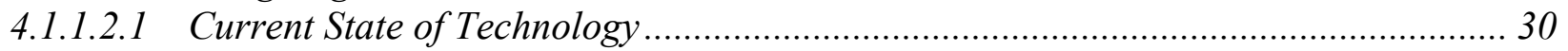

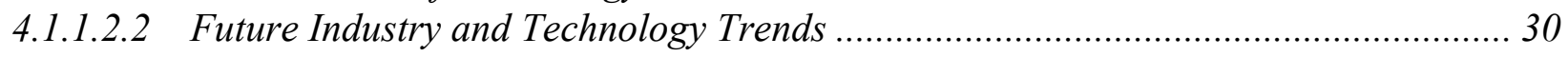

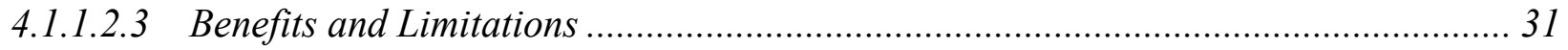

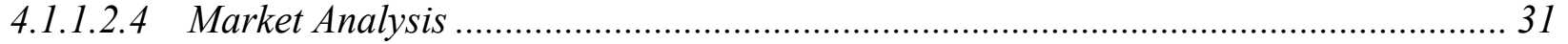

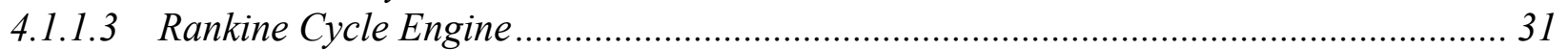

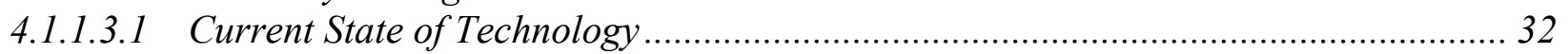

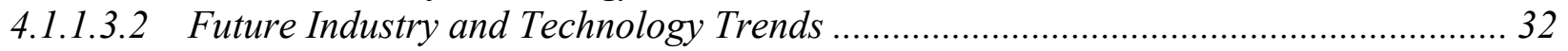

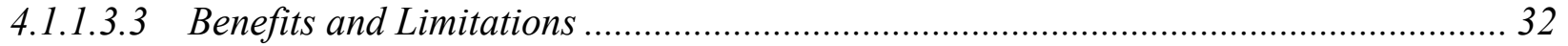

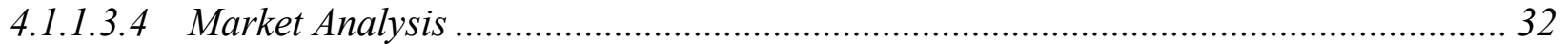

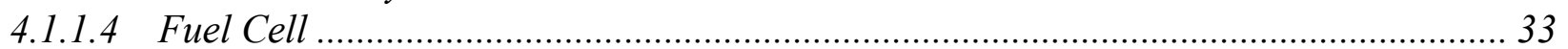

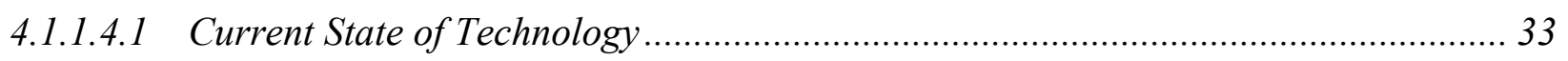

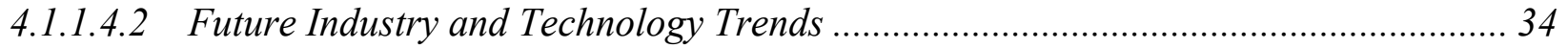

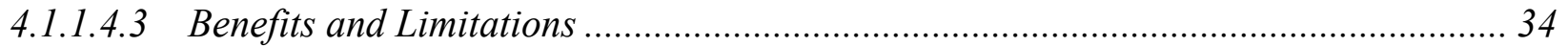




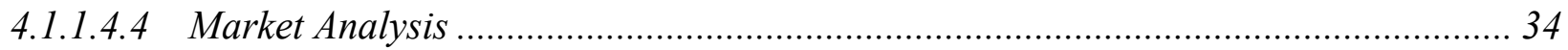

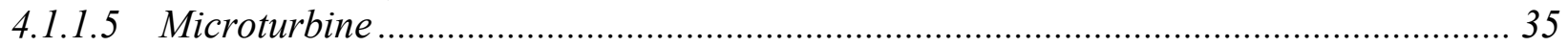

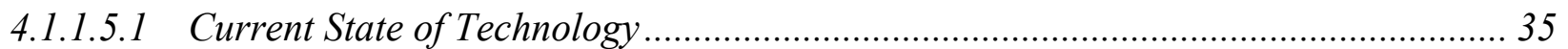

4.1.1.5.2 Future Industry and Technology Trends ............................................................ 36

4.1.1.5.3 Benefits and Limitations ................................................................................. 36

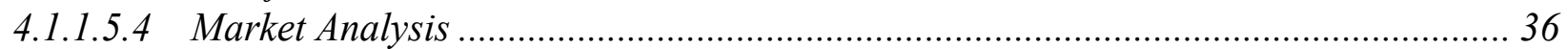

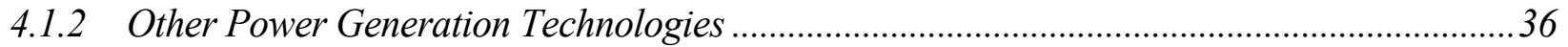

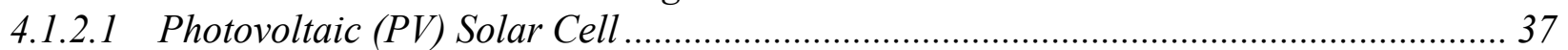

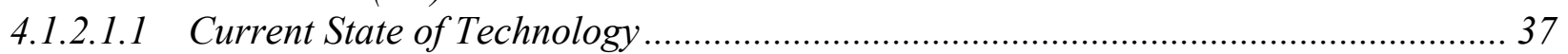

4.1.2.1.2 Future Industry and Technology Trends ............................................................. 38

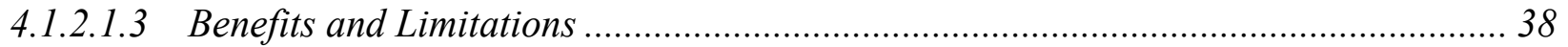

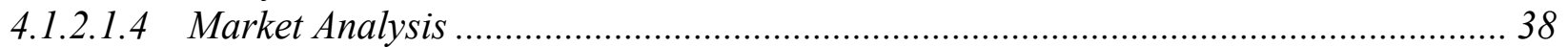

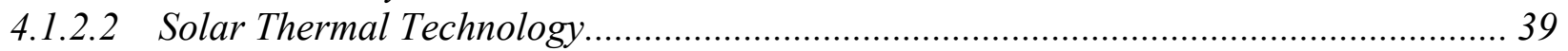

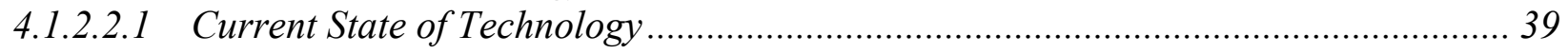

4.1.2.2.2 Future Industry and Technology Trends ............................................................ 40

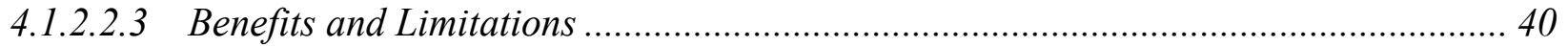

4.1.2.2.4 Market Analysis .................................................................................................... 40

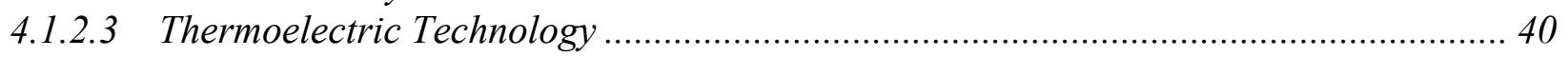

4.1.2.3.1 Current State of Technology ............................................................................. 41

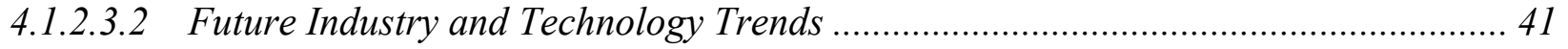

4.1.2.3.3 Benefits and Limitations ....................................................................................... 42

4.1.2.3.4 Market Analysis ............................................................................................ 42

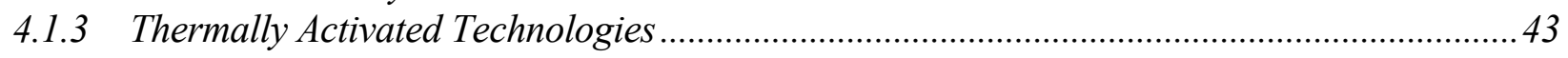

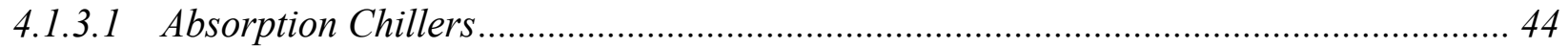

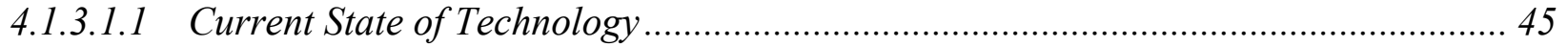

4.1.3.1.2 Future Industry and Technology Trends ............................................................. 46

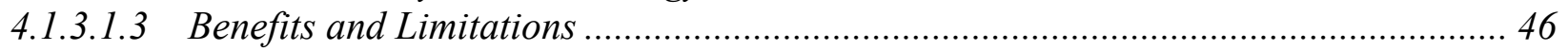

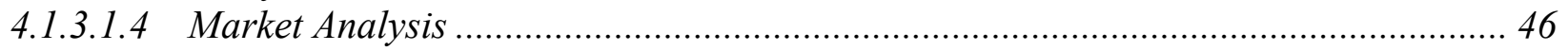

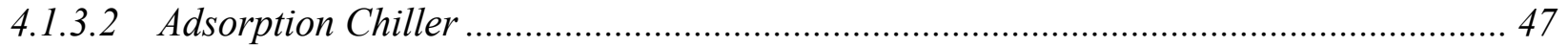

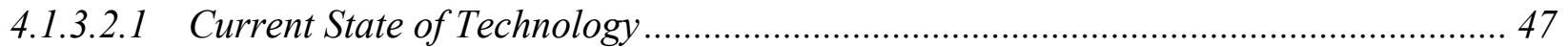

4.1.3.2.2 Future Industry and Technology Trends .......................................................... 48

4.1.3.2.3 Benefits and Limitations ................................................................................. 48

4.1.3.2.4 Market Analysis .................................................................................................. 48

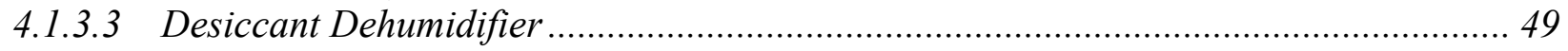

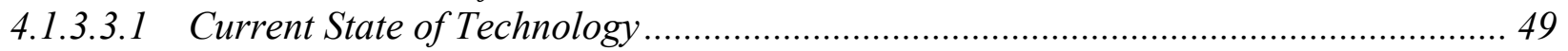

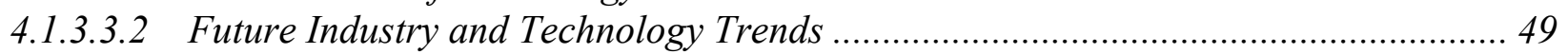

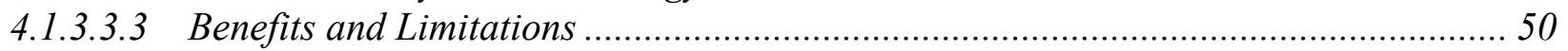

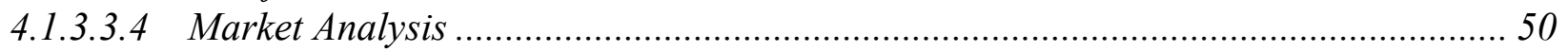

4.1.3.4 Heat Recovery Exchanger / Boiler ...................................................................... 51

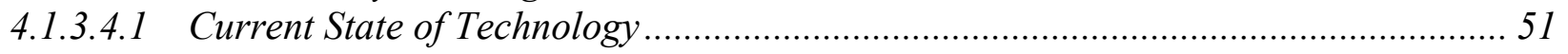

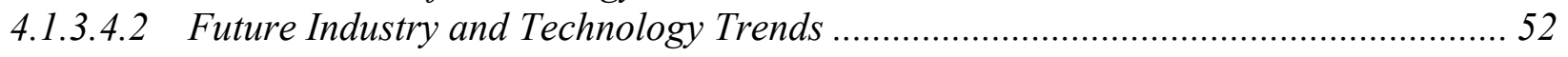

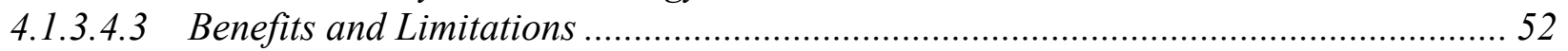

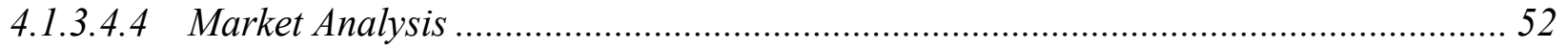

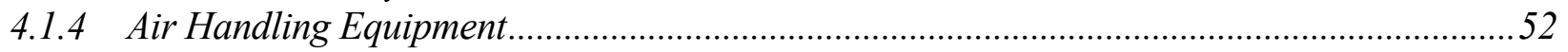

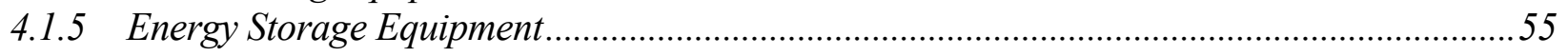

4.1.5.1 Electrical Energy Storage Devices ................................................................ 55 
4.1.5.1.1 Electrochemical Energy Storage ......................................................................... 55

4.1.5.1.2 Electromagnetic Energy Storage ........................................................................... 57

4.1.5.1.3 Electromechanical Energy Storage .................................................................. 57

4.1.5.2 Thermal Energy Storage ...................................................................................... 59

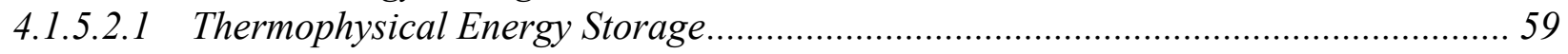

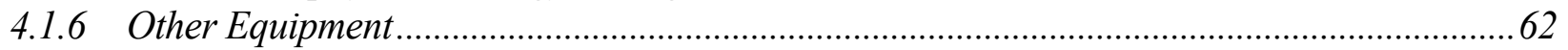

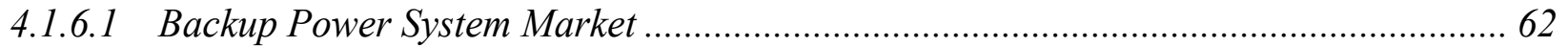

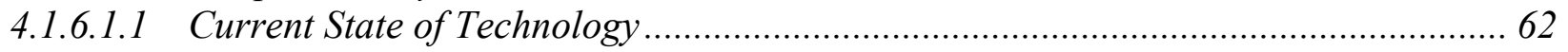

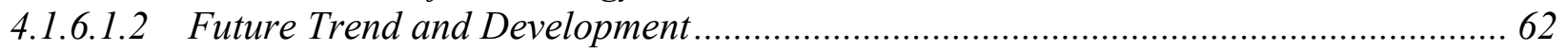

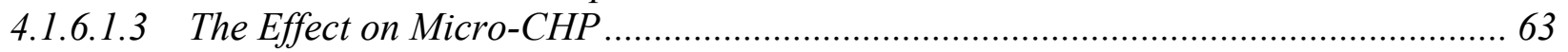

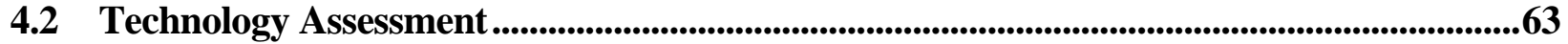

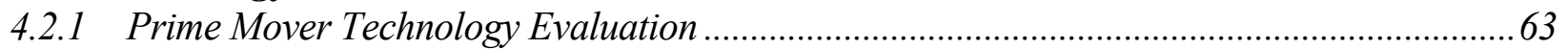

4.2.2 Thermally Activated Technology Evaluation ...........................................................................6 66

5 System Synthesis and Analysis .....................................................................69

5.1 System Configuration and Operation .................................................................................69

5.2 System Architecture Analysis.............................................................................................................70

5.2.1 The General Procedure of the Micro-CHP System Analysis .............................................. 70

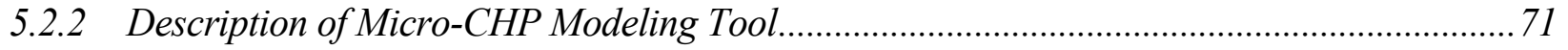

5.2.2.1 Residential Load Models ............................................................................................. 71

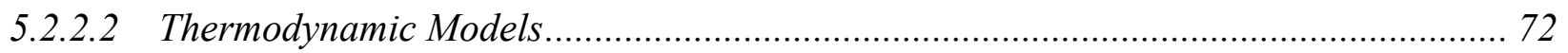

5.2.2.2.1 Objectives of Thermodynamic Modeling ........................................................ 72

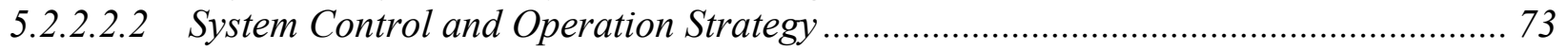

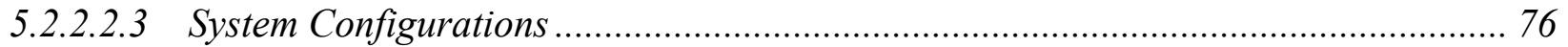

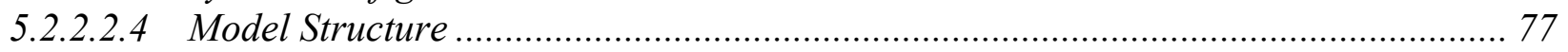

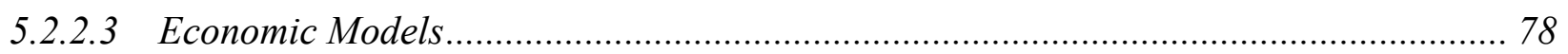

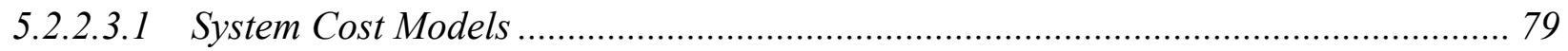

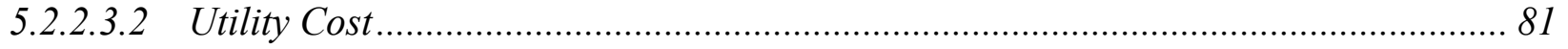

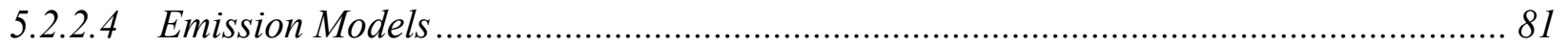

5.2.3 Analysis Results...................................................................................................... 82

6 Commercialization Strategy ..............................................................................84

6.1 Equipment Commonality .............................................................................................................................84

6.1.1 System Solutions for Various Regions and Market Segments .............................................84

6.1.2 System Solutions for Northern U.S. Regions .................................................................8

6.1.2.1 Micro-Cogen: Power and heat generation ........................................................... 86

6.1.2.1.1 Product Requirements.......................................................................................... 87

6.1.2.1.2 System Design ............................................................................................ 87

6.1.2.2 Micro-Trigen: Power, Heat and Cooling Generation ............................................... 90

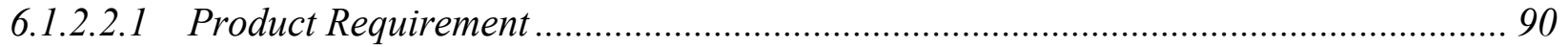

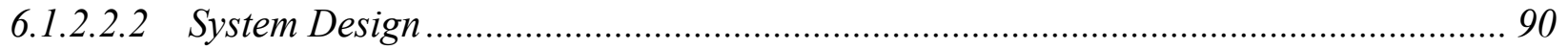

6.1.3 System Solutions for Southern Regions........................................................................... 91

6.1.3.1 Co-generation Solution for Southern Climates ........................................................ 92

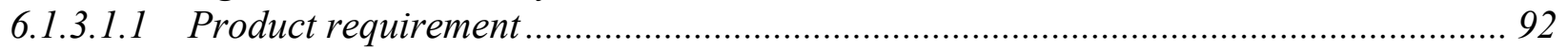

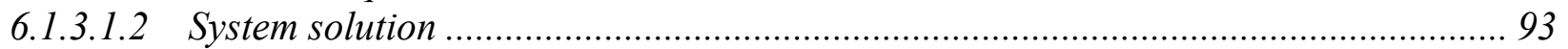

6.1.3.2 Tri-generation Solution for Southern Climates ......................................................... 93

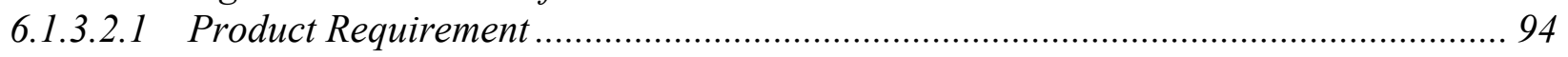




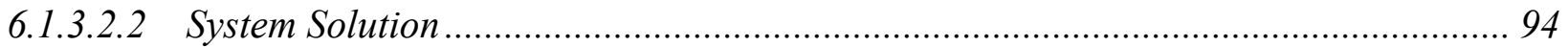

6.1.4 Two Versions of Micro-CHP Development .......................................................................... 95

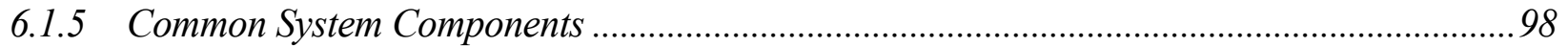

6.2 System Development Incentives..................................................................................................98

7 Conclusions and Recommendations .............................................................. 100

8 Appendix..............................................................................................103

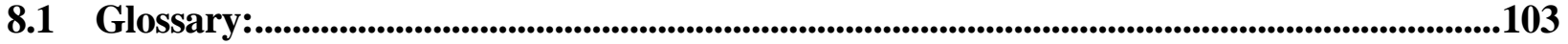

9 References..............................................................................................................105 


\section{List of Figures}

Figure 3-1 Projection of total European micro-CHP market.............................................................

Figure 3-2 2004 World market: installed micro-CHP units by region................................................. 9

Figure 3-3 Evaluated regions from the 2000 Census data................................................................. 10

Figure 3-4 U.S. annual normal heating and cooling degree days......................................................10

Figure 3-5 Annual heating \& cooling degree-days by census region ................................................11

Figure 3-6 Average Annual Expenditure on Heating and Cooling....................................................12

Figure 3-7 Heating solutions in existing housing stock...................................................................13

Figure 3-8 Heating and cooling system design used in new construction........................................13

Figure 3-9 Housing start trend and forecast in target states ........................................................ 16

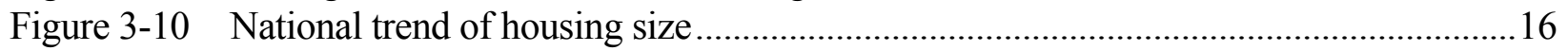

Figure 3-11 Distribution of fuel types in new construction............................................................18

Figure 3-12 Fuel usage in the Midwest and Northeast regions ...................................................19

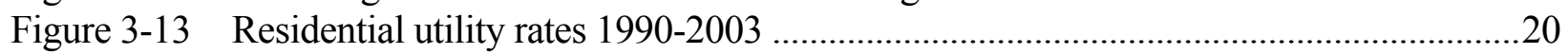

Figure 3-14 Spark spread at residential utility rates 1990-2003 ...................................................20

Figure 3-15 Spark spread at residential utility rates 1990-2003 assuming full utilization of fuel...21

Figure 3-16 Projected future natural gas price and consumption.....................................................22

Figure 3-17 Projected national average future residential electricity rate ………..........................22

Figure 4-1 The relation between different energy sources and prime mover technologies ..............27

Figure 4-2 Two-piston type Stirling engine working diagram ${ }^{[103]}$.................................................30

Figure 4-3 TCP-30 microturbine structure and flow chart ${ }^{[143]}$ ………...........................................35

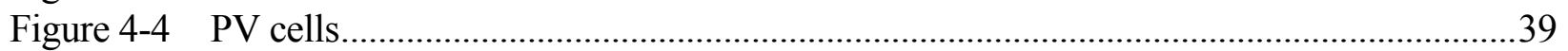

Figure 4-5 Different designs of solar thermal power systems ............................................................39

Figure 4-6 Thermoelectric power generation diagram .....................................................................4

Figure 4-7 1kW TEG equipment using the waste heat from a truck built by Hi-Z ...........................42

Figure 4-8 The relation between different thermally activated technologies ...................................4

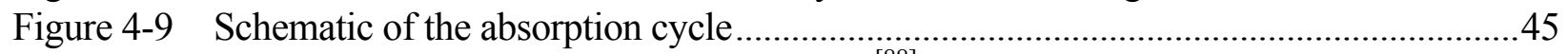

Figure 4-10 The diagram of a GBU adsorption chiller ${ }^{88]}$........................................................4

Figure 4-11 Air handling schematics for different heating / cooling systems ...................................53

Figure 4-12 Electrical Energy Storage Technologies ................................................................5

Figure 4-13 Superconducting Magnetic Energy Storage Schematic .................................................57

Figure 4-14 Thermal Energy Storage Device Categories...............................................................59

Figure 4-15 Schematic of Geothermal Energy Storage and Recovery ...............................................60

Figure 4-16 The weighted scores for evaluation of different prime movers ......................................66

Figure 4-17 The weighted scores for evaluation of different thermally activated technologies......67

Figure 5-1 Annual total heating load from Energy-10 and eQuest ....................................................72

Figure 5-2 Energy efficiency of conventional and thermally-led micro-CHP systems .....................74

Figure 6-1 ARI climate zones showing results of simulations in representative climates ${ }^{[82]} \ldots \ldots \ldots . .85$

Figure 6-2 Co-generating furnace schematic ....................................................................... 88

Figure 6-3 Pictorial representation of integrated Stirling based co-generating furnace concept.....89

Figure 6-4 Tri-generating furnace for northern climates .................................................................91

Figure 6-5 Basic co-generation system for southern climates......................................................93

Figure 6-6 Tri-generation solution for southern climate system solution.......................................95

Figure 6-7 Staged Micro-CHP product development plan...................................................................97 


\section{List of Tables}

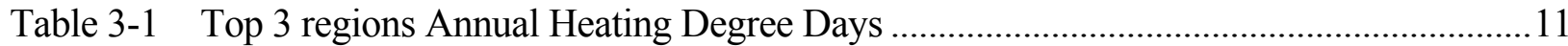

Table 3-2 Top 3 regions Annual Cooling Degree Days .................................................................. 11

Table 3-3 Top regions, Average Household Energy Usage for Heating or Cooling ...................... 12

Table 3-4 Population of homes exceeding 2,000 $\mathrm{ft}^{2}$................................................................. 14

Table 3-5 Number of households exceeding $75^{\text {th }}$ percentile income.......................................... 14

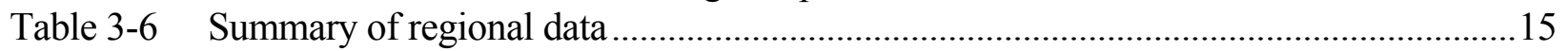

Table 3-7 Housing starts in target states based on Statistical abstract of the US, 2003 ................15

Table 3-8 National distribution of square footage in new construction for $2002 \quad$ (Statistical

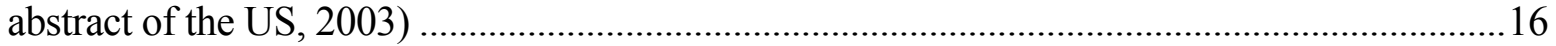

Table 3-9Average residential energy consumption and expenditure per household in target states ..17

Table 3-10 Household annual incomes in target states ..............................................................17

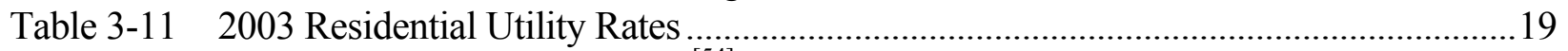

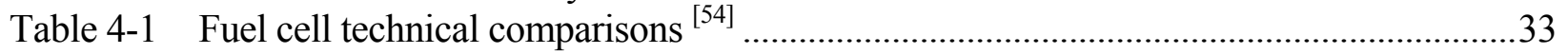

Table 4-2 Micro-CHP Prime Mover Evaluation Metrics And Weighting Factors ........................63

Table 4-3 Raw scores for micro-CHP prime mover evaluation......................................................65

Table 4-4 Raw scores for micro-CHP thermally activated technology evaluation ........................65

Table 4-5 Micro-CHP TAT Evaluation Metrics And Weighting Factors ......................................66

Table 5-1 Micro-CHP system configurations that have been modeled ...........................................76

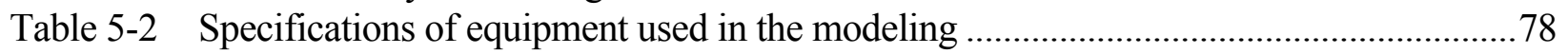

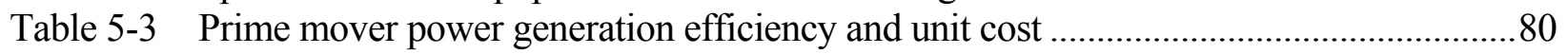

Table 5-4 Emission rate in a utility power plant and in a residential house (EPA statistics)..........82

Table 5-5 Comparison of Prime Mover Technologies with multiple sources in Chapter 9 Color code: green - good, yellow - medium, red - not acceptable .............................................. 83 


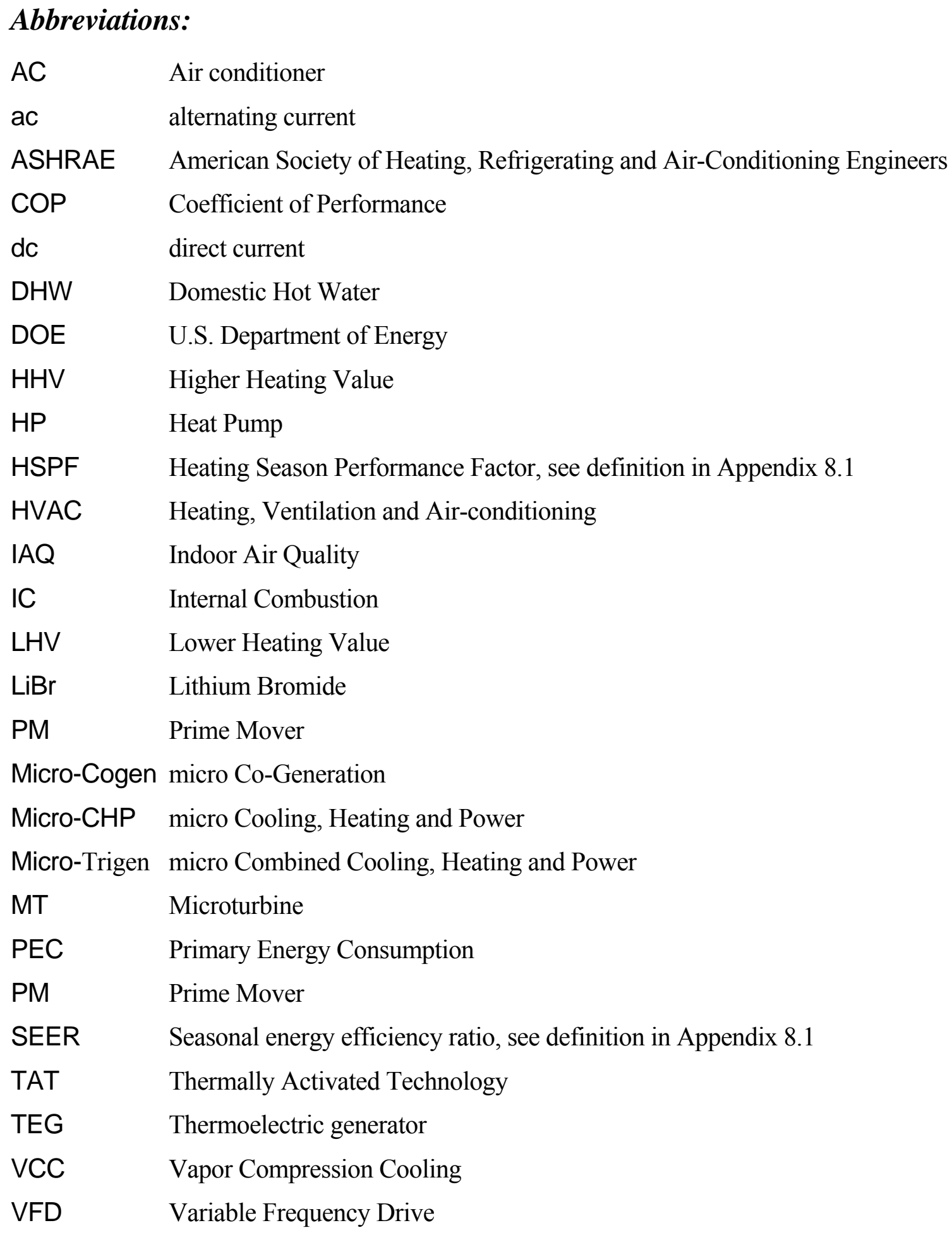




\section{Executive Summary}

Integrated micro-CHP (Cooling, Heating and Power) system solutions represent an opportunity to address all of the following requirements at once: conservation of scarce energy resources, moderation of pollutant release into our environment, and assured comfort for home-owners. The objective of this effort was to establish strategies for development, demonstration, and sustainable commercialization of cost-effective integrated CHP systems for residential applications. A unified approach to market and opportunity identification, technology assessment, specific system designs, adaptation to modular product platform component conceptual designs was employed. UTRC's recommendation to U.S. Department of Energy is to go ahead with the execution of the proposed product development and commercialization strategy plan under Phase II of this effort.

Recent indicators show the emergence of micro-CHP. More than 12,000 micro-CHP systems have been sold worldwide so far, around 7,500 in 2004. Market projections predict a world-wide market growth over 35\% per year. In 2004 the installations were mainly in Europe (73.5\%) and in Japan (26.4\%). The market in North-America is almost non-existent $(0.1 \%)$. High energy consumption, high energy expenditure, large spark-spread (i.e., difference between electricity and fuel costs), big square footage, and high income are the key conditions for market acceptance. Today, these conditions are best found in the states of New York, Pennsylvania, New Jersey, Wisconsin, Illinois, Indiana, Michigan, Ohio, New England states.

A multiple stage development plan is proposed to address risk mitigation. These stages include concept development and supplier engagement, component development, system integration, system demonstration, and field trials. A two stage commercialization strategy is suggested based on two product versions. The first version - a heat and power system named Micro-Cogen, provides the heat and essential electrical power to the homeowner. In its proposed embodiment, the system has a $2 \mathrm{~kW}$ prime mover integrated to a furnace platform. The second version is a Micro-Trigen system with heating, cooling and power. It has the same Micro-Cogen platform integrated with a $14 \mathrm{~kW}$ thermally activated chiller. A Stirling engine is suggested as a promising path for the prime mover. A LiBr absorption chiller is today's best technology in term of readiness level. Paybacks are acceptable for the Micro-Cogen version. However, there is no clear economically viable path for a Micro-Trigen version with today's available technology. This illustrates the importance of financial incentives to home owners in the initial stage of micro-CHP commercialization. It will help create the necessary conditions of volume demand to start transitioning to mass-production and cost reduction. Incentives to the manufacturers will help improve efficiency, enhance reliability, and lower cost, making micro-CHP products more attractive.

Successful development of a micro-CHP system for residential applications has the potential to provide significant benefits to users, customers, manufacturers, and suppliers of such systems and, in general, to the nation as a whole. The benefits to the ultimate user are a comfortable and healthy home environment at an affordable cost, potential utility savings, and a reliable supply of energy. Manufacturers, component suppliers, and system integrators will see growth of a new market segment for integrated energy products. The benefits to the nation include significantly increased energy efficiency, reduced consumption of fossil fuels, pollutant and $\mathrm{CO}_{2}$ emissions from power 
generation, enhanced security from power interruptions as well as enhanced economic activity and job creation. An integrated micro-CHP energy system provides advantages over conventional power generation, since the energy is used more efficiently by means of efficient heat recovery. Foreign companies are readily selling products, mostly in Europe, and it is urgent to react promptly to these offerings that will soon emerge on the U.S. market as well. For all these reasons, UTC urges the U.S. Department of Energy to fund the Phase II Development Program in the nation's interest. 


\section{Project Summary}

The objective of this study of micro-CHP systems was to establish strategies for development, demonstration, and sustainable commercialization of cost-effective integrated Cooling, Heating and Power (CHP) systems for residential applications. Successful commercialization will ultimately involve component suppliers both for the micro-CHP system, and for the building electric power, heating, cooling, ventilation, and hot water supply systems. All of these components must be compatible and integrated as a system with their safe and reliable operation coordinated by an overall supervisory control system.

\subsection{Project Approach}

Successful development of a micro-CHP system for residential applications has the potential to provide significant benefits to users, customers, manufacturers and suppliers of such systems and, in general, to the nation as a whole. The benefits to the ultimate user are a comfortable and healthy home environment at an affordable cost, potential utility savings, and reliable energy supply. Manufacturers, component suppliers and system integrators will see growth of a new market segment for energy products. The benefits to the nation will include significantly increased energy efficiency, reduced consumption of fossil fuels, reduced pollutant and $\mathrm{CO}_{2}$ emissions from power generation, enhanced security from power interruptions as well as enhanced economic activity and job creation.

An integrated CHP energy system provides advantages over conventional power generation, since the total energy is used more efficiently by means of heat recovery and utilization. Micro-CHP denotes the concept of smaller scale CHP systems suitable for a residential house. A micro-CHP system can have different configurations ranging from simple to complex ones. The proposed micro-CHP systems comprise a prime mover, which generates electricity, and the heat recovery and utilization components which use the heat rejected by the prime mover provide space heating, hot water, and/or even cooling.

Traditionally, utility electric power systems have not been designed to accommodate active generation and storage at the distribution level. When properly located and applied, Distributed Generation (DG), such as micro-CHP installations, can provide a number of benefits for both utilities and end-users. A traditional household energy solution includes a furnace or boiler and/or a hot water heater, as well as a vapor compression chiller, together with electric power supplied from the utility grid.

The technical approach was based on a search for suitable residential market segments, viable micro-CHP systems adapted to these markets, and conditions under which the systems will be competitive and significant benefits accrue to customers, suppliers, and the public. The proprietary micro-CHP Analysis Tool developed at UTRC was suitable for performing these techno-economic 
evaluations of micro-CHP systems. The evaluation of micro-CHP systems was based on the following set of criteria: energy conservation, environmental impact, economics (both capital cost and operational costs), scalability, flexibility, noise, reliability, and security of the proposed configurations.

The micro-CHP system in the context of this study is basically another household appliance that can satisfy various residential building energy needs - space and water heating, electricity, and, potentially, cooling. Major advantages include:

- Energy Efficiency Benefit

The principle behind cogeneration is simple. In a micro-CHP system, high grade heat is converted to electricity and the rest of the heat is recovered from the electric power generation process for space heating, hot water, or space cooling.

- Environmental Benefits

The United States consumed roughly 96 quadrillion BTUs (quads) of primary energy in 2001. There were about 107 million households in the U.S., which consumed approximately 10 quads of the total energy and about $30 \%$ of all electricity generated nationally. Energy generation for consumption in buildings is also a major cause of acid rain, smog, and greenhouse gas emissions in the United States.

- Technology Advancement

The most powerful initial approach was to consider a wide range of technologies, component and system integration options for micro-CHP systems and to aim at modular platform integration, and simple plug and play approaches. Integration should involve not only the components of the micro-CHP system but also the related elements of the residential space and overall energy supply systems.

- Fuel Diversity

Accommodation of fuel diversity is an important consideration in achieving large-scale distribution of micro-CHP systems. The importance of fuel diversity results from the price and availability of fuel sources in different geographical locations as well as the uncertainty of future fuel prices.

- Economic Viability

Economic viability is driven by both fuel cost and efficiency of the systems employed as well as by the capital and maintenance costs of the equipment. While current fuel cost can be used to estimate system operating cost, future fuel cost are expected to be volatile and a risk to the economic viability of the proposed system.

- Reliability and Suitability for Grid Interconnection

The future of micro-CHP systems is strongly dependent on requirements for interconnections with the power and fuel grids. Grid connected micro-CHP systems can contribute to improved reliability of the national electric supply by adding independent sources at the point of usage.

- Backup power capability or secure heating Electric power is generated by the micro-CHP system can, e.g., drive the fans or pumps used in a furnace or boiler. If extra electricity is available, it can be used for refrigeration, lighting, entertainment and work. The provision of power generation equipment enables the house to have heating in cold seasons and hot water, or run electric appliances, even when the external electric grid fails. 


\subsection{Report Organization}

Chapter 3 provides a market analysis, including descriptions of market segments and data regarding U.S. residential house types, electric and gas utilities. Based on the review of the status of current worldwide micro-CHP, the potential market for micro-CHP in the U.S. is identified in terms of climate zone, energy consumption, and demographics.

Chapter 4 gives a technology assessment of micro-CHP, by providing data on the following set of prime movers: reciprocating engines, Stirling engines, Rankine cycle engines, fuel cells, and microturbines. Other technologies covered include: photovoltaic solar cells, solar thermal, and Thermally Activated Technologies (TAT), such as absorption chillers, adsorption chillers, desiccant dehumidifiers and heat recovery exchangers / boilers. The above listed types of prime movers and thermally activated technologies are reviewed and assessed for their possible application in microCHP systems.

Chapter 5 deals with the system architecture and performance analysis. A flexible computer model was set-up to analyze the thermo-economic performance of a micro-CHP system. Using this model, more than a dozen of micro-CHP configurations are analyzed with different prime movers, heat recovery devices, control schemes, utility rates and geographic locations. Based on this, desirable micro-CHP configurations and climate zones were identified.

Chapter 6 provides the micro-CHP commercialization strategy, including equipment commonality assessment, equipment requirements and specifications, grid interconnect and safety standards, equipment interfaces, equipment sourcing strategy, technology development needs, and the commercial value proposition. The system solutions for various regions and market segments are analyzed and a two-staged development strategy is postulated for progressive market entry.

The grid interconnection and safety standards section addresses issues related to system protection, personnel safety, service reliability and power quality. The future of micro-CHP is strongly correlated to the installed system cost. Different lay-outs for both grid-independent and gridinterconnected electrical interconnection of micro-CHP systems are illustrated. The technology development needed for mature micro-CHP products is outlined in the subsections on development need and commercial value proposition, which include information on prime mover, thermally activated technologies, and control. Customer and manufacturer's value propositions are provided and analyzed.

In Chapter 7, major conclusions regarding micro-CHP market, technology, economics, and commercialization are outlined. A recommendation in form of go/no-go is provided. 


\section{$3 \quad$ Market Analysis}

The potential design space for micro-CHP (combined heating and power) systems is nearly unlimited. Since there is no established market as of this writing, it will be important to identify the market not only in terms of overall needs based on customer economics, but also in terms of the market evolution over time in order to build a strategy for the introduction and further growth of this type of products. An optimal approach is to identify the geographic areas that have the most suitable combination of energy rates, climate and demographics and base initial offering and technology strategies to best serve this market. It is believed that the market will evolve over time where the needs of early adopters will be different from the mainstream customers that will follow later.

\subsection{World Market Characteristics}

According to a report from Platts Research \& Consulting ${ }^{[124]}$, the Micro-CHP market is gradually coming into shape. Residential customers in parts of the UK, Germany, Japan and North America now have the opportunity to purchase micro-CHP products. As of May 2004, there were five products sold on a commercial basis.

In Europe and Japan, the outlook for micro-CHP is promising, with big rewards for developers able to bring products to market that can be sold as replacements for heating systems. A number of utilities are starting to recognize the opportunities and are taking steps to gain a piece of this emerging market. In North America, niche markets are starting to emerge, although there remain significant challenges to overcome for mass markets to materialize.

More than 12,000 micro-CHP systems - each generating less than 10 kilowatts $(\mathrm{kW})$ of electricity have been sold worldwide to homes and small commercial energy users by six manufacturers. Around 4,500 units were sold in 2003, and sales in the coming years are expected to increase significantly. It is estimated that the sales in 2004 were about 7,000 units ${ }^{[124]}$. Sales growth after that will depend on the success of products entering various markets. All systems that have been sold to date are almost exclusively thermally-led micro-CHP systems, which satisfy the building thermal requirement first and then provide electricity as a secondary output. Potential markets are estimated to be large - by the end of the decade, annual sales could amount to hundreds of thousands of units in Europe and Japan. Sales will probably lag behind somewhat in the U.S., where the micro-CHP market is just emerging ${ }^{[124]}$. Figure $3-1$ is a total European micro-CHP market projected by Frost \& Sullivan ${ }^{[86]}$. Figure $3-2$ shows the world micro-CHP market ${ }^{[124]}$. 


\section{Total European Micro CHP Market}

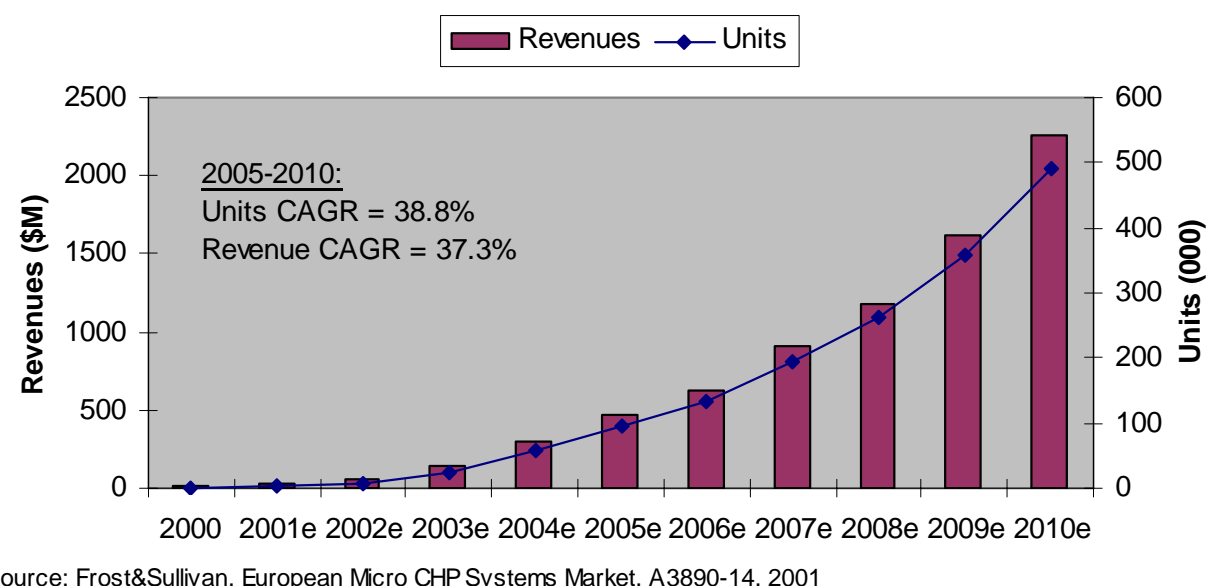

Source: Frost\&Sullivan, European Micro CHP Systems Market, A3890-14, 2001

Figure 3-1 Projection of total European micro-CHP market

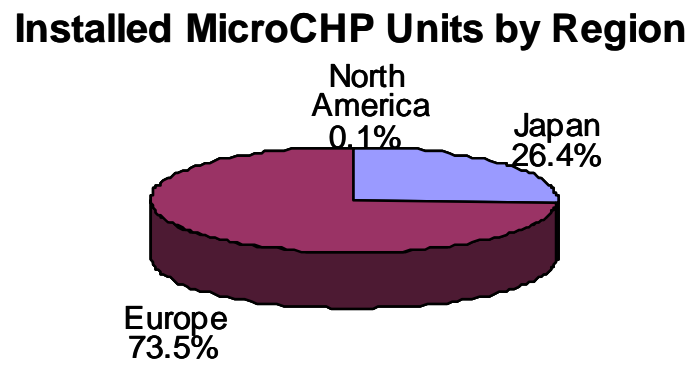

Figure 3-2 2004 World market: installed micro-CHP units by region

\subsection{U.S. Market Characteristics}

The strategy used in identifying the characteristics of the U.S. residential market is as follows: high level technology characteristics impacting the marketability are used to identify desirable microCHP features in different market segments. Publicly available data, primarily from the Department of Energy and the U.S. Census Bureau, are used to characterize the size of these segments. The details are discussed below.

\subsubsection{Market Segments}

The primary sources used to analyze the potential market, energy usage and demographics are the DOE 2001 Residential Energy Consumption Survey (RECS) ${ }^{[67]}$ and the U.S. Census data in the year 2000 .

The data has been evaluated for the nine main regions defined in the Residential Energy Consumption Survey and shown in Figure 3-3. The nine main regions are: New England, Middle 
Atlantic, South Atlantic, East North Central, East South Central, West North Central, West South Central, Mountain, and Pacific.

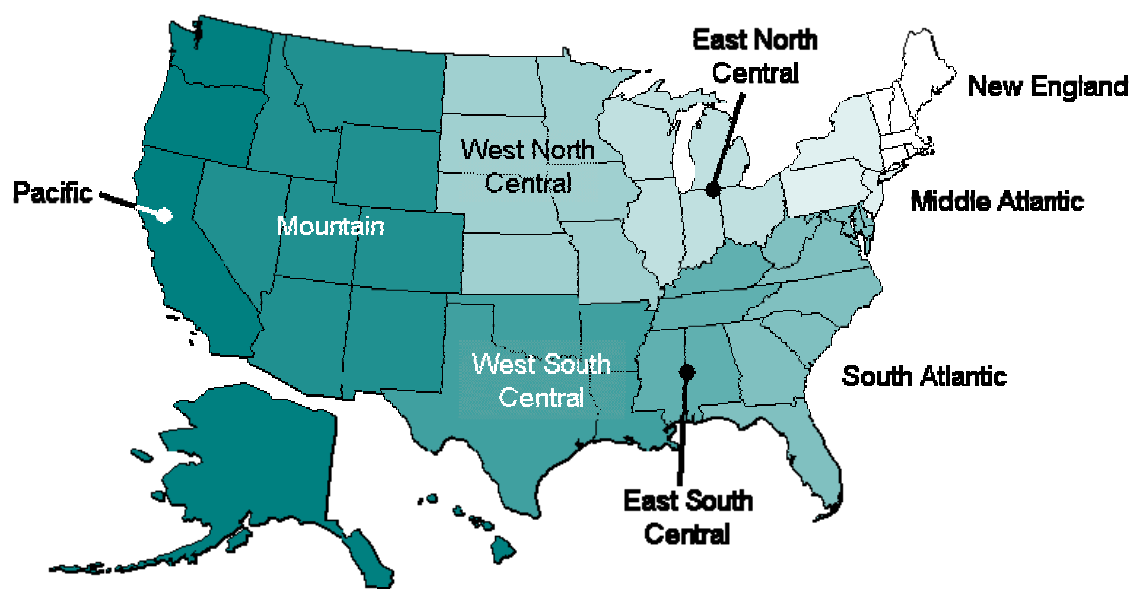

Figure 3-3 Evaluated regions from the 2000 Census data

\subsubsection{Regional Climate Data}

The regions under consideration cover a large area, resulting in potential variability both in climate and in demographics. The regions with the largest variation are Mountain, Pacific and South Atlantic as shown in Figure 3-4. As it will be shown later in this report, the regions with the best potential for significant deployment of CHP have fairly consistent climate throughout the region. Besides the dependency of climate on the economics, local utility rates and demographics are key factors that will affect the economic potential.

Annual Normal Heating Degree Days

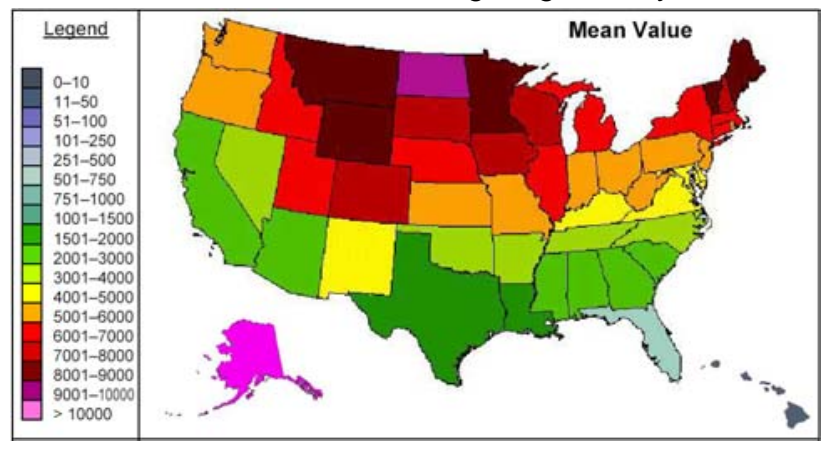

Figure 3-4 U.S. annual normal heating and cooling degree days
Annual Normal Cooling Degree Days

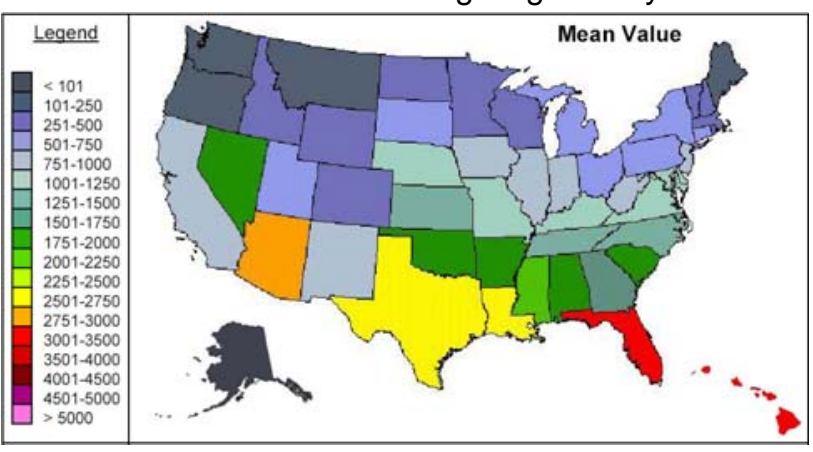

The three regions identified with the highest heating loads measured in degree days are listed in Table 3-1. The definition of cooling and heating degree days are shown in Appendix 8.1. The regions with the highest cooling loads are listed in Table 3-2. 
Table 3-1 Top 3 regions Annual Heating Degree Days

\begin{tabular}{|l|c|}
\hline Region & Annual Normal Heating Degree Days \\
\hline West North Central & 6750 \\
\hline New England & 6612 \\
\hline East North Central & 6498 \\
\hline
\end{tabular}

Table 3-2 Top 3 regions Annual Cooling Degree Days

\begin{tabular}{|l|c|}
\hline Region & Annual Normal Cooling Degree Days \\
\hline West South Central & 2448 \\
\hline South Atlantic & 1964 \\
\hline East South Central & 1549 \\
\hline
\end{tabular}

The data from Figure 3-4 are reduced to census regions in Figure 3-5 so that it can be correlated with the data from the Residential Energy Consumption Survey (RECS). The map in Figure 3-5 reflects the effects of population density, temperature, and time length. It shows that the dominant energy usage is for heating and, not surprisingly, lies in the north central (East and West North Central) and northeastern (Middle Atlantic and New England) regions of the country. Because one of the major advantages of micro-CHP is that it has high overall energy efficiency by recovering heat for space heating or other thermal loads from power generation, southern states, without large thermal loads, may not fully utilize the waste heat therefore and therefore are not good candidates to start with, unless there is a thermally activated chiller. In such case, the capital cost of the system is likely to increase dramatically, as going to be discussed later.

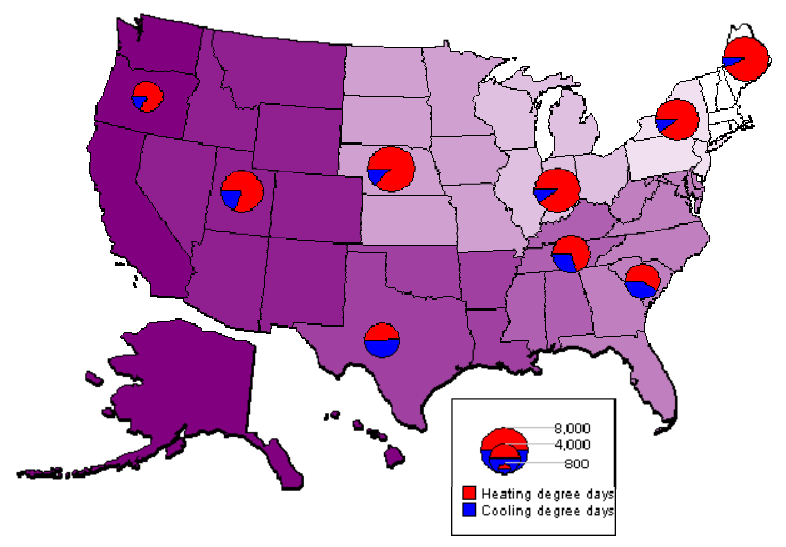

Figure 3-5 Annual heating \& cooling degree-days by census region

\subsubsection{Regional Annual Energy Consumption \& Expenditure Data}

The economics of CHP systems depends not only on heating and cooling loads but also on the annual expenditure for energy by household. These data are available in the Residential Energy Consumption Survey (RECS) and have been used for this analysis. The data as summarized in Table 
3-3 show that the largest contributor to energy expenditure is heating during the cold season, indicating that a heating centric approach is the preferred path for micro-CHP applications. This is further illustrated in the map shown in Figure 3-6 where the expenditure on heating and cooling is shown graphically for the regions.

Table 3-3 Top regions, Average Household Energy Usage for Heating or Cooling

\begin{tabular}{|l|l|l|l|l|}
\hline Region & $\begin{array}{l}\text { Energy usage } \\
\text { Heating } \\
\text { MWh }\end{array}$ & $\begin{array}{l}\text { Energy cost } \\
\text { Heating } \\
\$\end{array}$ & $\begin{array}{l}\text { Energy usage } \\
\text { Cooling } \\
\text { MWh }\end{array}$ & $\begin{array}{l}\text { Energy cost } \\
\text { Cooling } \\
\$\end{array}$ \\
\hline New England & 31.1 & 1032 & 2.7 & 92 \\
\hline Middle Atlantic & 26.5 & 894 & 3.4 & 117 \\
\hline East North Central & 29.7 & 796 & 4.6 & 117 \\
\hline West North Central & 26.6 & 816 & 6 & 135 \\
\hline South Atlantic & 13.2 & 593 & 10.7 & 271 \\
\hline East South Central & 15.6 & 610 & 9.9 & 195 \\
\hline West South Central & 15.1 & 539 & 13.7 & 348 \\
\hline Mountain & 19.4 & 562 & 9.7 & 244 \\
\hline Pacific & 13.6 & 484 & 3.2 & 113 \\
\hline
\end{tabular}

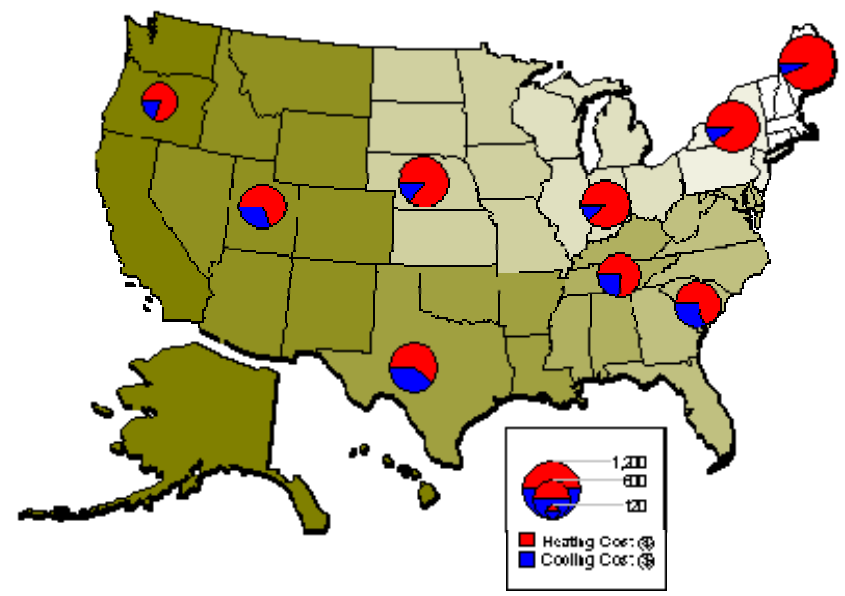

Figure 3-6 Average Annual Expenditure on Heating and Cooling

\subsubsection{Heating and Cooling System Solutions}

The two main types of heating and cooling systems are warm air or steam/hot water. Steam systems are rarely installed in new residential construction. Hot water heating was previously popular in the North East regions of United States. It is now less commonly installed in the US, especially in the regions outside the North East, because most new construction today is based on warm air system driven by the lower cost and better integration with central air conditioning. 

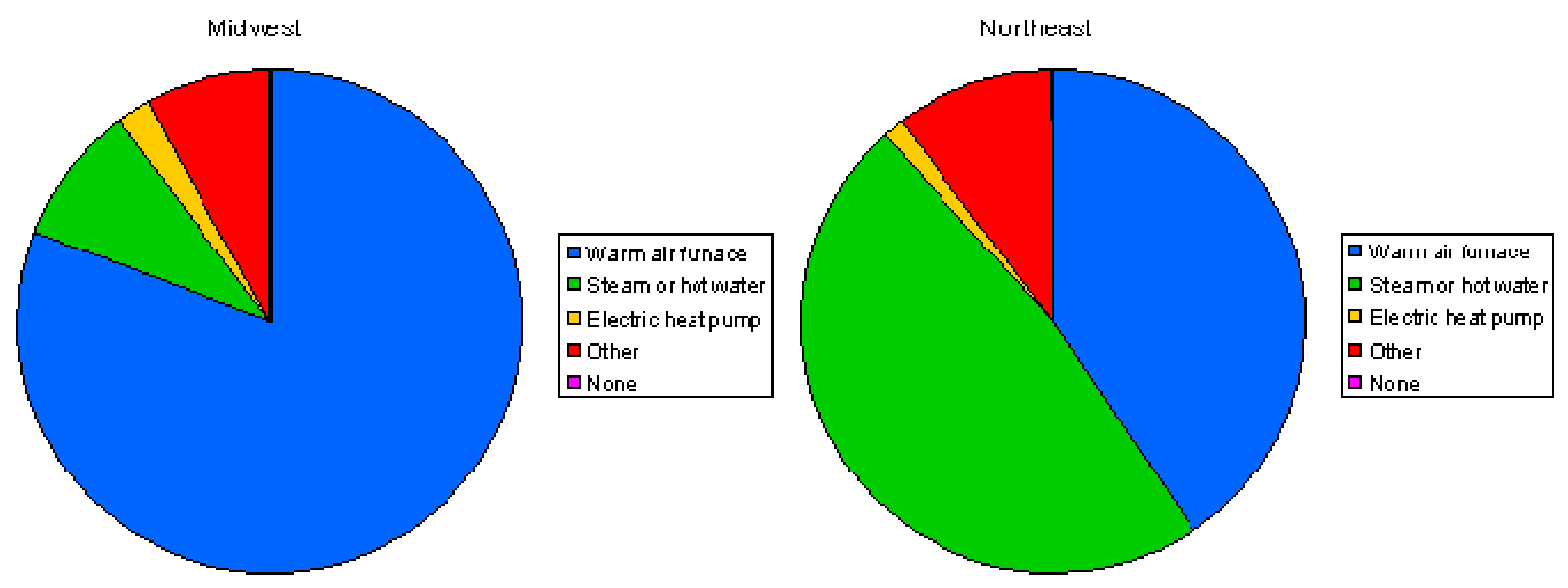

Figure 3-7 Heating solutions in existing housing stock

As shown in Figure 3-7, the dominant design in the Midwest region is warm air, capturing over $80 \%$ of the market, while the Northeast where hydronic systems are the traditional technology shows a significant installed base of air systems. As shown in Figure 3-8, warm air systems are the dominant design for new construction, based on the statistical abstract of the United States between 19972003. This trend is correlating with the increased use of central air conditioning.
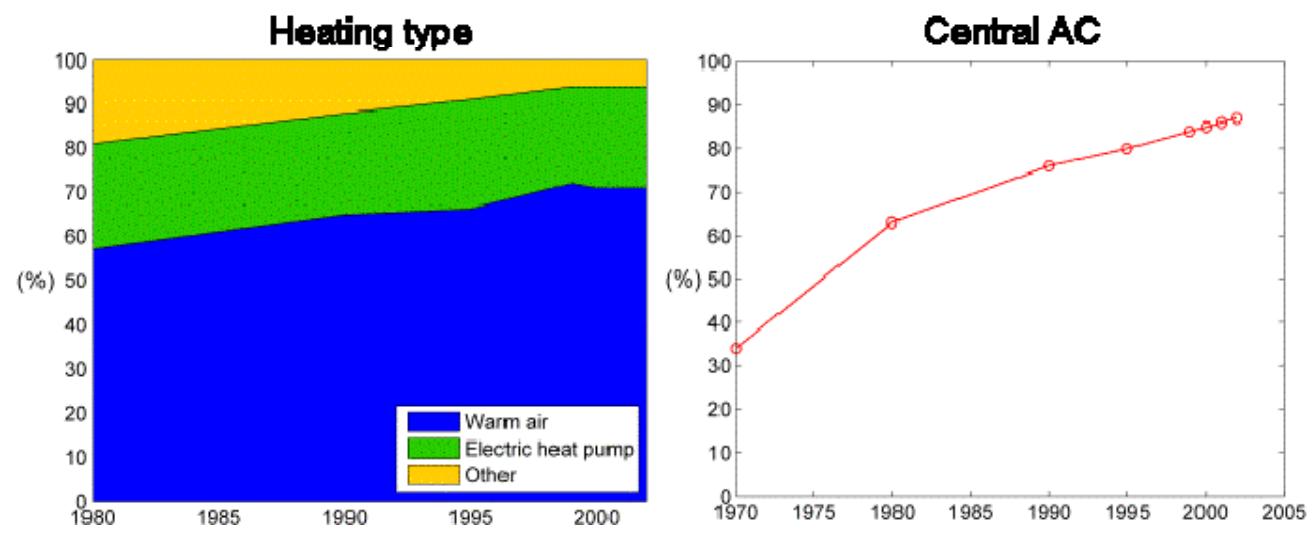

Figure 3-8 Heating and cooling system design used in new construction

\subsubsection{Residential House Types}

\subsubsection{Housing Size Data and Income Demographics}

Intuitively it can be concluded that Micro-CHP solutions will have a more favorable economics for larger homes both from a payback analysis and from a spending priority standpoint where larger homes naturally use more resources for heating and cooling and they are also more often customized for the owner. Furthermore the original owner tends to stay longer in the house in comparison to smaller homes that tend to be more of transitional nature or "starter homes". The national median square footage of the occupied housing unit ${ }^{[67]}$ is $1728 \mathrm{ft}^{2}$. As will be shown in Chapter 5, System 
Synthesis and Analysis, the economics for heat based CHP solutions looks more favorable for house size above 2,000 $\mathrm{ft}^{2}$. The regions with the most houses that are larger than $2,000 \mathrm{ft}^{2}$ are shown in Table 3-4.

Table 3-4 Population of homes exceeding 2,000 $\mathrm{ft}^{2}$

\begin{tabular}{|c|c|}
\hline \multicolumn{2}{|c|}{ Housing units $>2,000 \mathrm{ft}^{2}$ Top 4 regions: } \\
\hline East North Central & 8.8 million \\
\hline South Atlantic & 7.4 million \\
\hline Middle Atlantic & 6.5 million \\
\hline Pacific & 4.5 million \\
\hline
\end{tabular}

It is assumed that the early adopters of residential CHP solutions will likely have above median income. The national median household income reported in the 2000 census data is $\$ 42,409$ with a $75^{\text {th }}$ percentile of approximately $\$ 75,000^{[67]}$. This is illustrated in Table 3-5 where the percentage of homes with combined income exceeds the $75^{\text {th }}$ percentile of the national median income.

Table 3-5 Number of households exceeding $75^{\text {th }}$ percentile income.

\begin{tabular}{|c|c|}
\hline \multicolumn{2}{|c|}{ Households with income $>$ \$75k, Top 4 regions: } \\
\hline Pacific & 3.3 million $(20.1 \%)$ \\
\hline South Atlantic & 2.9 million $(14.4 \%)$ \\
\hline Middle Atlantic & 2.7 million $(18.1 \%)$ \\
\hline East North Central & 2.5 million $(14.7 \%)$ \\
\hline
\end{tabular}

Table 3-6 summarizes and compiles the data presented in the previous section into one table. As can be seen in the table, the regions that conform to the criteria of energy consumption and expenditure, number of large homes and high household income are the East North Central and Middle Atlantic regions. Together these regions cover 5.2 million households with an above 75-percentile income and there are 15.3 million housing units larger than $2,000 \mathrm{ft}^{2}$ conforming to these criteria. Specifically, these regions include the following states: New York, Pennsylvania, New Jersey, Wisconsin, Illinois, Indiana, Michigan and Ohio.

Since the consumption and the expenditure determine the viability for an individual home, it is obvious that many regions in New England will be viable markets for this technology. 
Table 3-6 Summary of regional data

\begin{tabular}{|c|c|c|c|c|}
\hline Rank & Consumption & Expenditure & $\begin{array}{c}\text { Square } \\
\text { Footage }\end{array}$ & Income \\
\hline 1 & New England & New England & $\begin{array}{c}\text { East North } \\
\text { Central }\end{array}$ & Pacific \\
\hline 2 & $\begin{array}{c}\text { Middle } \\
\text { Atlantic }\end{array}$ & $\begin{array}{c}\text { East North } \\
\text { Central }\end{array}$ & South Atlantic & South Atlantic \\
\hline 3 & $\begin{array}{c}\text { West North } \\
\text { Central }\end{array}$ & $\begin{array}{c}\text { West North } \\
\text { Central }\end{array}$ & $\begin{array}{c}\text { Middle } \\
\text { Atlantic }\end{array}$ & $\begin{array}{c}\text { Middle } \\
\text { Atlantic }\end{array}$ \\
\hline 4 & $\begin{array}{c}\text { East North } \\
\text { Central }\end{array}$ & $\begin{array}{c}\text { Middle } \\
\text { Atlantic }\end{array}$ & Pacific & $\begin{array}{c}\text { East North } \\
\text { Central }\end{array}$ \\
\hline
\end{tabular}

\subsubsection{New Housing Construction}

The target for Micro-CHP solutions is both new construction and retrofit application. Table 3-7 lists the new housing starts in some of the target states. The data show that single-family houses are the dominant part of new construction.

Table 3-7 Housing starts in target states based on Statistical abstract of the US, 2003

\begin{tabular}{|l|l|l|}
\hline \multicolumn{2}{|l|}{ New privately owned housing units started in 2000 (thousands) } \\
\hline & Total Units & Single family \\
\hline Michigan & 50.9 & 44.2 \\
\hline New Jersey & 31.2 & 25.4 \\
\hline New York & 34.9 & 22.7 \\
\hline Totals: & 117 & 92.3 \\
\hline
\end{tabular}

There has been a strong increase in new housing construction in the states listed in Table 3-7. Data from the US census data between 1997-2003 and Fannie Mae forecast suggest a continuous growth in these states as illustrated in Figure 3-9. 


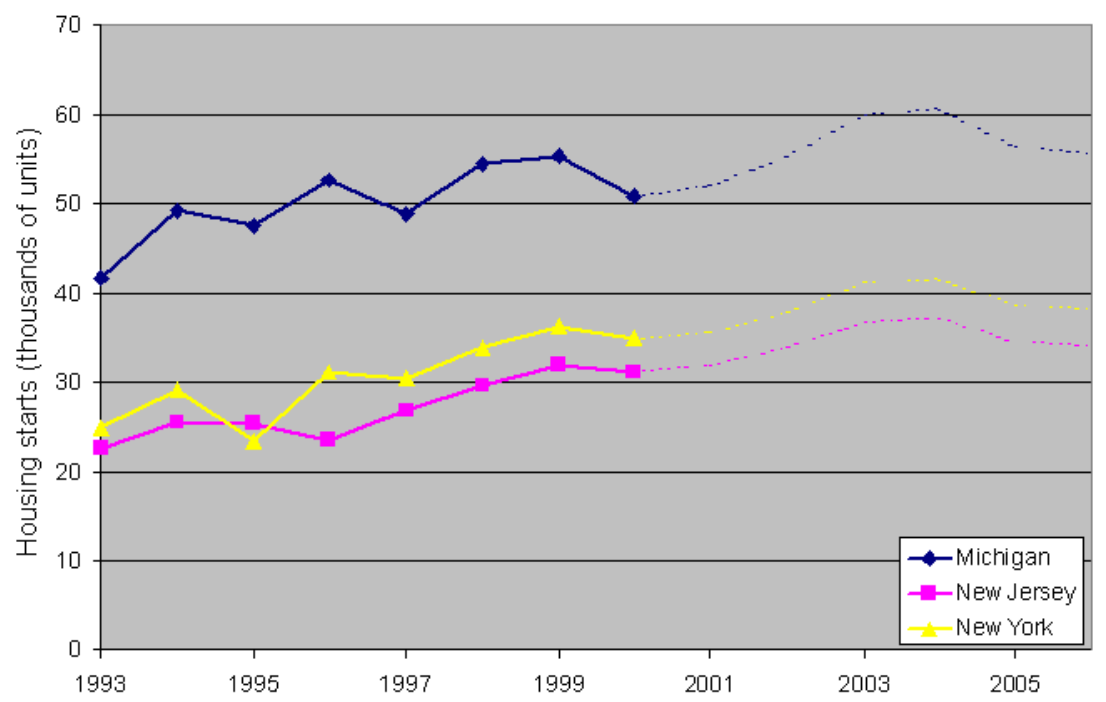

Figure 3-9 Housing start trend and forecast in target states

Since the data represents national averages, it is likely that the new construction in the MI, NJ and NY in average is larger homes due to the above average income in those states.

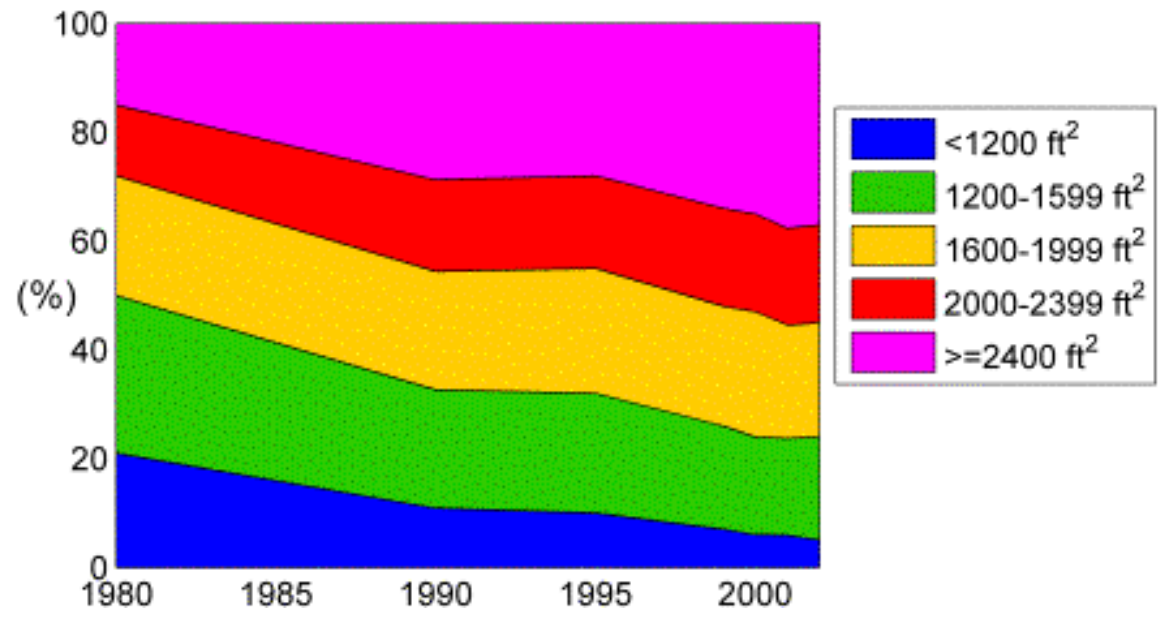

Figure 3-10 National trend of housing size

There is an overall trend toward larger houses that has been steady for a long time as shown in Figure 3-10. The median new house size has increased from $1400 \mathrm{ft}^{2}$ in 1970 to $2114 \mathrm{ft}^{2}$ in 2002 as shown in Table 3-8.

Table 3-8 National distribution of square footage in new construction for 2002 (Statistical abstract of the US, 2003)

Single family home square footage for units completed in 2002 (National) 


\begin{tabular}{|l|l|}
\hline$<2,000 \mathrm{ft}^{2}$ & $45 \%$ \\
\hline $2,000-2,399 \mathrm{ft}^{2}$ & $18 \%$ \\
\hline$>2,400 \mathrm{ft}^{2}$ & $37 \%$ \\
\hline Average: & $2,320 \mathrm{ft}^{2}$ \\
\hline Median: & $2,114 \mathrm{ft}^{2}$ \\
\hline
\end{tabular}

Based on the trend shown in Figure 3-10 it is likely that the data in Table 3-9 showing the average spending on energy underestimates spending on energy in newly constructed houses. Further studies would be needed to resolve this since improvement in heating systems, increased insulation etc also play a significant role in this.

\subsubsection{Energy Consumption and Expenditure in Target States}

The above data have identified three initial target states as most promising for the establishment of a Micro CHP market based on heating needs, utility rates and demographics. Statistics for energy usage state by state is available in the 2001 Residential Energy Consumption Survey ${ }^{[67]}$. Table 3-9 lists the average expenditure per household for these states.

Table 3-9 Average residential energy consumption and expenditure per household in target states

\begin{tabular}{|c|c|c|}
\hline \multicolumn{3}{|c|}{ Average residential energy consumption and expenditure per household: } \\
\hline Michigan & $146 \mathrm{MMBtu}(42.8 \mathrm{MWh})$ & $\$ 1372$ \\
\hline New Jersey & $126 \mathrm{MMBtu}(36.9 \mathrm{MWh})$ & $\$ 1599$ \\
\hline New York & $125 \mathrm{MMBtu}(26.6 \mathrm{MWh})$ & $\$ 1816$ \\
\hline
\end{tabular}

It is believed that the energy expenditure has to be significant enough to motivate potential customers to undertake the additional capital investment in CHP systems. It is also believed that the likely customer will have an above average income. Table 3-10 illustrates the income distribution in these states. As can be seen in the table between $24 \%$ and $35 \%$ of the target state households have annual incomes above $\$ 75,000$.

Table 3-10 Household annual incomes in target states

\begin{tabular}{|l||l|l||l|l||l|l||l|}
\hline \multicolumn{6}{|c|}{ Household annual income distribution among the population (thousands) } \\
\hline & $>\$ 75 \mathrm{k}$ & $\%$ & $>\$ 100 \mathrm{k}$ & $\%$ & $>\$ 150 \mathrm{k}$ & $\%$ & Total \\
\hline Michigan & 913 & 24 & 480 & 13 & 155 & 4.1 & 3,790 \\
\hline New Jersey & 1,070 & 35 & 654 & 21 & 263 & 8.6 & 3,070 \\
\hline New York & 1,820 & 26 & 1,080 & 15 & 457 & 6.2 & 7,060 \\
\hline Total: & 3,810 & 27 & 2,210 & 16 & 856 & 6.2 & 13,920 \\
\hline
\end{tabular}

\subsubsection{Utilities}

Utilities affect the micro-CHP option in two ways: 1) Customers will choose micro-CHP based on what fuel the micro-CHP systems use. In a region where there is no natural gas pipeline, customers 
could only use oil or propane based micro-CHP, if they want to have one; 2) One of the potential benefits of the micro-CHP is utility savings, which results from the difference between the gas and grid electricity prices, or spark-spread. If the spark-spread is large, the utility savings will be larger and the micro-CHP will be more favorable from the financial standpoint. Therefore, it is necessary to look at the utilities in studying the micro-CHP market.

\subsubsection{Fuel Types}

The use of natural gas as heating fuel for new construction increased dramatically from 1980 until 1995 where it stabilized at around 60\% on a national level as shown in Figure 3-11.

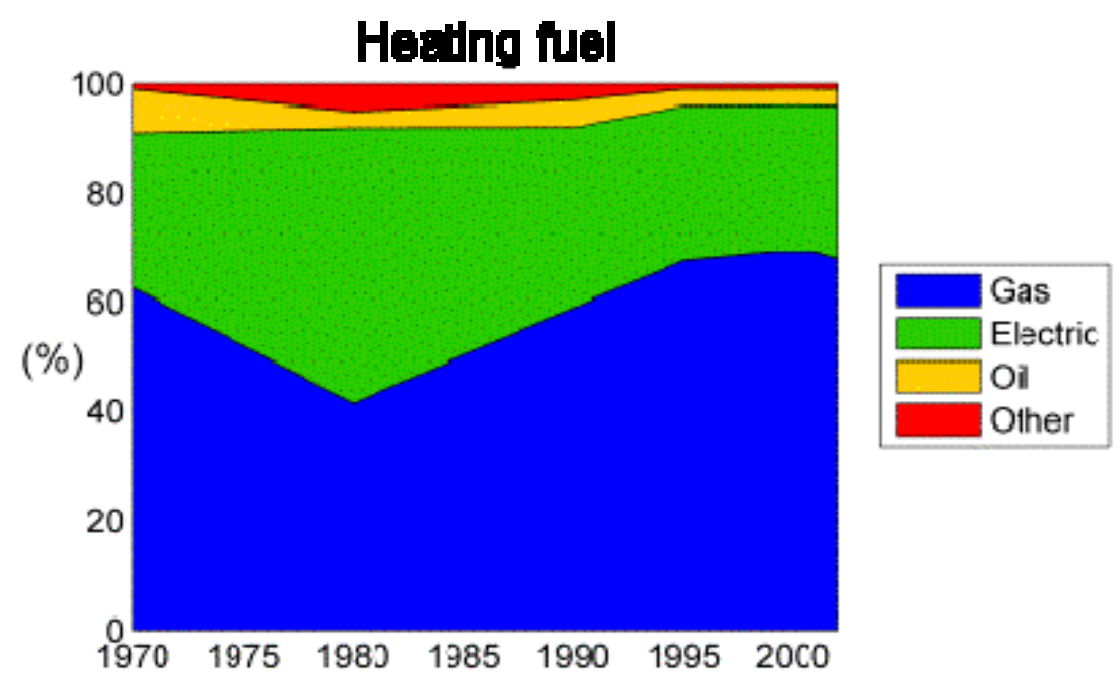

Figure 3-11 Distribution of fuel types in new construction

In the targeted areas of the Midwest and Northeast of the United States, the relatively high heating loads and cold winters make heat pumps less attractive and the main fuels are natural gas and fuel oil as shown in Figure 3-12. The Midwest region is totally dominated by natural gas while fuel oil is widely used in the Northeast area. 

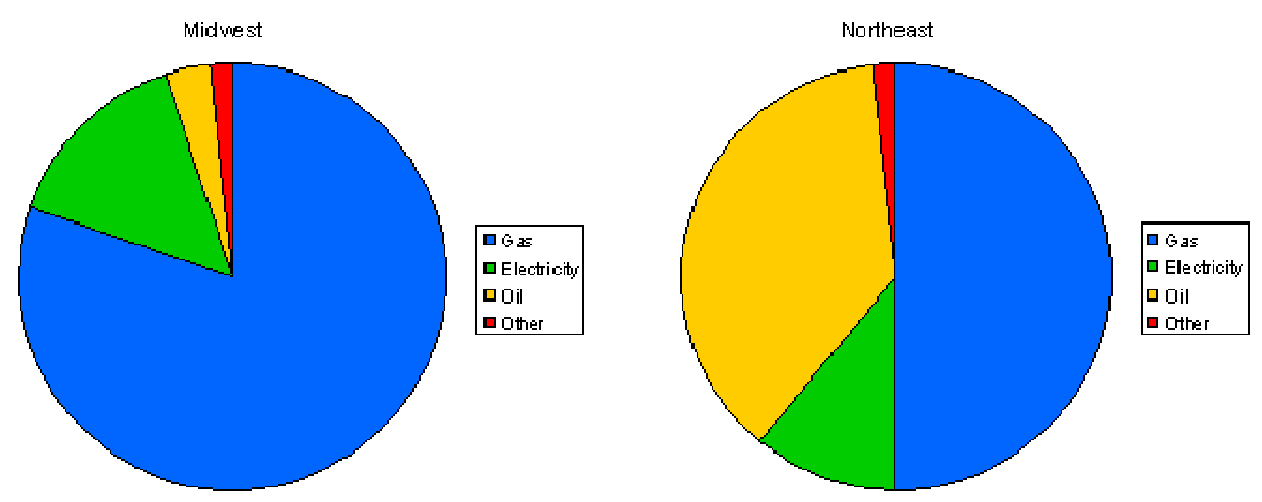

Figure 3-12 Fuel usage in the Midwest and Northeast regions

\subsubsection{Residential Utility Rates}

Combined Heat and Power solutions generally shift energy consumption from electricity to gas or oil. To be economically viable the natural gas price has to be relatively low compared to the electric price per unit of energy. The markets identified as most promising from the previous discussion have a relatively large variability in natural gas price and electric rates. Table 3-11 summarizes utility rates for the 8 States identified. The spark spread is calculated from an assumed $32 \%$ efficient electric generation and distribution. ${ }^{[75],[78],[76]}$

Table 3-11 2003 Residential Utility Rates

\begin{tabular}{|l|l|l|l|l|l|}
\hline $\begin{array}{l}\text { Census } \\
\text { region }\end{array}$ & State & $\begin{array}{l}\text { Electricity } \\
(\varnothing / \mathrm{kWh})\end{array}$ & $\begin{array}{l}\text { Natural gas } \\
(\$ / \mathrm{Mcf})\end{array}$ & $\begin{array}{l}\text { Ratio } \\
\text { NG/Elec }\end{array}$ & Spark spread \\
\hline \multirow{3}{*}{$\begin{array}{l}\text { Middle } \\
\text { Atlantic }\end{array}$} & New York & 14.23 & 10.48 & 0.74 & 3.36 \\
\cline { 2 - 6 } & New Jersey & 10.72 & 7.76 & 0.72 & 2.67 \\
\cline { 2 - 6 } & Pennsylvania & 9.59 & 9.86 & 1.03 & -0.64 \\
\hline \multirow{4}{*}{$\begin{array}{l}\text { East North } \\
\text { Central }\end{array}$} & Wisconsin & 8.60 & 9.23 & 1.07 & -0.97 \\
\cline { 2 - 6 } & Illinois & 8.39 & 8.18 & 0.97 & -0.09 \\
\cline { 2 - 6 } & Indiana & 7.02 & 9.24 & 1.32 & -2.56 \\
\cline { 2 - 6 } & Michigan & 8.48 & 6.45 & 0.76 & 1.79 \\
\cline { 2 - 6 } & Ohio & 8.26 & 8.35 & 1.01 & -0.40 \\
\hline
\end{tabular}

Over the last few years the natural gas price has increased at a faster rate than the electric price, based on multiple publications from Energy Information Administration from 2002-2004 [75],[76],[77]. Many of the identified markets have had a rather constant electric rate but the natural gas price has increased significantly over the last 5 years as shown in Figure 3-13. 

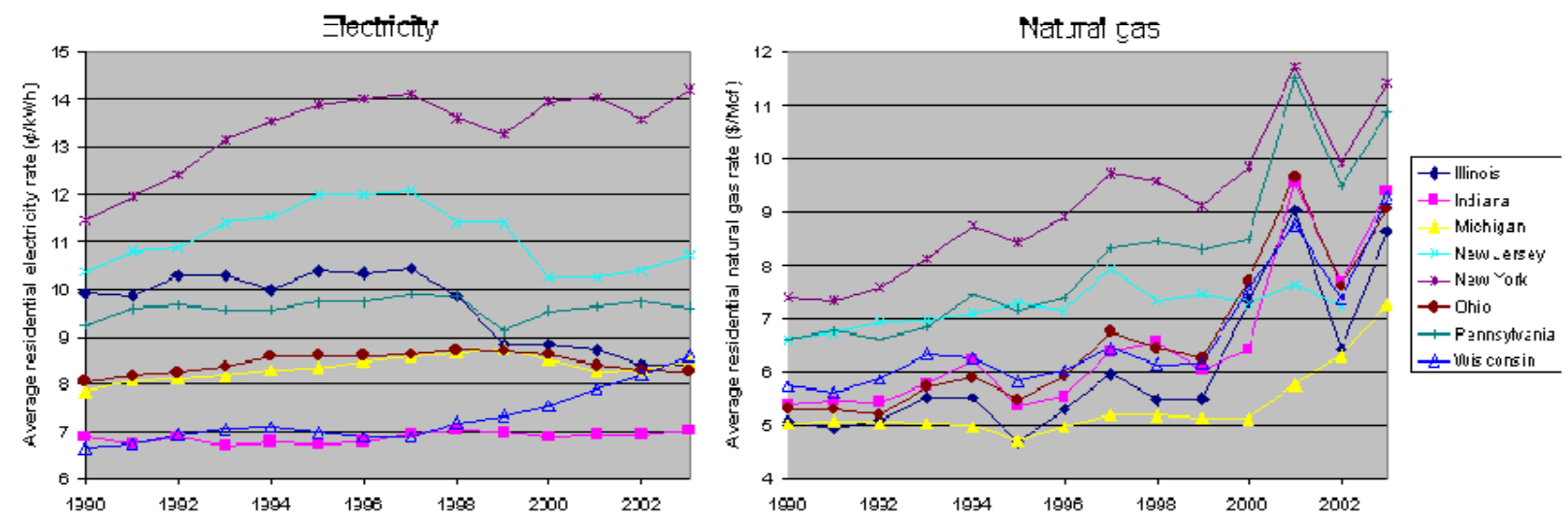

Figure 3-13 Residential utility rates 1990-2003

The impact of these changes in utility rates has resulted in a decreasing spark spread over the last few years as shown in Figure 3-14 and only New York, New Jersey and Michigan show a positive spark spread with the assumption of a $32 \%$ effective power production and distribution. These states coincide with the states identified earlier as meeting all four criteria for consideration of micro-CHP options.

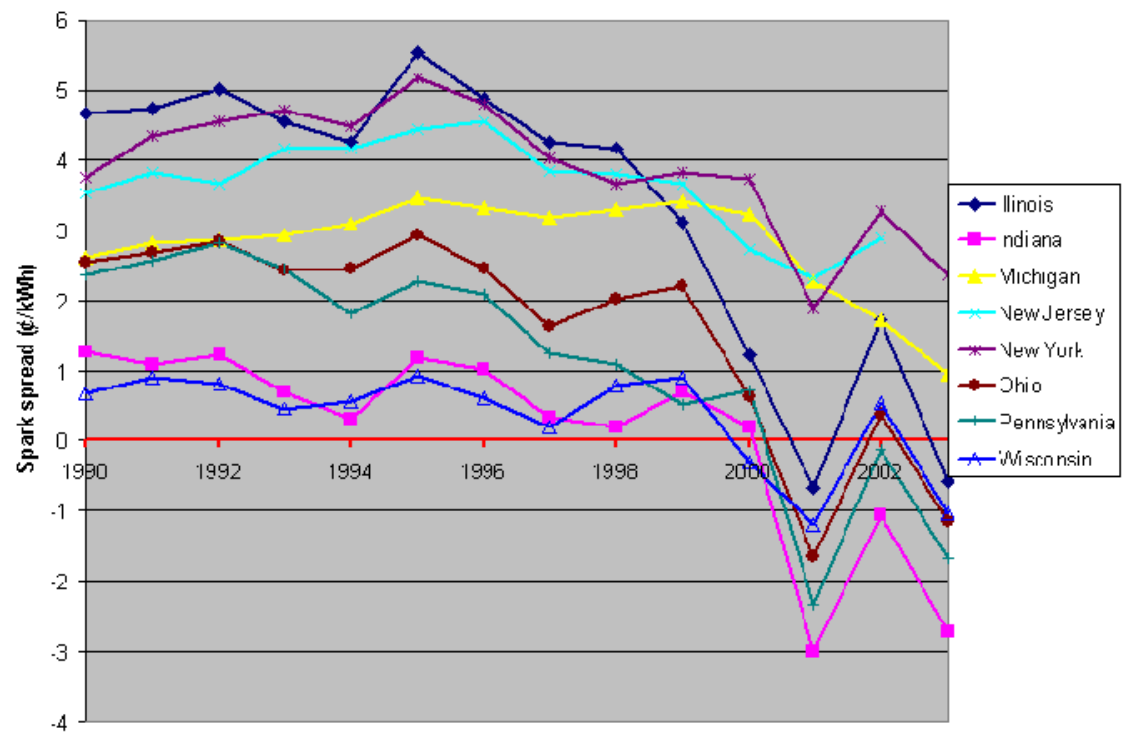

Figure 3-14 Spark spread at residential utility rates 1990-2003

This reduction in spark-spread makes distributed generation of electricity less economical. However the overall increase in energy cost, both for gas and for electricity, makes efficient electricity production more important. In the latter case, micro-CHP is still economically viable as long as the spark spread is calculated taking the overall efficiency into account. Systems where the waste heat is 
fully utilized will have positive payback as long as the cost for the gas is less than electricity measured on direct energy content.

Approaches to thermally-led micro-CHP do not depend on overall power generation efficiency for payback, because the additional cost of the prime mover will be amortized by the electricity generated multiplied by the difference between fuel cost and electricity cost as shown in Figure 3-15. The data show that the best economics prevail in New York and New Jersey and that the states identified in Figure 3-14 as being marginal are potentially viable for heat led concepts because all the heat from the fuel is utilized. This would enable the market in states with 5,000-6,000 heating degree-days, which include Pennsylvania, Ohio, Illinois and states with higher heating loads but lower fuel costs such as Wisconsin.

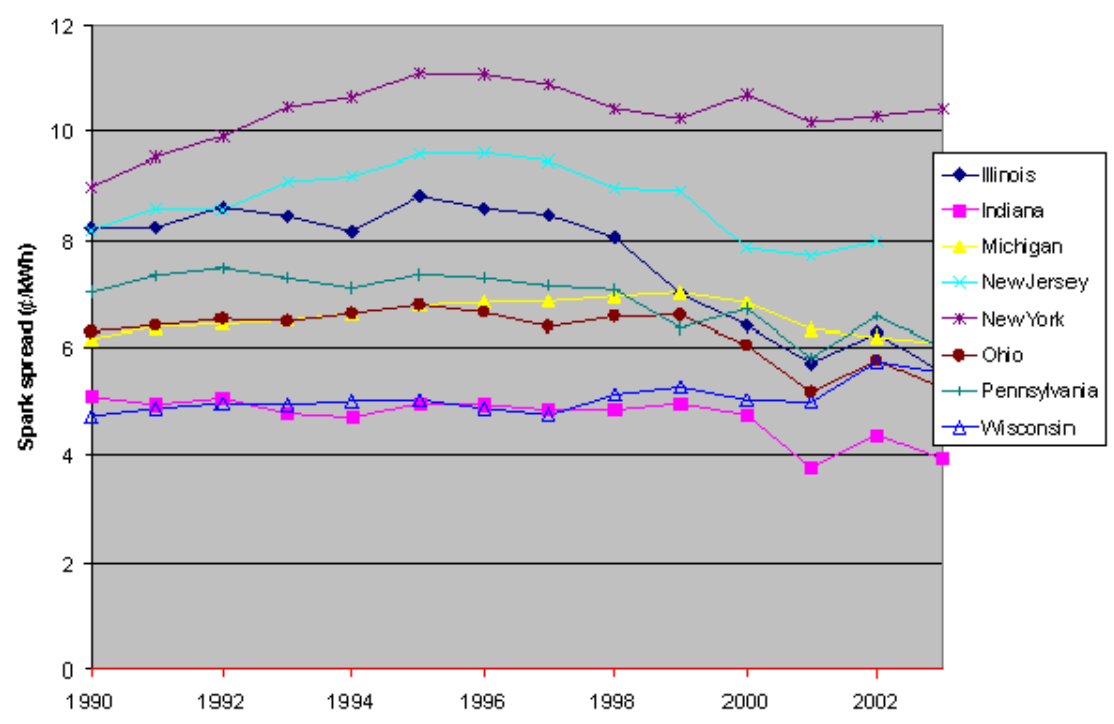

Figure 3-15 Spark spread at residential utility rates 1990-2003 assuming full utilization of fuel

The decision to invest in CHP solutions for individual customers will depend on their view of future pricing of energy since CHP solutions are long-term investment for the homeowner. Furthermore the viability of an American CHP business is equally dependent on future cost of electricity and fuel.

The future outlook for the electric and natural gas prices as presented by DOE in the 2004 energy outlook are illustrated in Figure 3-16 and Figure 3-17. 

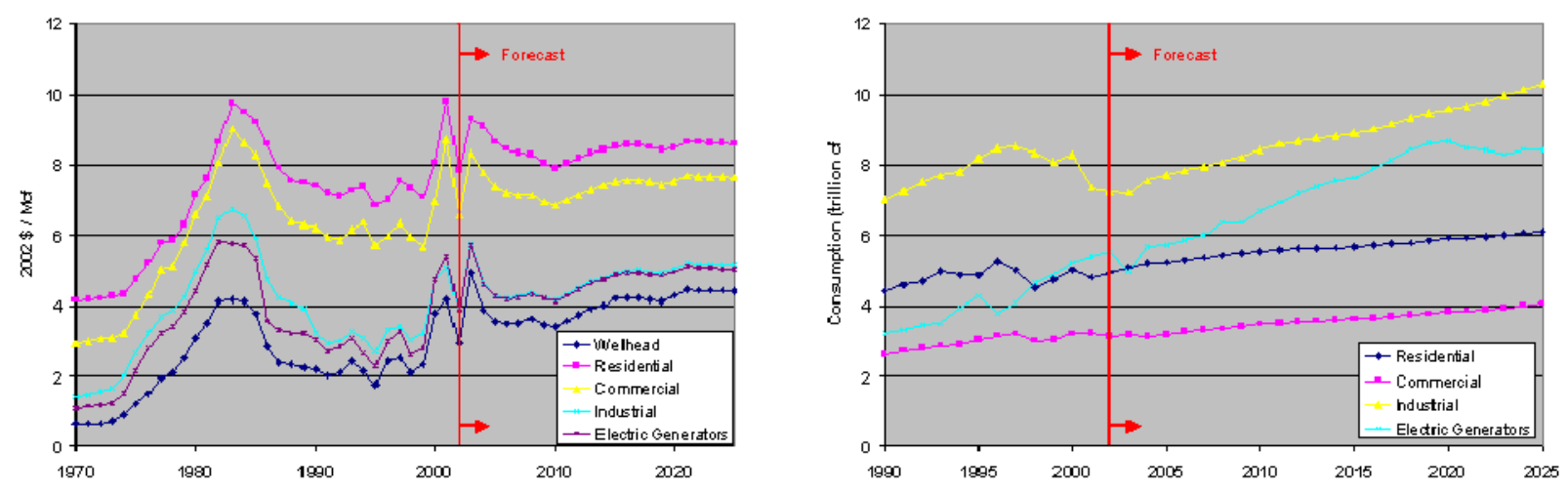

Figure 3-16 Projected future natural gas price and consumption

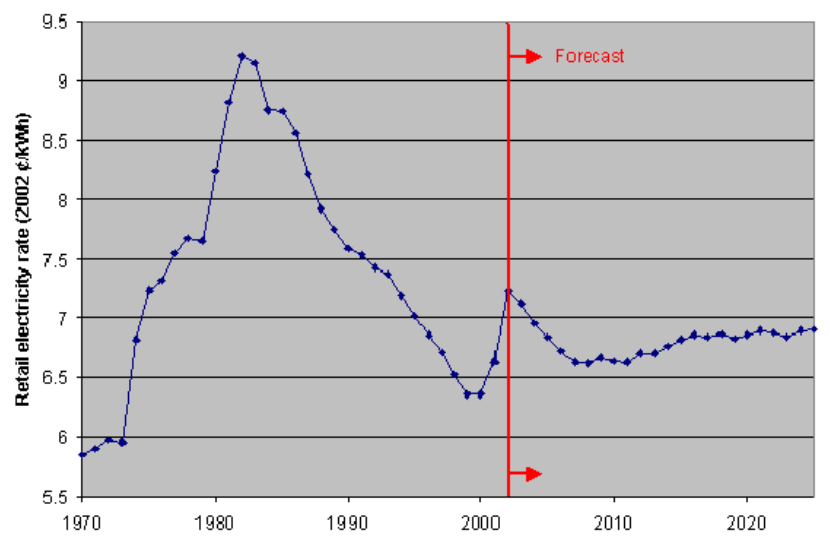

Figure 3-17 Projected national average future residential electricity rate

The DOE forecast predicts an increased overall consumption of natural gas but also a relatively constant price level.

The sensitivity of the spark spread for variations of electric and gas pricing makes it questionable to try to predict the future spark spread. Therefore, the analysis results presented in section 5 are based on today's utility rate data.

\subsubsection{Market Opportunity}

Some of the high-level characteristics of micro-CHP systems that might impact the marketability of the technology are believed to be as follows. (i) Emergency power provided by the prime mover in the micro-CHP system will attract both high-end customers and where no reliable grid is available. (ii) Remote locations with no power distribution. (iii) Energy cost savings resulting from the difference in electricity and fuel price. (iv) "High-tech" label than may be attractive to early adopters. (v) "Green technology" label associated to high-efficiency and/or high fuel utilization, to CFC-free cooling and to low emissions. 
These advantages will have to overweight the barriers to the deployment of micro-CHP technology. (i) Immature technology that translates in low reliability, high warranty costs and poor market acceptance. (ii) First cost intensive investment technology in a market driven by first cost. (iii) Establishment of a disruptive technology in the existing boiler, heater or chiller market. Micro-CHP will meet initial market resistance and sluggishness, in particular due to the fear of a new technology and to the development of new skills required to install and service micro-CHP systems. (iv) Low initial volume that translates in high production cost.

The technology characteristics suggest that the residential micro-CHP system may appeal first to a "premium" market segment having the following features:

- Above average size single family homes

- Above average household income

- High annual energy expenditures to justify increased capital costs.

- Regions with favorable spark spread since CHP shifts building loads from electricity to gas.

The data presented in this section suggest that the establishment of combined cooling-heating and power market may occur in several steps. According to the above analysis, the East North Central and Middle Atlantic regions gather the best conditions for the emergence of combined heating and power market as a first step. The regions cover the following states: New York, Pennsylvania, New Jersey, Wisconsin, Illinois, Indiana, Michigan and Ohio. Since the consumption and the expenditure determine the viability for an individual home, many regions in New England will be viable markets for this technology as well (see Table 3-6). Combining cooling with heating and power for residential applications still include important technology gaps, operation challenges and commercialization challenges as it will be described in the subsequent sections. This latter market should be addressed once the combined heating and power market is mature.

\subsubsection{Requirements and Constraints}

The previous sections of this chapter indicate the emerging of a micro-CHP market. From the market need to the manufacturing of the product, a few steps are needed. First, the high level common requirements for the micro-CHP products need to be defined. Second, candidate technologies that can be used for micro-CHP will be identified, including possible necessary development. Finally, the typical product development cycle can be applied, from building of the prototype to the mass production of the product. This section discusses the common micro-CHP requirements and constraints before moving onto the technology discussion.

The requirements and constrains for micro-CHP can be divided into five categories. The requirements are detailed in Chapter 6:

1. Function

The primary function of Micro-CHP is to bring safely, reliably and at any time the comfort level required to residential buildings by means of combined cooling, heating, and/or power..The requirements on the integrated system solution should be similar to the conventional HVAC, backup power and grid-supplied commodities. 


\section{Operation}

The micro-CHP, as designed for residential applications, should be able to start and operate automatically, e.g., during a grid outage or normal grid operation. On the other hand, to provide flexibility and easy maintenance, the system operation should have human override capabilities. And, of course, it should meet all relevant code and standard, such as UL requirements and any applicable electric regulations.

\section{Reliability}

The system life, reliability and maintenance should be similar to typical residential HVAC equipment.

\section{Emission}

The micro-CHP system should meet any applicable emission standard, either for residential furnace or small scale power generators.

\section{Economics}

Economics is a major factor affecting the marketability of the product. Although adding the power generation capability inevitably increases the system cost, such increase should be within acceptable limits. Costing is a complex task as it depends on large number of factors, usually competing against each other. The cost requirements will depend largely on the primary function of the micro-CHP system, its intended operation, the system benefits over conventional systems, on the technology it is displacing, and somewhat on customer acceptance. For example, if the micro-CHP is meant to provide backup power and does not run most of the time, the premium cost should be consistent with the price of a backup genset and the other aspects outlined above. On the other hand, if the micro-CHP system is designed for continuous operation most of the time, such system should bring positive cash flow and the market acceptance would be based on a different basis.

Other features such as aesthetics and user-friendly interface may also be important requirements to meet the customer need. These requirements or constraints, when applied to a specific system, may sometimes be in conflict, e.g., between cost and features. Although these aspects have not been the primary focus of the present development Phase, they should be carefully evaluated in the subsequent Phase activities. 


\section{Technology Assessment}

In this chapter, the prime mover and thermally activated technology options for the micro-CHP system will be discussed. The respective technology or equipment performance, cost and technology maturity, etc., will be evaluated.

\subsection{Technology Options}

Quantitative performance and costs of a sufficiently broad range of technology options will be defined to allow detailed techno-economic assessment of potential CHP system solutions from a technology neutral perspective. Technologies to be considered include both existing equipments as well as technologies currently under development or envisioned.

\subsubsection{Prime Movers}

A prime mover in a micro-CHP system generates electricity and the waste heat is recovered downstream. The prime mover characteristics, including performance and cost, will be discussed in more details below. The prime movers to be evaluated include micro steam and gas turbines, Stirling engines, reciprocating engines, proton exchange membrane (PEMFC), solid oxide (SOFC), molten carbonate (MCFC) and phosphoric acid (PAFC) fuel cell systems.

The diagram in Figure 4-1 shows the relation between different energy sources and technologies. 

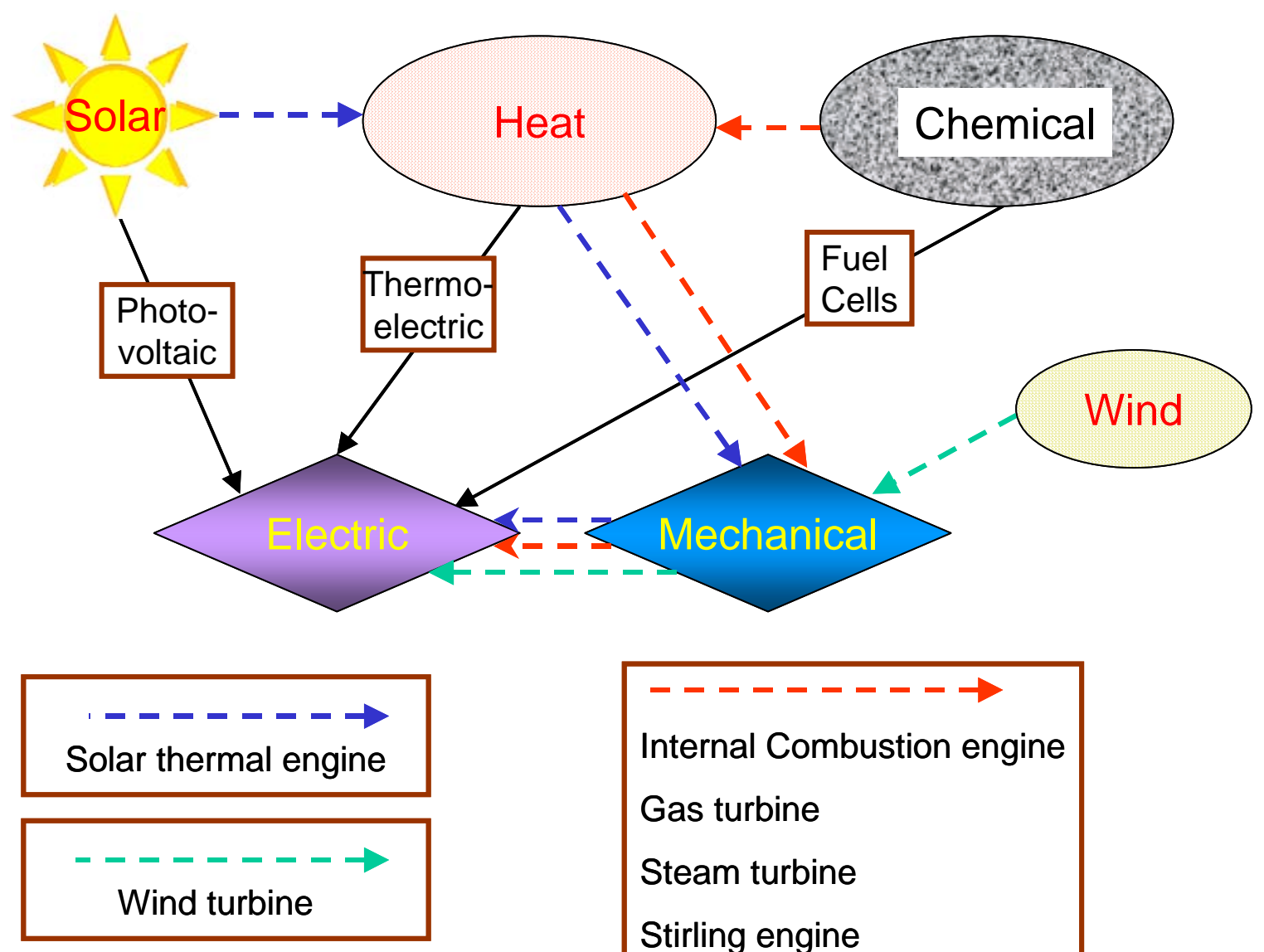

$---------\rightarrow$
Internal Combustion engine
Gas turbine
Steam turbine
Stirling engine

Figure 4-1 The relation between different energy sources and prime mover technologies

\subsubsection{IC Engines or Reciprocating Engines}

IC engine typically is a synonym for internal combustion (IC) engine, although rotary engines are also a type of IC engine. In this report, IC engines and reciprocating engines are treated the same, unless noted otherwise.

In IC engines fuel is burnt inside the engine cylinder and the hot combustion gas imparts motion to the piston. The piston motion is then transferred to the crankshaft that drives external loads.

There are two types of reciprocating engines: gasoline engines running on the Otto cycle and diesel engines running on the Diesel cycle. A gasoline engine is ignited using an electric spark. It has relatively low combustion temperature thus lower efficiency. However it is quieter than a diesel engine. A diesel engine is ignited when the diesel mist/air mixture reaches a high temperature when the mixture is compressed in the cylinder. Because of the higher compression ratio, diesel engines usually have higher combustion temperature and higher efficiency. They are usually heavier than gasoline engines for the same power, and traditionally are used in heavy-duty applications such as trucks or ships, although some small passenger cars do use a diesel engine. 
IC engines for micro-CHP ideally take natural gas or heating oil as fuel. Gasoline fired IC engines are close to natural gas engines and heating oil fired engines are essentially diesel engines, since home heating oil is very close to diesel oil in composition. The engine discussion addressed here therefore is applicable to IC engines for micro-CHP.

\subsection{Current State of Technology}

Reciprocating engines have been used for over a century. The technology is very mature and has been used in all types of applications. It can be used in large applications such as vehicles as well as small machines, e.g., lawn mowers. It is an obvious option for the micro-CHP prime mover.

Small engines used to have much higher cost per $\mathrm{kW}$ and higher emission. A lot of progress has been made on these issues. For example, lean-burning mode, three-way catalyst and oxidation catalyst techniques have been used that enable the NOx to be below $50 \mathrm{ppm}$, sometimes around 20 ppm.

Small engines such as those for lawn mowers are usually very noisy. However, micro-CHP prime movers are supposed to be located indoors and noise levels must be reduced to acceptable levels. Noise level reduction has been quite successful for the micro-CHP. For example, the ECOWILL 1$\mathrm{kW}$ gas engine achieves $44 \mathrm{dBA}$ at 1 meter and 5-kW micro-CHP unit noise level is around $50 \mathrm{dBA}$ at 1 meter ${ }^{[124]}$.

Longer engine maintenance is strongly desired for micro-CHP. Servicing includes engine oil change, changing filters and the spark plugs, etc. Typical reciprocating engine service interval is around 3,000 hours. However, the ECOWILL 1-kW reciprocating engine based micro-CHP requires servicing only every 6,000 hours. Considering that micro-CHP does not run year-round, the 6,000hour service schedule means the system needs service only once a year, which is comparable to the house hot water or heating furnace schedules.

Diesel engines usually have higher compression ratio therefore higher efficiency than gasoline or natural gas engines. Gasoline engines are ignited with spark and diesel with compression. Typically gasoline engines are lighter and have smaller noise.

\subsection{Future Industry and Technology Trends}

Although some progress has been made to improve the reciprocating engine technology, the noise, service interval and emission control for NOx and CO still need more work to be desirable for micro-CHP. The NOx target for the Advanced Natural Gas Reciprocating Engine is $0.1 \mathrm{~g} / \mathrm{hp}-\mathrm{hr}$ $(0.134 \mathrm{~g} / \mathrm{kWh})$. To increase the fuel flexibility of engines, natural gas-fired engines are to be adaptable to future firing with dual fuel capabilities ${ }^{[55]}$.

\subsection{Benefits and Limitations}

Reciprocating engines have several advantages for micro-CHP. First it is a mature and wellunderstood technology. It can be designed for different fuels including gasoline, diesel, natural gas or landfill gas, etc. Large engines can run more than 20 years although smaller engines have somewhat shorter life. The efficiency of the reciprocating engine is around $25-45 \%$, which is higher 
than steam engines and current Stirling engines. Also reciprocating engines have a short startup time than external combustion engines.

One of the limitations of reciprocating engines is the frequent maintenance. The current maintenance cost is around $\$ 0.007-0.015 / \mathrm{kWh}$ (for gas engines) and $\$ 0.005-0.01 / \mathrm{kWh}$ (diesel engines) ${ }^{[55]}$. In general, noise and emissions are two issues for the reciprocating engines.

\subsection{Market Analysis}

Several companies have been developing or marketing the reciprocating engine based micro-CHP. For example, SenerTec has sold more than $8,0005.5 \mathrm{~kW}$ units (gas engine) in Europe with the installed cost of $\$ 14,990$. EcoPower developed a $4.7-\mathrm{kW}$ gas engine micro-CHP that can be modulated down to $2 \mathrm{~kW}$. The cost is around $\$ 14,950^{[124]}$. VectorCogen has developed $15-\mathrm{kW}$ systems with the cost around $\$ 30,000^{[124]}$. A much smaller unit is available from Honda/Osaka Gas, with $1-\mathrm{kW}$ of electric power at the cost of $\$ 6800$.

Typical stand-alone reciprocating engines are much cheaper. For example, $1 \mathrm{~kW}$ gasoline engine generator can be as low as $\$ 400$ in the consumer store (Lowe's). However micro-CHP requires noise reduction device, power conditioning equipment, emission control and waste heat recovery system. Therefore reciprocating engine micro-CHP is much more expensive. Even though the market is growing and there are competitions from multiple players, great reduction in cost is not expected from high volume sales, which is different from other technologies such as Stirling engine or fuel cells ${ }^{[124]}$.

\subsubsection{Stirling Engine}

Stirling cycle engines were patented in 1816, and were commonly used before the First World War. Stirling engines are external combustion engines in which the working fluid, usually helium or hydrogen, runs the Stirling cycle in a sealed compartment. A Stirling cycle has two isothermal processes and two isochoric (constant volume) processes. There are two major types of Stirling engines: Displacer Type and Two Piston Type. Figure 4-2 shows a schematic of a two-piston type Stirling engine.

The theoretical efficiency of the Stirling engine is equal to that of the Carnot engine, which is the highest possible of all heat engines.

Stirling engines generally are small in size, ranging from $1-25 \mathrm{~kW}^{[53]}$ although some can be up to $500 \mathrm{~kW}^{[74]}$. 


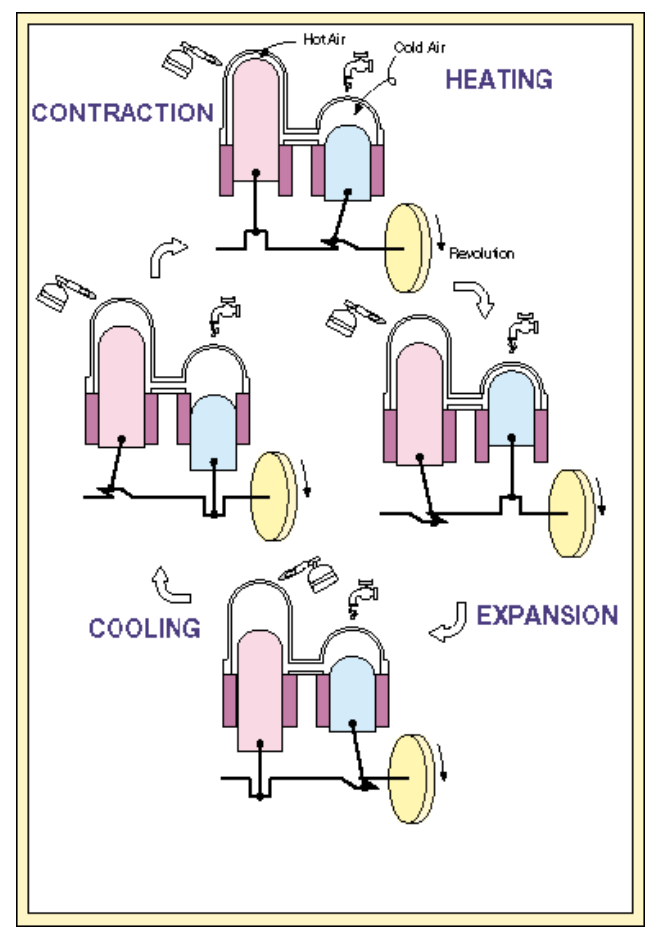

Figure 4-2 Two-piston type Stirling engine working diagram ${ }^{[103]}$

\subsection{Current State of Technology}

Stirling engine related technology development is following primary paths: the engine design and development and the system design and development.

From the engine design point of view, the most important performance indicator is efficiency. The electrical efficiency of Stirling engines is usually low. Current electric efficiency of typical Stirling engines is $12-30 \%{ }^{[53]}$. For electric power generation purposes, the higher efficiency, the better, and the current goal is above $30 \%$.

Whisper Tech, which has targeted Stirling based micro-CHP, patented the Wobble Yoke transmission system, which converts the linear motion of the engine's four pistons into the rotary motion, which is necessary to drive an alternator

\subsection{Future Industry and Technology Trends}

Durability and cost are two major shortcomings of current Stirling engine technology ${ }^{[53]}$. The durability challenges include shaft seal, piston rings and bearings leakage, minimization of material stress and corrosion in the high temperature region, as well as problems with abrasive particles generated at the piston rings. Stirling engines are expected to have long life and low maintenance ${ }^{[53]}$. 


\subsection{Benefits and Limitations}

Due to the nature of external combustion, the Stirling engine can use almost any fuels such as natural gas, gasoline and solar energy. The combustion can be controlled relatively easily and the emissions have the potential to be very low. The noise of the Stirling engine is lower than that of the IC engines. The maintenance is also supposed to be low and the life is usually long ${ }^{[53] .}$

A great advantage for the Stirling engine is that, in a micro-CHP, the heat from the burner that is not used by the Stirling engine can be readily used for hot water and space heating.

The major disadvantages of the Stirling engines include: 1) the high cost. Currently the Stirling engine price is around $\$ 2,000-\$ 50,000 / \mathrm{kW}^{[53]}$. 2) The engine needs a few minutes to warm up before producing power and the engine cannot change its power quickly ${ }^{[101]}$. 3) Durability of certain parts is still an issue, as mentioned earlier.

\subsection{Market Analysis}

There are more than 20 Stirling engine manufacturers worldwide ${ }^{[53]}$. Currently Stirling engines have been used in various applications, which include residential, space and marine industries, and vehicle, such as on a Segway scooter ${ }^{[35] .}$ But the total Stirling engine market is rather small as of this writing.

Stand-alone Stirling engine is mainly aimed at waste heat recovery for power generation. Stirling engine based micro-CHP has been has been under development and deployment by WhisperTech in the United Kingdom at engine capacity of $1 \mathrm{~kW}^{[124]}$. If these Stirling miro-CHP applications are successful, Stirling engine based micro-CHP may see increased sales volume coming to the housing industry. Related Stirling engine technology will be improved and the cost is likely to reduce.

\subsubsection{Rankine Cycle Engine}

The Rankine cycle is a thermodynamic cycle that is used to generate electricity in major power stations. In this cycle, superheated, high pressure steam is generated in a boiler, and then expanded in a steam turbine. The turbine drives a generator to convert the work into electricity. The remaining steam has low pressure and is then condensed. Condensed fluid is recycled to the boiler..

The water/steam Rankine cycle is mainly used in large scale (1MW hundreds of MW scale) because Rankine cycle efficiency is roughly proportional to the working fluid temperature and pressure, and high fluid temperatures can be achieved in a boiler by external combustion of fuels. This type of cycle is called topping power generation cycle. If the heating source temperature is relatively low, e.g., $400^{\circ} \mathrm{C}$, steam cannot reach very high pressure, and organic working fluids can be used to achieve higher pressures and conversion efficiencies. Therefore Organic Rankine Cycle (ORC) is more often used in a bottoming cycle, based on the fact that the cycle is at the bottom stage of an energy system to recover the waste heat. 


\subsection{Current State of Technology}

Although typical Rankine cycle systems are in the order of MW or above, some small scale systems have capacity as low as $50 \mathrm{kWe}{ }^{[107]}$. In recent years, Rankine cycle engines in the order of $1 \mathrm{kWe}$ have appeared for the micro-CHP application. Enginion, a German company, is developing a 4.6 $\mathrm{kWe}$ Rankine cycle micro-CHP unit that uses a piston engine with water as the working fluid. Cogen Micro in Australia has developed a $2.5 \mathrm{kWe}$ Rankine cycle machine, which also uses a piston engine with water as the working fluid. Energetix, on the other hand, uses organic working fluid with scroll expander for a 1-kW Rankine machine ${ }^{[124]}$. The Rankine cycle for micro-CHP is less expensive than most other prime mover technologies and is likely to be a competitive prime mover technology.

These units are currently still in testing stage.

\subsection{Future Industry and Technology Trends}

Rankine cycle machines developed so far can use standard components, such as the scroll compressor as the expander, and no special material is needed. Some of these components have been in large volume production for a long time. This keeps the system cost low. It is likely that the small Rankine engine developers will continue to use more standard or existing equipment or technology to save the engine cost and to be competitive with other technologies.

\subsection{Benefits and Limitations}

The Rankine cycle engines used in large systems usually have a design life of 30 years. Small scale Rankine engines, without any real application data yet, are expected to have similar life since the cycle temperature and pressure are even lower than large equipments. Rankine cycle engines are also a type of external combustion engine, which can use a conventional burner. Also it makes the electric/thermal load balancing in micro-CHP easier. Much of the system can be from the standard equipment list thus saving equipment cost.

The major disadvantage of the Rankine cycle engines is that the efficiency is low. Small-scale Rankine engines typically do not have superheaters or reheaters as in large power plants. Therefore the electric conversion efficiency of the small engines are much lower, around $10 \%$, down from about $40 \%$ in large power stations. However, this does not constitute a problem for micro-CHP because matching the thermal and electric loads for a typical residence can be achieved even if the micro-CHP prime mover does not operate at high efficiency. On the other hand, there haven't been any Rankine cycle engines in commercial sales for micro-CHP and more testing data are needed to really evaluate this promising technology.

\subsection{Market Analysis}

Without any commercial data, some estimated costs are available from the developers ${ }^{[124]}$. Climate Energy expected to offer 3-kW micro-CHP system for $\$ 5,000$, or $\$ 1,667 / \mathrm{kW}$. Enginion is targeting an end user price of $\$ 6,900$ or $\$ 1,500 / \mathrm{kW}$ for its $4.6 \mathrm{~kW}$ micro-CHP system. Cogen Micro estimated that the $2.5 \mathrm{~kW}$ system it developed is around $\$ 3,900$, or $\$ 1,560 / \mathrm{kW}$. Compared to the $\$ 5,100$ WhisperTech 1kW Stirling micro-CHP and \$6,800 Honda/Osaka Gas 1kW engine CHP, the Rankine cycle micro-CHP appears to be competitive. However, this has to be confirmed once real product come to market. 


\subsubsection{Fuel Cell}

A fuel cell generates electricity from a chemical fuel directly by means of electrochemical reactions. There are four types of fuel cells today:

- Proton exchange membrane FC (PEMFC)

- Solid oxide FC $\quad$ (SOFC)

- Molten carbonate FC (MCFC)

- Phosphoric acid FC (PAFC)

The comparison of different fuel cells is listed in Table 4-1.

Table 4-1 Fuel cell technical comparisons ${ }^{[54]}$

\begin{tabular}{|c|c|c|c|c|}
\hline FC type & PAFC & MCFC & SOFC & PEMFC \\
\hline Need reformer & Yes & No & No & Yes \\
\hline Size Range & $100-200 \mathrm{~kW}$ & $1 \mathrm{~kW}-10 \mathrm{MW}$ & $20 \mathrm{~W}-10 \mathrm{MW}$ & $1-250 \mathrm{~kW}^{*}$ \\
\hline Fuel & $\begin{array}{l}\text { NG, landfill gas, } \\
\text { digester gas, } \\
\text { propane }\end{array}$ & $\begin{array}{l}\text { Natural gas, } \\
\text { hydrogen, landfill } \\
\text { gas, fuel oil }\end{array}$ & $\begin{array}{l}\text { Natural gas, } \\
\text { hydrogen }\end{array}$ & $\begin{array}{c}\text { Natural gas, } \\
\text { hydrogen, propane, } \\
\text { diesel }\end{array}$ \\
\hline Efficiency & $36-42 \%$ & $45-60 \%$ & $45-55 \%$ & $30-40 \%$ \\
\hline Commer. Avail. & Yes & No & Yes & No \\
\hline Waste heat & HW (hot water) & HW, LP/HP steam & HW, LP/HP steam & $80^{\circ} \mathrm{C} \mathrm{HW}$ \\
\hline Commer. Avail. & Yes & No & Yes & No \\
\hline Current Cost & $\$ 4000 / \mathrm{kW}$ & N/A & N/A & $\sim \$ 5000 / \mathrm{kW}$ \\
\hline Life & $\sim 40,000$ hours & & & \\
\hline Other Features & Proven reliability & & & Synergy with auto \\
\hline
\end{tabular}

SOFC is a type of high temperature fuel cell. There are two types of SOFCs: planar cells and the tubular cells. PEMFC operates at low temperature and is not suitable for micro-CHP if it is fueled by hydrogen. PAFC typically have larger capacity and high operating temperature, an advantage for micro-CHP. MCFC has not been commercially available. SOFC and PEMFC have been developed for micro-CHP and will be discussed in more details below.

\subsection{Current State of Technology}

Several companies have been developing fuel cell-based micro-CHP systems. For example, Sulzer Hexis of Europe has field tested more than 100 SOFC units in European households but has recently terminated further development. Kyocera, a Japanese company, has developed a 1-kW SOFC microCHP prototype and targeted commercialization in 2005.

PEM fuel cell based micro-CHP is also under development provided the system is fueled by natural gas and reformers are used to prepare hydrogen for the fuel cell. Plug Power, IdaTech and UTC Fuel 
Cell are partnering to develop $\sim 5 \mathrm{~kW}$ PEMFC micro-CHP. Ballard of Japan is involved in developing 1-kW PEM FC based micro-CHP.

Generally, there are still many technical issues in either SOFC or PEMFC. The technology for tubular SOFC has shown durability exceeding 70,000 hours for single cell and $>20,000$ hours for a $200 \mathrm{~kW}$ power plants. The technology for planar SOFC is still under development and the major issues arise from interconnect lifetime, seal integrity, and robustness to thermal cycling. For PEMFC, the membrane lifetime is rather short and there is no clear path yet to achieve the desired 40,000-hour durability.

\subsection{Future Industry and Technology Trends}

The major drawback for all fuel cells is the high capital cost. Fuel cell manufacturers are seeking to make the economic picture more attractive by integrating fuel cells into CHP systems. The commercial potential of the micro-CHP with fuel cell relies heavily on the unit capital cost, while cost could only go down when there is enough sales. The first step is to remove the existing technology barriers such as the performance stability and robustness to thermal cycling in the case of SOFC.

It is estimated that there could be several years for fuel cell based micro-CHP to be commercialized. The development work is more likely to focus on the fuel cell stack itself rather than the CHP system design since nothing is special or demanding in terms of the needed heat recovery devices for the system.

\subsection{Benefits and Limitations}

Fuel cells have several benefits: they have higher efficiency than most other prime movers. Emissions are essentially absent. Maintenance is needed for balance-of-plant components such as pumps, blowers and the reformer. However, the major limitations of fuel cell stacks are also obvious. The high operating temperature of SOFC leads to slow in transient behavior and as a result $\mathrm{SOFC}$ is better for base-loading. But the typical house electric load is extremely peaky so SOFC may not be a good solution if the system is electrically led for residential micro-CHP. PEMFC does not operate at high temperature, can work better at part load and responds faster. Its major problem is that the short lifetime of the membrane. In addition, for all fuel cells, the cost is very high.

\subsection{Market Analysis}

There are no fuel cell based micro-CHP systems commercially available at this moment. Some price projections are available for the systems in field testing. The Kyocera 1-kW SOFC micro-CHP is planned to reach the market in 2005 . The price would be around $\$ 10,900$. The company plans to produce and sell about 1,000 units in 2005. Other companies are a few years behind in terms of market entry. Fuel Cell Technologies plans to sell its product starting in 2007.

Commercially priced PEMFC micro-CHP systems are likely to enter the market even later. Considering that the cost of the PEM cell stack is presently estimated at around $\$ 5,000 / \mathrm{kWe}$, the PEMFC micro-CHP system price would be in the neighborhood of $\$ 10,000$ for a $1 \mathrm{~kW}$ unit. 
Because the fuel cell technology is still relatively immature, it is probably too early to derive any meaningful conclusions about the market of fuel cell based micro-CHP as of this writing.

\subsubsection{Microturbine}

Microturbines are small combustion turbines with the electrical capacity of 25 to $500 \mathrm{~kW}$. They are designed mainly to meet the load for small or mid size commercial customers as standby power, peak shaving or cogeneration. The technologies used in microturbines are similar to large combustion turbines except that they are less sophisticated and thus have relatively lower efficiency compared to the larger turbines. For example, small microturbines usually have only one stage expander and the pressure ratio is lower. A typical microturbine structure is shown in Figure 4-3.

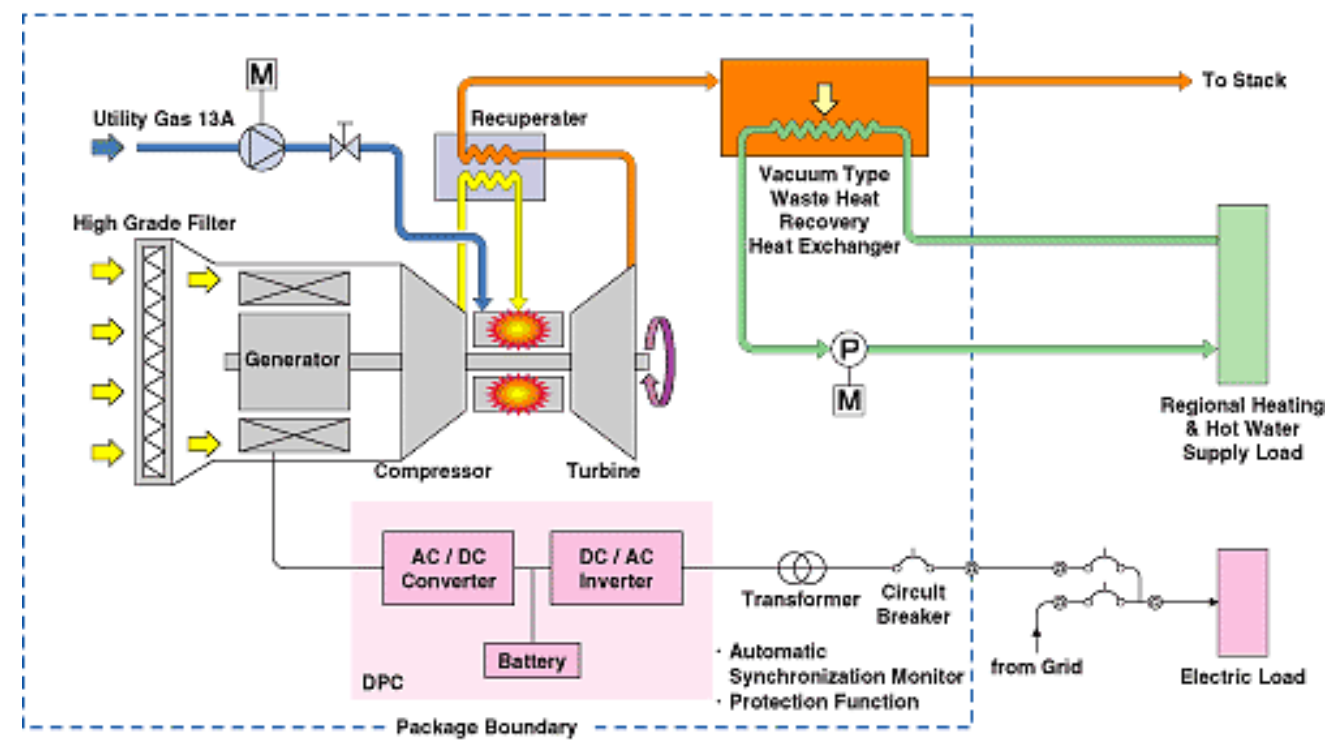

Figure 4-3 TCP-30 microturbine structure and flow chart ${ }^{[143]}$

\subsection{Current State of Technology}

Many companies are developing microturbine products both in the US and the rest of the world. Some products such as the Capstone C60 have gone through field testing and are being offered commercially.

Certain microturbines are equipped with heat recuperators, which lead to higher electric efficiency of around 20-30\%. Microturbines without a recuperator have efficiencies of only about $15 \%$.

For power generation purposes or commercial CHP, it is desirable to have as high efficiency as possible. Current development work is focused on improving the mechanical design for higher efficiency and lower equipment cost. The microturbine equipment cost is around $\$ 700-\$ 1100 / \mathrm{kW}$ and the installation is another $\$ 500 / \mathrm{kW}$ roughly. The total microturbine cost is higher than the internal combustion engine cost. 


\subsection{Future Industry and Technology Trends}

Current microturbine research effort includes the use of different fuels (such as landfill gas), heat recovery and cogeneration design, application to vehicles and integrated fuel cell/microturbine. These will hopefully expand the market for microturbines ${ }^{[56]}$.

The electric capacity of current microturbines, usually $25 \mathrm{~kW}$ or above, is too high to be in a residential micro-CHP unit. For residential purposes, a prime mover should be of the order of $1 \mathrm{~kW}$. Micro Turbine Technology (MTT) in Germany has created a proof-of-concept prototype that produces $\sim 4 \mathrm{~kW}$ of mechanical power. Their target is to design a $1 \mathrm{~kW}$ microturbine, this having the size of a coffee cup and electrical efficiency of $10-15 \%$. The company is expecting to have a microturbine based micro-CHP product in three years with the microturbine price around 80 Euro $(\mathrm{US} \$ 92)^{[124]}$.

\subsection{Benefits and Limitations}

Microturbines are favored because they have lower NOx emission compared to IC engines due to lower combustion temperature. Also microturbines have smaller weight than the IC engines of the same power. They have fast response, of the order of seconds, and, therefore are a good candidate for backup power. Microturbines are compact in size and are easy to maintain. The maintenance interval typically is every 5,000-8,000 hours, about double of the IC engine maintenance interval. It can be used for different fuels, including natural gas, hydrogen, propane or diesel.

The major disadvantages of this technology include the high cost $(\$ 700-1,100 / \mathrm{kW})$, relatively shorter life ( $\sim 10$ years) and high O\&M cost, which is around $\$ 0.005-0016 / \mathrm{kWh}$. The efficiency of microturbines is not very high, although this is enough or more than enough for residential microCHP because of the high thermal/electric load ratio. Finally, microturbine power output will decrease with higher elevation and higher temperature. This is not desirable for certain locations and in hot weather.

\subsection{Market Analysis}

Microturbines have been considered as a good option for distributed generation or cogeneration and are used for commercial applications. Although more development is needed such as fuel flexibility and higher efficiency, the major hurdle for the micro-CHP market is likely to be non-technical. For example, if microturbines are allowed to send the power to the grid at reasonable price, the microturbine may be well accepted by commercial building owners such as hotels or restaurants.

On the micro-CHP side, if the 1-kW scale microturbines are available and can have low price as expected, microturbines will be very competitive compared to Stirling or Rankine cycle machines.

\subsubsection{Other Power Generation Technologies}

Several other technologies can be used to generate power. They are introduced here as well in case they could be considered for micro-CHP. 


\subsubsection{Photovoltaic (PV) Solar Cell}

There are two basic PV system configurations that are currently utilized. The first is a flat-plate array, which is designed to collect all the sunlight that strikes it, both direct sunlight and diffuse sunlight that is reflected from clouds, the ground, and nearby objects. The second is a concentrator array, which is designed to capture a large area of direct solar energy and focus it onto a small area where the solar cell resides. Concentrators can produce high cell efficiency but they are significantly more expensive than flat-plate arrays, see Figure 4-4, because they require concentrating optics and control systems that track the sun throughout the day and year to be effective. The DC electrical output produced by a PV cell can be conditioned into grid quality $\mathrm{AC}$, used to charge a battery or other electrical energy storage device, or used to split water to produce $\mathrm{H}_{2}$.

\subsection{Current State of Technology}

Flat-plate cells are constructed from either crystalline silicon or from thin films using amorphous silicon. Other materials such as copper indium diselinide (CIS) and candium telluride also hold promise as thin-film materials. The majority of systems installed today are in flat-plate configurations. These systems are generally fixed in a single position, but can be mounted on structures that tilt toward the sun on a seasonal basis or on structures that roll east to west over the course of the day.

Photovoltaic concentrator systems use optical concentrators to focus direct sunlight onto solar cells for electricity generation. PV concentrator module components include solar cells, an electrically isolating and thermally conducting housing for mounting and interconnecting the cells, and optical concentrators. The solar cells in today's concentrators are predominantly silicon, although gallium arsenide (GaAs) solar cells may be used in the future because of their high-conversion efficiencies. The optical concentrators are generally Fresnel lenses but can also be reflectors.

PV systems can be installed as either grid supply technologies or as customer-sited alternatives to retail energy. As suppliers of bulk grid power, PV modules would typically be installed in large array fields ranging in total peak output from a few megawatts on up. However, very few of these systems have been installed to date. There has been growing interest in customer-sited systems, including residential systems on the order of a few kilowatts and commercial systems on the order of several hundred kilowatts. The number of residential and commercial applications is expected to increase in the US to meet the following needs.

- Distributed utility system for grid support

- Peak power shaving

- Intermediate daytime load following

- Electric storage for power dispatch

- Improved power transmission

- Production of portable $\mathrm{H}_{2}$ fuel

The highest efficiency for single-crystal or polycrystalline wafers is $24 \%$ and for commercial modules is $13-15 \%$. Silicon modules cost about $\$ 2-3$ per We to the manufacture. The highest efficiency for single-crystal Si and multi-junction gallium arsenide alloy cells for concentrators is 
$25-34 \%$ and for commercial modules is $15-17 \%$. Prototypes are being tested in the US southwest desert. There are other materials that have been studied by federally funded universities, national labs, or industries, such as copper indium gallium diselenide (19\% cells and $12 \%$ modules) and cadmium telluride (16\% cells and $11 \%$ modules).

\subsection{Future Industry and Technology Trends}

Most PV systems installed to date use crystalline silicon cells, which is a relatively mature technology. In the future, cost-effectiveness will be achieved through incremental efficiency improvements, enhanced yields, and advanced lower cost manufacturing techniques. Thin film technology is already commercially available, but its real impact is expected to become significant during the next three to ten years. Its success will depend on investment levels for technology and manufacturing development. Thin film using amorphous silicon has several advantages over crystalline silicon, including low cost and greater responsiveness to indoor light. As thin film PVs are produced in larger quantities and achieve expected performance gains, they will become more economical for the whole range of PV applications. As for multi-junction cells with efficiencies of $38 \%$ at very high concentrations, major development efforts have been underway. The NREL GaAs alloy cell was spun off to the space power industry, leading to a record cell efficiency of $34 \%$ and a shared R\&D Award for NREL/Spectrolab in 2001. Manufacturing research and supporting technology development also holds keys to future cost reductions. Large scale manufacturing of PV cells and modules and development of advanced power electronics and non-islanding inverters will allow major cost reductions and lessen barriers to customer adoption and utility interface.

\subsection{Benefits and Limitations}

Photovoltaic arrays convert sunlight into electricity without moving parts and without producing fuel wastes, air pollution, or green house gases (GHGs). The use of PV cells to generate electricity will help reduce levels of $\mathrm{CO}_{2}$ worldwide. Currently the greatest limitation to the use of PV systems is their cost, which prohibits the technology from being commercially available in large scale, even though a substantial market exists for PV power generation applications.

\subsection{Market Analysis}

Almost all locations in the US and worldwide have enough sunlight to take advantage of PV cells (e.g. US sunlight varies by only $25 \%$ from an average in Kansas). Land area is also not a problem for PV cells since there is abundant open space or available area on rooftops and above parking lots. In 2,000, about $288 \mathrm{MW}$ of PV power units were sold, worth more than $\$ 2$ billion, with more than 1 GW of potential PV power installed. The share of the world market in the US is about $26 \%$. The annual growth rate for PV cells has been around $25 \%$ as a result of reduced prices, successful global marketing, and tax incentives. Recently, sales growth has accelerated to almost $40 \%$ per year. Almost two-thirds of US manufactured PV cells are exported. The fastest growing segment of the market is grid-connected PV cells, such as roof-mounted arrays on homes and commercial buildings in the United States. 


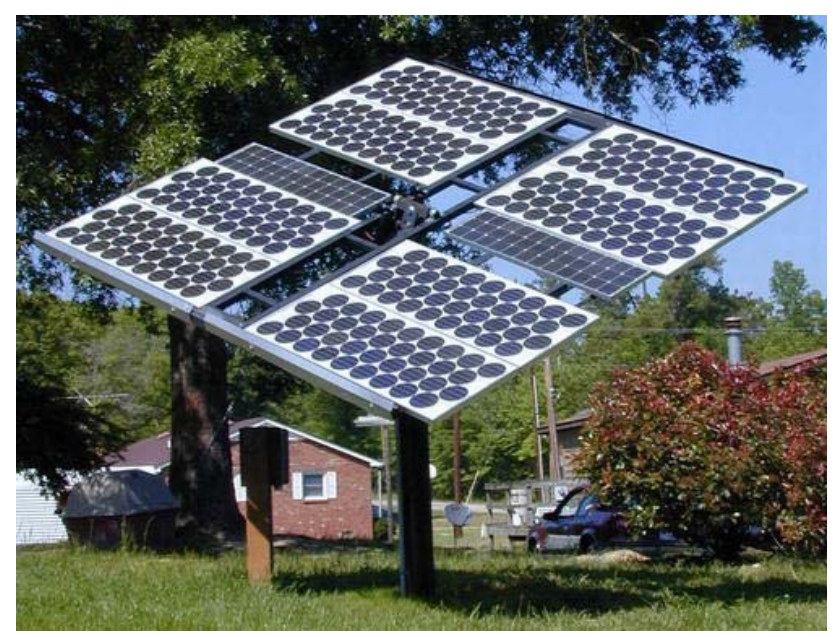

Figure 4-4 PV cells

\subsubsection{Solar Thermal Technology}

Different from PV, which changes solar energy to electricity directly, a solar thermal electric system first collects and concentrates the solar energy using a receiver. The receiver contains a fluid, such as molten salt, that circulates in the receiver and heats an engine, such as a Stirling or Brayton cycle machine, to produce power. Figure 4-5 shows the working principle of solar thermal power systems.

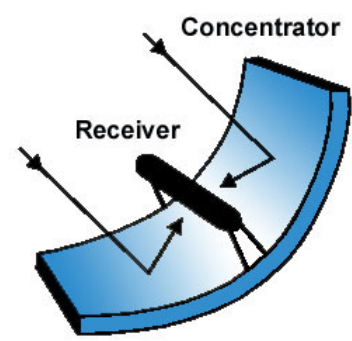

(a)

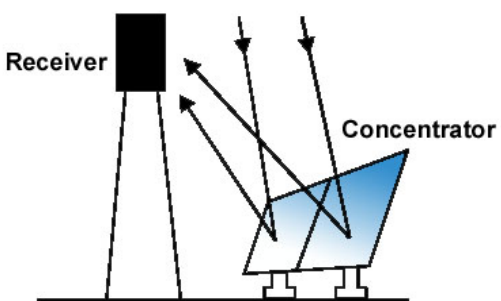

(b)

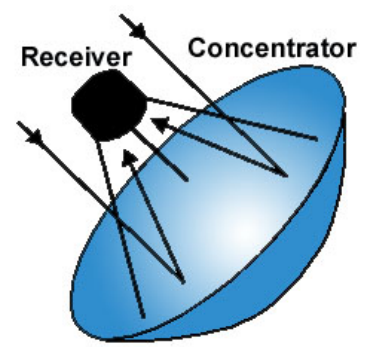

(c)

Figure 4-5 Different designs of solar thermal power systems

\subsection{Current State of Technology}

Solar thermal electricity involves two pieces: a concentrator and an engine/receiver. Different concentrators have been developed to collect the solar energy in different applications. Figure 4-5(a) shows a parabolic trough. The installation of the parabolic trough can be horizontal or vertical and is easier than a 2-D parabolic dish or power tower that require more complex tracking systems. The LUZ Solar Electric Generating Systems (SEGS) in San Bernardino, California generates 355 MW of electricity using a trough arrangement. The temperature that molten salt reaches in this system is as high as $1050^{\circ} \mathrm{F}$. Power towers use a number of heliostats (large sun tracking flat plane mirrors) to focus sunlight onto a central receiver that is situated on a tower. A parabolic dish has the best collection efficiency for the solar energy. In 1984, a 25-kW parabolic dish/Stirling system achieved 29.4 percent net efficiency. 


\subsection{Future Industry and Technology Trends}

There has not been a lot of progress on solar thermal power generation for the past two decades. Most solar thermal applications focus on low or medium temperature applications such as pool heating, hot water or space heating. Solar power generation requires high temperature fluids, typically $1,000^{\circ} \mathrm{F}$ or above. The requirements for the material, engine design and installation are all very high. On the other hand, solar thermal power generation has higher efficiency than solar PV. Therefore the technology is still attractive to the regions such as US west but faces competition from more mature PV power generation.

\subsection{Benefits and Limitations}

As a technology for renewable energy, the solar thermal power generation has other common advantages: clean and no emission issues. Compared to solar PV, the major benefit of solar thermal power is higher efficiency. The major disadvantage for all solar power generation is that it is affected by location and weather and the cost is very high. If it is used for residential applications, back up systems are needed, although the solar thermal system is already very expensive. Also for a CHP application, waste heat from the prime mover is needed to drive thermal loads. It is difficult to send the waste heat from the receiver to the inside of the house. Therefore, solar thermal power generation may not be a good option for micro-CHP at present.

\subsection{Market Analysis}

Although the sales for solar thermal equipment have been increasing, these are mainly for low to medium temperature ranges. For example, in 2001, the sales for low, medium and high temperature solar collector are 10919, 185 and 2 thousand square feet, and the prices are 2.15, 20 and 108 dollars/square foot, respectively. In the year 2001 and 2002, there were no sales for thermal power generation in the US. Among all micro-CHP products, either in commercial production or testing, no solar thermal power is used as a prime mover.

\subsubsection{Thermoelectric Technology}

Thermoelectric involves two physical phenomena: one is temperature difference causes electric voltage in a circuit containing two different metals, or semiconductors, by keeping the junctions between them at different temperatures. It is called the Seebeck effect, discovered by the German physicist Thomas Seebeck, and is the basis for thermocouples. Another phenomenon is called the Peltier effect, in which current flow causes a temperature difference between the junctions of different metals. Here we are only interested in the thermoelectric power generation, or Seebeck effect.

In a thermoelectric power generation device (TEG), the thermoelectric working pair is contacting a heat source of temperature $T_{\text {sh }}$ in one end and a cold source of temperature $T_{\mathrm{sc}}$ on the other end, as shown in Figure 4-6. The voltage generated is proportional to the temperature difference between the hot and the cold side. The efficiency is based on the material's non-dimensional figure of merit (ZT) and the temperature different $(\Delta \mathrm{T})$ across the TEG device. The hot side temperature should be as high as possible, provided that the hot side material does not melt. On the cold side, active cooling 
is helpful to maintain low temperature but may involve higher cost. It is desirable to minimize the heat transfer from the hot side to the cold side, which is a loss in thermoelectric power generation.

When there is no load applied to the electric circuit, the voltage generated will be higher than that with an electric load, because the TEG device has its own electric resistance and an electric current in the TEG device will consume some voltage. Therefore it is desirable to have small electric resistance for the TEG working material.

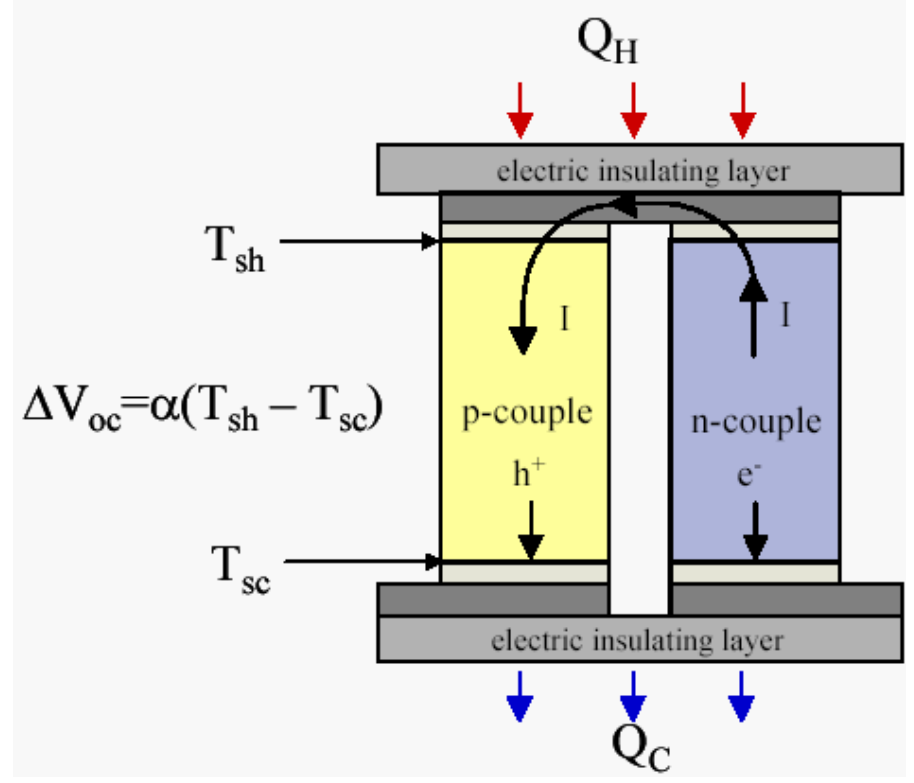

Figure 4-6 Thermoelectric power generation diagram

\subsection{Current State of Technology}

TEG device has rather low electric efficiency. From the late 1950's until the late 1990's, the highest ZT achieved in practice was around 1, with little improvement during that period. With ZT $=1$ and $\Delta \mathrm{T}=100^{\circ} \mathrm{C}$, device efficiency of $\sim 5 \%$ can be achieved with current technology.

Some breakthrough has been made in TEG materials recently. In 2001, superlattice thin-film materials have been demonstrated to have $\mathrm{ZT}=2.4$ at room temperature by Research Triangle International (RTI) researchers. Also in 2001, filled skutterudites $\left(\mathrm{LnT}_{4} \mathrm{Pn}_{12}\right)$ has been found to have ZT of 1.8 at $650{ }^{\circ} \mathrm{C}$ in the Jet Propulsion Lab, Pasadena, CA ${ }^{[71]}$. These examples of progresses make the TEG technology a promising candidate for power generation.

\subsection{Future Industry and Technology Trends}

To get better performance, both the material characteristics and the mechanical design need to be improved. It is estimated by MIT researchers ${ }^{[71]}$ that using the quantum well devices, ZT $=2.0$ at $300 \mathrm{~K}$ could be achieved. Efficiencies would approach 20-25\% with large temperature differences, e.g., larger than $400 \mathrm{~K}$. 
From the energy design standpoint, $50 \%$ to $120 \%$ improvement in thermal performance is achievable by isolating each thermoelectric couple in the direction of the fluid flow. If these are used in conjunction with advanced thermoelectric materials, the efficiencies could approach $50 \%{ }^{[71]}$.

\subsection{Benefits and Limitations}

The major advantage of TEG is that it is solid-state power generation and there are no moving parts. This brings in small maintenance cost, no noise, high reliability and long life. A hermetically sealed TEG device is estimated to have a service life of 20 years. In addition, it is lightweight and environmentally friendly since it does not involve any harmful refrigerants.

One of the major drawbacks of TEG is its low electric conversion efficiency, although, from the micro-CHP standpoint, some improvements to increase the efficiency from 3-5\% to the desired 8$10 \%$ would suffice and may be achievable. The other drawback is the high cost of thermoelectric power generation. Finally due to the material and heat transfer constraints, the maximum power generation is only up to a few kilowatts for a single unit.

\subsection{Market Analysis}

Thermoelectric power generation is still emerging. Some commercial products are available from a few watts device to the $\mathrm{kW}$ scale. Hi-Z ${ }^{[98]}$ has built a $1 \mathrm{~kW}$ generator to utilize the waste heat from the engine of a class- 8 diesel truck, as shown in Figure 4-7. However, as can be seen above, many technical barriers exist before large scale commercialization is available and more technical advancement is needed.

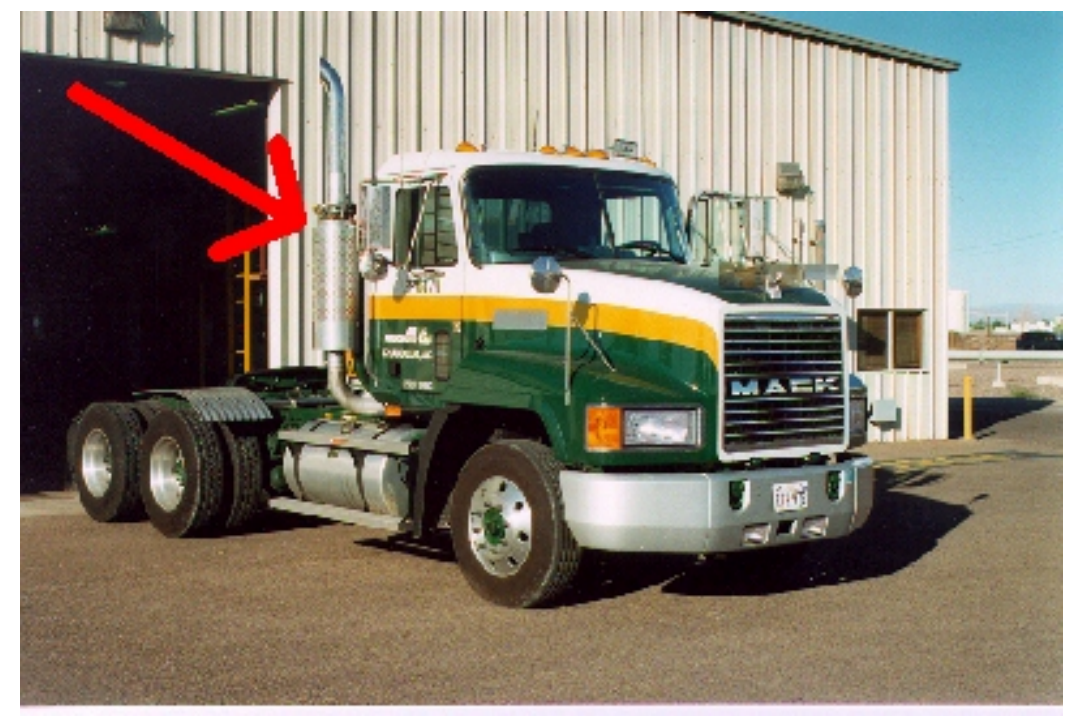

Figure 4-7 1kW TEG equipment using the waste heat from a truck built by Hi-Z

TEG has a few attractive features for micro-CHP. It is quiet and easy to maintain. In addition, microCHP does not require very high electrical efficiency. The way that TEG works is similar to external combustion engines, i.e., it does not interfere with the heat utilization of other devices such as hot water or space heating. So far no micro-CHP manufacturers have used TEG in micro-CHP. 
However, the technology may be competitive in micro-CHP when the devices are readily available and their cost becomes acceptable.

\subsubsection{Thermally Activated Technologies}

This section discusses different thermally activated technologies (TAT). TAT typically refers to thermally activated cooling (adsorption and absorption chillers), dehumidification (solid and liquid desiccant systems), heating (heat recovery exchangers and boilers) or power generation (organic Rankine cycle bottoming devices). TAT devices can use the waste heat that leaves a prime mover in a CHP system so that the overall energy utilization is increased. The relation between different thermally activated technologies is shown in

ORC: organic Rankine cycle

SDes: solid desiccant

VCC : vapor compression chiller

Ammo: ammonia absorption chiller
LPG: liquid petroleum gas

LDes: liquid desiccant

$\mathrm{LiBr}$ : lithium bromide chiller

GAX: generator-absorber-heat exchanger cycle Figure 4-8. The major ones will be covered in more details below.

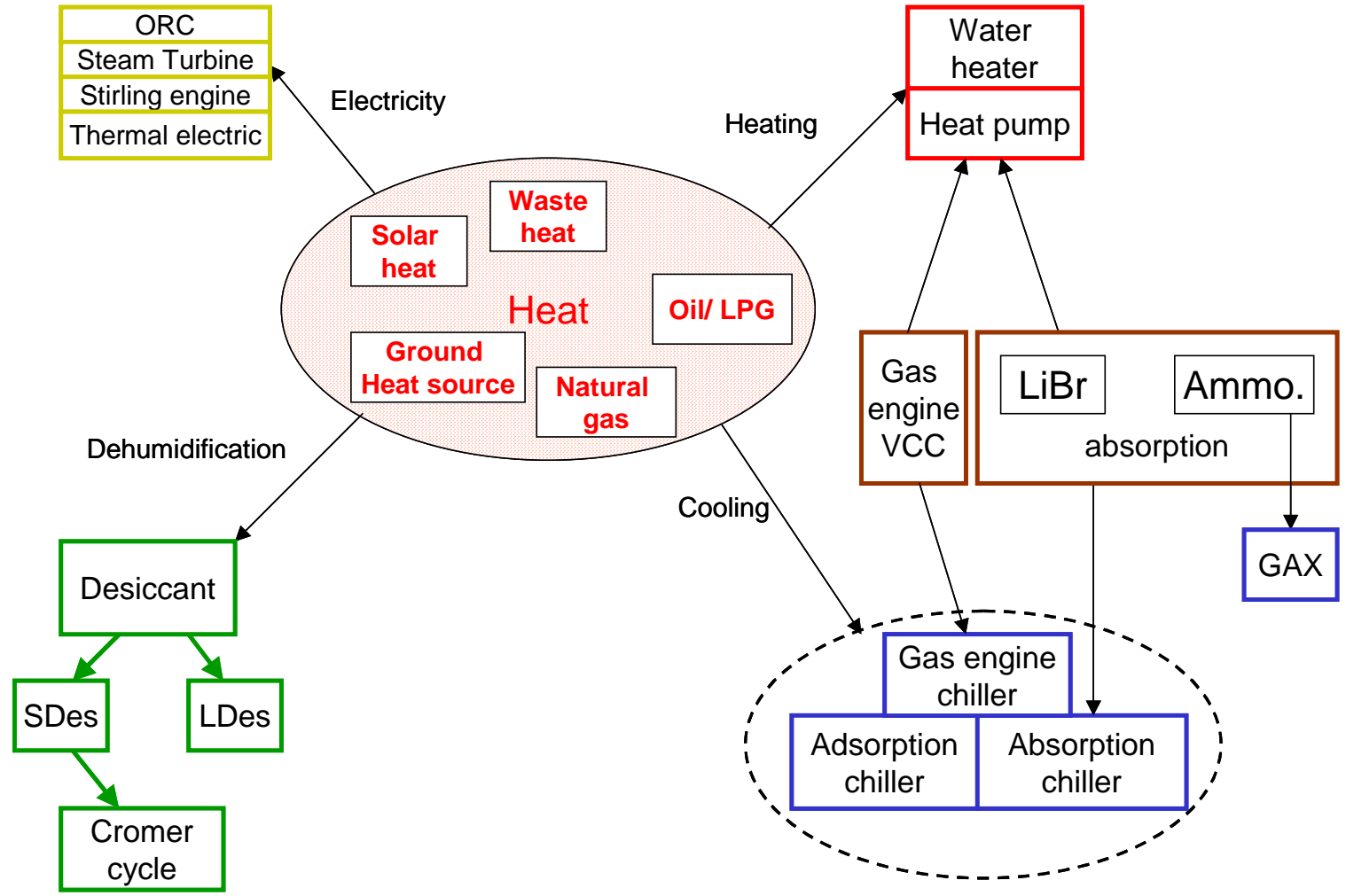

ORC: organic Rankine cycle

SDes: solid desiccant

VCC : vapor compression chiller

Ammo: ammonia absorption chiller
LPG: liquid petroleum gas

LDes: liquid desiccant

$\mathrm{LiBr}$ : lithium bromide chiller

GAX: generator-absorber-heat exchanger cycle 
Figure 4-8 The relation between different thermally activated technologies

\subsubsection{Absorption Chillers}

An absorption chiller operates on the absorption cooling cycle, which involves a pair of working fluids: an absorbent and a refrigerant. There are two dominant working fluid pairs currently: $\mathrm{LiBr}$ solution/water and ammonia/water (or ammonia aqueous refrigeration - AAR). LiBr/water has been used mainly for space cooling applications and cannot produce cooling load below freezing point. Ammonia/water can produce cooling load with temperature typically at $-30^{\circ} \mathrm{C}$. Therefore AAR can be used for refrigeration purposes and heat pump in winter.

In an absorption cycle, refrigerant is separated from the absorbent when heated in the generator, as shown in Figure 4-9. The refrigerant vapor then condenses in the condenser, releasing the latent heat. The liquid refrigerant enters a low pressure space after an expansion valve. It evaporates there by absorbing energy from the fluids to be cooled, thus creating useful cooling. The vapor is then absorbed by the condensed absorbent solution, which becomes diluted and then pumped back to the generator to complete the cycle.

If there are a high stage generator and a low stage generator in the cycle, the system can be designed to generate more refrigerant vapor by utilizing part of the refrigerant latent heat that would otherwise be removed by the cooling water. The COP can then be improved dramatically, from 0.7 to about 1.3. Such a chiller is called a double effect chiller. If there are three stages of generators, it is called a triple effect chiller. Theoretically, the higher the number of stages, the higher the chiller COP.

In the ammonia absorption cooling, because both the absorbent (water) and the refrigerant (ammonia) can leave the generator, which is not desirable, a rectification process is needed and the system is more complex than the $\mathrm{LiBr}$ absorption cycle. 


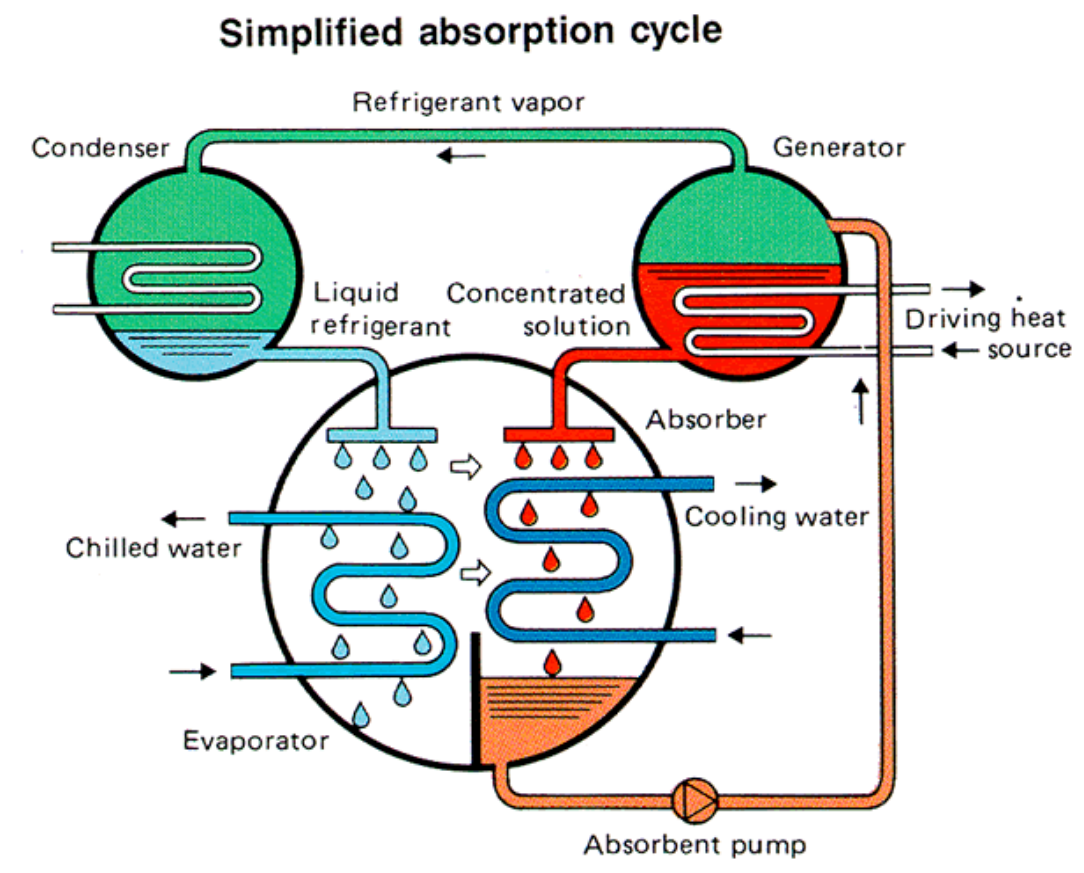

Figure 4-9 Schematic of the absorption cycle

\subsection{Current State of Technology}

Because the heating source fluid does not contact the chiller working fluids directly, absorption chillers can be heated with different heating sources without changing the chiller major structure significantly. Chillers heated by hot water, water steam, direct gas or liquid fuel firing as well as waste heat have been developed.

Absorption chillers can also provide heating when the cooling water to the chiller is disconnected. In that case, the heat is carried from the heating source in the generator to the evaporator so that the chiller serves as a boiler. Although it seems that the chiller components are not fully used in heating mode, this configuration can save a boiler, additional heating coils and piping.

DOE is working with Trane and York to develop triple effect LiBr absorption chillers ${ }^{[122]}$. Other major developments in the $\mathrm{LiBr}$ absorption chiller technology in recent years is focused on the integration with a prime mover in CHP. The development of ammonia water absorption chiller, which perceived undesirable because of the ammonia toxicity, especially in North America, is still focused on the absorption cycle itself. For example, the Generator-Absorber-Heat exchanger (GAX) cycle is being developed with the sponsorship from DOE to improve the COP of the ammonia absorption cycle ${ }^{[158]}$. 


\subsection{Future Industry and Technology Trends}

Large commercial absorption chillers would be favored in regions where there is a power shortage. Research for large chillers is likely to entail improvement of triple effect chillers to fully take advantage of the high heating temperature from direct firing.

For the mid to small scale absorption chillers, which are typically below 300 Refrigiration Tons (RT) (or $\sim 1,000 \mathrm{~kW}$ since 1 Refrigeration Ton $=3.517 \mathrm{~kW}$ ), the research is focused on CHP or cogeneration applications. This includes better control of the CHP, increasing the waste heat utilization and development of smaller sizes. For the absorption chiller to be used in micro-CHP, it is desirable to have a chiller in the size of a few RT (or $10 \mathrm{~kW}$ ).

\subsection{Benefits and Limitations}

Absorption chillers have the advantage that they are driven by heat, not electricity. This helps to reduce the peak power load in summer if the cooling would otherwise be provided by an electricity driven vapor compression chiller. An absorption chiller does not have moving parts, other than small liquid pumps, which consume only a small amount of electricity. Also it is quieter than typical vapor compression chillers. In winter, the chiller can serve as a boiler thus saving partial heating equipment cost. It usually has a long life, around 15-25 years. As a thermally driven device, it can utilize the heat from a prime mover.

The disadvantages of the absorption chiller include: 1) they are roughly twice as expensive as a vapor compression chiller with the same capacity. 2) Absorption chillers use a large amount of working fluid and, therefore, have slow transient response. Chiller start-up and shutdown processes take much longer time than those for VCC. 3) Absorption chillers need a cooling tower to operate, which is not desired by some building owners such as a supermarket. It is also difficult for regions where water supply is an issue.

\subsection{Market Analysis}

Today the absorption chiller has only about $10-15 \%$ of the entire chiller market. The vapor compression based chillers are still dominant due to its lower price and good performance. While the sales of stand-alone absorption chillers are determined by the electricity shortage, cost benefit and other consideration such as noise, CHP based absorption chillers are mainly determined by the waste heat availability, spark spread (the relative price of electricity and natural gas), thermal/electric load balancing and overall economics etc. For commercial CHP, absorption chillers can be modified easily from a direct-fired chiller.

For micro-CHP in a residential market, the absorption chiller must be very small in capacity, which is less cost-effective than larger chillers. Broad, a Chinese absorption chiller company, offers a 5RT $(16 \mathrm{~kW}) \mathrm{LiBr}$ absorption chiller used for residence. Rubur in Italy offers a $3.6 \mathrm{RT}(12.8 \mathrm{~kW})$ ammonia absorption chiller commercially, the lowest capacity known for commercial absorption chillers today. VectorCogen is partnering with Climate Technologies for an IC engine/absorption chiller micro-CHP system, which uses a 5-ton absorption chiller priced at around $\$ 7,500^{[124]}$. These models may serve as the prototype for micro-CHP absorption chillers. 


\subsubsection{Adsorption Chiller}

An adsorption chiller is different from an absorption chiller in that the absorbent is not a liquid, but a solid substance that can adsorb the refrigerant vapor. Typical working adsorbent/absorbent pairs are silica-gel/water and methanol/carbon. In an adsorption chiller, there is no continuous adsorbent flow so that the chiller is designed to have two chambers and the chiller is to run intermittently. Figure 4-10 shows an adsorption chiller diagram.

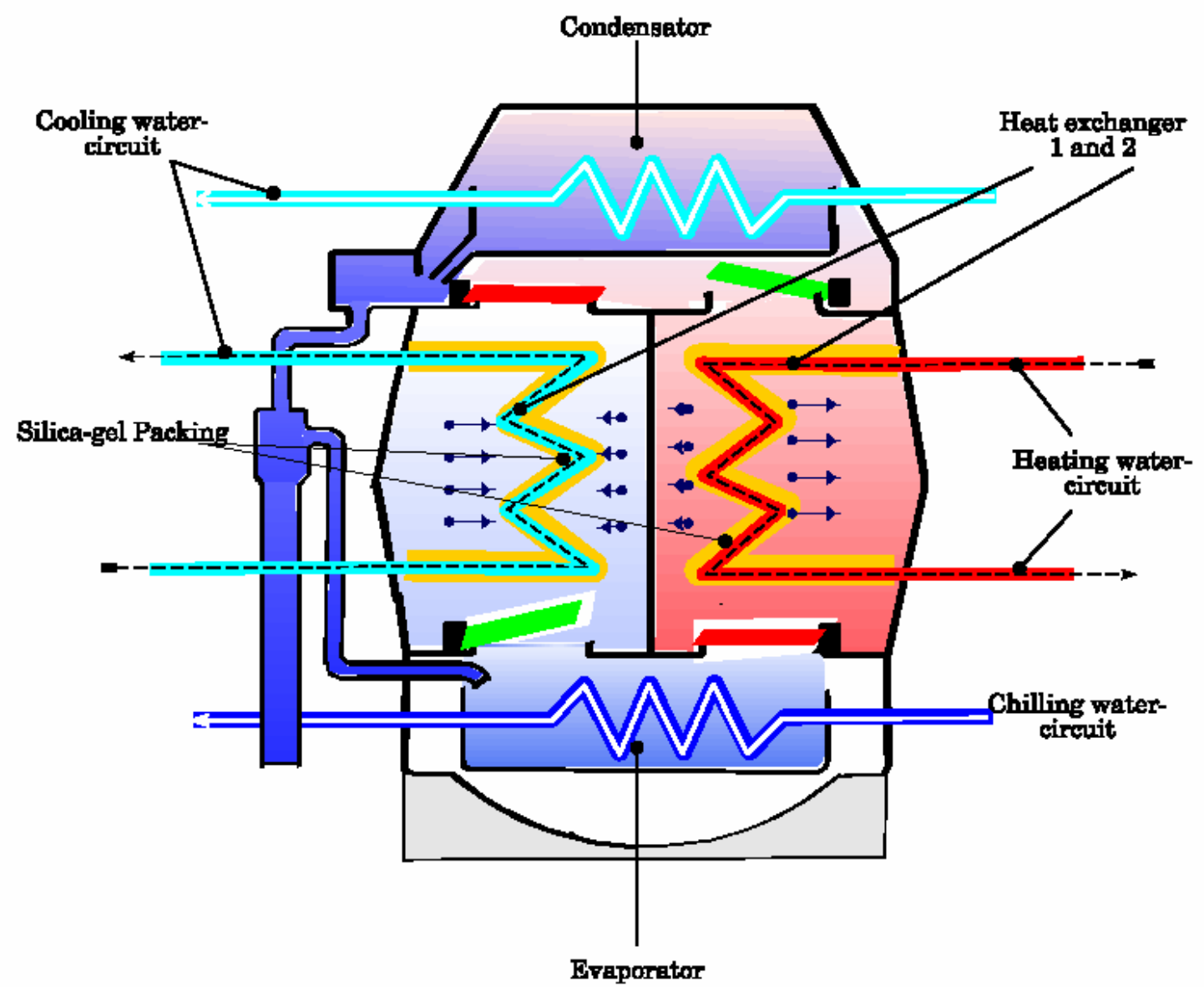

Figure 4-10 The diagram of a GBU adsorption chiller ${ }^{[88]}$

During operation, water is brought into the evaporator and evaporates, which generates useful cooling load in the cooling circuit. The water evaporated above is adsorbed on the receiver, the silica-gel. The adsorbed water is de-adsorbed with the supply of thermal energy. The receiver turns into the generator. The de-adsorbed water vapor is condensed in the condenser (cooling cycle). After the cycle-time expiration the machine switches over by means of pneumatically actuated valves.

\subsection{Current State of Technology}

The adsorption chiller was developed and first produced by Nishiyodo Kuchou Manufacturing Company (Japan) in 1986. Since then, the adsorption chiller has been used and closely evaluated in a 
wide area of applications in Japan and Europe with high initial acceptance and about one hundred customers of adsorption chillers in total ${ }^{[96]}$.

Today adsorption chillers are not as popular as absorption chillers. However, adsorption chillers do have a few advantages that absorption chillers do not have, as going to be shown below. For this reason, adsorption chillers have attracted some research interest. For example, a university team in China looked at the solar powered adsorption chiller to make ice ${ }^{[126]}$. Some other researchers have modeled the transient behavior of a solar powered adsorption chilling process ${ }^{[81]}$.

\subsection{Future Industry and Technology Trends}

One of the greatest barriers for adsorption chillers is the cost. Currently the adsorption chiller cost per refrigeration ton (RT) is about 6 times that of an absorption chiller. Bringing the cost down to the range close to absorption chiller will make the adsorption chillers much more competitive.

Secondly, current adsorption chillers need to switch two chambers every few minutes. This causes some cooling discontinuity. Also, the equipment is prone to mechanical malfunctions. The reliability and the mechanical design of adsorption chillers need to be improved.

Commercially available adsorption chillers are offered at a minimum of $50 \mathrm{~kW}$ in capacity. For micro-CHP, 10-20 kW of cooling capacity is needed. In order for adsorption chillers to be considered for micro-CHP, there is a need to scale down the chillers and, preferably, without much increase of the unit price.

\subsection{Benefits and Limitations}

Compared to $\mathrm{LiBr}$ absorption chillers, the benefits of adsorption chillers are:

- Lower temperature heat source $\left(60-100{ }^{\circ} \mathrm{C}\right)^{[88]}$

- Good for solar energy

- Short start-up time claimed (0-7 min ${ }^{[88]}$

- No corrosion, no crystallization issues

- $\quad$ Longer chiller life (30 years) ${ }^{[96]}$

The major limitations are:

- $\quad$ Lower COP $(0.6)^{[88]}$

- Intermittent operation

- More mechanical problems

- Not as widely used as LiBr chillers and likely need more development

\subsection{Market Analysis}

There is only one company that commercially manufactures adsorption chiller products. The equipment cost quoted from a manufacturer for a $20 \mathrm{RT}(70 \mathrm{~kW})$ adsorption chiller is US\$50,000. The high cost and the small market are likely inter-related. Nevertheless, adsorption chillers are still not a mainstream product today and both technical and marketing potentials are yet to be resolved. 


\subsubsection{Desiccant Dehumidifier}

Dehumidification can be realized in two ways: 1) Use a vapor compression chiller. When the humid air passes through the cold coil, water vapor condenses so that the supply air is dehumidified. 2) Use a desiccant system in which the solid or liquid desiccant absorbs the water vapor.

There are two types of solid desiccant systems: a passive system and an active system. The passive desiccant system utilizes the waste heat from the building exhaust air while the active system utilizes a heater or, preferentially, waste heat from either a condenser or CHP system to regenerate the desiccant material.

The simplest and most common design is a rotating desiccant coated honeycomb wheel in which approximately $75 \%$ of the wheel is exposed to the air stream to be conditioned while the remaining $25 \%$ portion is used to regenerate the desiccant. The most commonly used material is typically silica gel. Other materials such as zeolites, molecular sieves, activated aluminas, carbons and synthetic polymers have also been used ${ }^{[37]}$.

Liquid desiccant systems provide dehumidification by spraying the liquid desiccant, usually $\mathrm{LiCl}$ solution, into an incoming air stream to remove moisture.

\subsection{Current State of Technology}

Both solid desiccant and liquid desiccant systems have been used for decades to control the humidity level in buildings. There had been little change to the basic desiccant technologies until very recently. A new solid desiccant dehumidification cycle called Cromer Cycle has lately been developed ${ }^{[59]}$. In this cycle, moisture removal is enhanced by using desiccant material subjected to low temperature. It is claimed to double or triple the moisture removal capacity of a standard coil. However, no Cromer Cycle products have become available yet.

For liquid desiccant technologies, a new integrated water cooled conditioner has been developed and patented by AIL Research Inc (US Patent No. 20020023740). The advantage of this design is that the liquid desiccant temperature does not increase substantially due to the presence of cooling water. The water can be cooled in a cooling tower, rather than from an active cooling device such as a vapor compression chiller and the cooling load on the vapor compression chiller is reduced.

Some other progress in the desiccant technology includes research on the integration of desiccant system with a chiller or a CHP system. When the moisture is removed from the air to be processed, the latent load to be handled by the chiller will be reduced. If waste heat is available to regenerate the desiccant material, it is possible to reduce the overall operating cost, depending on how much waste heat is available and how much moisture is removed from the air stream ${ }^{[61] .}$

\subsection{Future Industry and Technology Trends}

Air treatment for public areas is a growing concern. In some areas around the world, there is a high degree of relative humidity. Air conditioning equipment tends to overcool the air; otherwise it cannot dehumidify the air sufficiently, making people uncomfortable. It is anticipated that growth 
opportunities will be in industrial plants in Asia and the public and commercial buildings in the United States.

\subsection{Benefits and Limitations}

Solid desiccant systems offer several benefits to the building operator/owner. These benefits include reduced electrical energy consumption, reduced condensation and growth of molds and downsizing of cooling equipment. Additional benefits resulting from downsized equipment include reduced housing space and lower initial costs of the chiller. Limitations include an added high cost of the desiccant equipment and limited application potential depending on building geographical location and conditioning needs. Another limitation of solid desiccants is potential desiccant lifetime degradation due to clogging from foreign particles in the air stream ${ }^{[37]}$. Prevention of this requires the use of particle filters, which will increase the overall life cycle cost of the system.

Liquid desiccants have several advantages over solid desiccants. First liquid desiccants have a higher-water holding capacity than solid desiccants thus providing deeper drying capabilities. Second, further improvement in IAQ (other than moisture removal inhibiting mold growth) is also accomplished through the disinfecting attributes of the liquid desiccants. Another advantage is the fact that the liquid desiccants have the capability of being used as a potential energy storage media. On the other hand, there are several limitations to this technology. Specifically, there is a higher complexity factor (i.e., more components than a solid desiccant system), resulting in higher initial costs and reduced reliability confidence. Also, because liquid desiccants are usually toxic/corrosive, carry-over concerns arise. Carry over occurs when small droplets of the liquid desiccant are entrained with the process air. As a result, human heath issues arise as well as the possibility of increased maintenance costs due to corroding HVAC ducting. Another limitation of liquid desiccants relates to the potential desiccant lifetime degradation due to chemical reactions with, for example, sulfur compounds in the air stream ${ }^{[37]}$.

\subsection{Market Analysis}

As stated earlier, air dehumidification is accomplished through either condensation-based technology (i.e., vapor compression or mechanical refrigerant) or through drying (i.e., desiccants). The global desiccant dehumidification market for industrial and commercial application was estimated to be approximately $\$ 390 \mathrm{M}$ in 2002 with a steady potential growth in following years. The market has been growing at a rate of $6 \%$ per year for the past ten years. Currently, Munters is the market leader with a 40-60\% market share followed by Seibu Geiken in Japan ${ }^{[42]}$. In North America, revenues in the dehumidifier market including both mechanical refrigerant and desiccant was $\$ 250 \mathrm{M}$ in 1999 with potential growth to $\$ 510 \mathrm{M}$ in 2006 . The major players include Munters, Air Technology Systems, Bry-Air, and others ${ }^{[42] .}$

Desiccant dehumidifiers have been installed in schools, institutional facilities, commercial buildings, industrial buildings, and processing plants. Food and beverage, pharmaceuticals and electronic companies are traditional customers. Desiccant dehumidification systems provide controlled humidity levels in sensitive production areas such as storage, water works, temporary shutdown, cold spaces, blasting, product drying, coating, cooling tunnels, transport and moisture-controlled indoor climates. 
Desiccant systems typically suffer from the following marketing restraints:

1. High initial cost of dehumidifiers deters a large percentage of installations. The average price of desiccant dehumidification is $\$ 8$ - $\$ 15$ per cubic foot per minute (cfm) and a $3000 \mathrm{ft}^{2} \mathrm{New}$ York residential house's latent load is equivalent to the humidity of a few hundred to $1000 \mathrm{cfm}$ of fresh air.

2. Energy efficiency of mechanical refrigerate dehumidifiers restricts the growth of desiccant dehumidifier market.

3. Economic slowdown restricts the expansion for the overall dehumidification market.

4. Lack of end-user education limits dehumidifier sales.

Currently, the competition within the dehumidification market is fragmented. There are strong local or regional competitors offering low prices to gain access to the end-user market. It is possible for larger air treatment companies to enter this market by making acquisitions but the current market for dehumidification is too small to attract large HVAC companies. Companies compete on product quality, price, and compatibility with other HVAC systems. In addition, manufacturers are taking steps to educate their sales forces who in turn will educate engineers and end users.

Finally, when considered for micro-CHP in residential applications, attention should be paid to the fact that the fresh air ratio for house is typically close to zero, assuming that the infiltration is very small. If desiccant is used for the process air, the house air humidity would decrease steadily. Two possible effects are that: 1) The air humidity is too low so that people may feel uncomfortable; 2) If the air humidity is too low, desiccant system may not be able to decrease the latent load but just causes the sensible load higher. In that case, desiccant system will end up being defective.

\subsubsection{Heat Recovery Exchanger / Boiler}

In a house, a boiler usually provides domestic hot water for washing or space heating by burning liquid fuel or natural gas. Although this is one of the simplest and most primitive energy conversion methods, i.e., from fuel chemical energy to heat, it is the most important and widely used method of energy utilization for a house, either in developing or developed countries.

Many single family houses use a furnace for space heating and a gas or electric boiler for domestic hot water. Some houses use a combined furnace for space heating and hot water. If a micro-CHP is to be installed, it is desirable to use the micro-CHP waste heat for both space heating and hot water. A heat recovery exchanger/boiler will be needed instead of the furnace/hot water heater. Here we assume the heat recovery exchanger /boiler is a flue gas- liquid water heat exchanger. If the house uses forced air heating, air will be heated by the water coil. If a hydronic heating system is used, the hot water from the heat recovery equipment may be used directly.

\subsection{Current State of Technology}

From the heat transfer standpoint, there is no difference between a direct-fired boiler and a heat recovery boiler. The difference lies in that a heat recovery boiler usually is subject to lower gas temperature than in a direct-fired one. In a direct-fired boiler, the flue gas temperature is high enough so that bare tubes can be used to provide enough heating load, although the efficiency of 
heat utilization and the cost of the boiler are lower. For waste heat recovery, depending on the temperature of the waste heat, fin tubes may be needed to recover enough heat.

\subsection{Future Industry and Technology Trends}

In the micro-CHP applications, the heat recovery design should be focused on the following aspects: 1) Integration with the prime mover or burner as well as related thermal/electric load balancing and control. For example, in a Stirling engine based micro-CHP system, the engine and the heating load both get the heat from the burner. The burner fuel flow rate needs to consider both the electric and heating load, which is more complex than ordinary boilers; 2) Extent of heat recovery from the flue gas and the effects of potential water vapor condensation. In case of condensation both material corrosion and mold development would likely necessitate raising the gas leaving temperature above the dew point.

\subsection{Benefits and Limitations}

The benefit of heat recovery by means of heat exchangers is that the technology is simple. Typical houses have large heating and/or hot water load so that a heat recovery exchanger can well fit into the micro-CHP blueprint. If there is enough waste heat, extra hot water generated can be used for absorption/adsorption cooling. More importantly, the cost of the heat recovery exchanger, which is essentially a gas/liquid heat exchanger, is smaller compared to other TAT technologies such as heat driven cooling or dehumidification. The only disadvantage appears to be the fact that this is a very common technology and there will be less competitive advantage except for load control strategies.

\subsection{Market Analysis}

Waste heat recovery exchanger / boiler has been adopted by existing micro-CHP systems and, as a matter of fact, it is the only technology used in current micro-CHP. It is likely that waste heat recovery exchangers will be a major application in the future, even if other more complicated TAT makes financial sense and becomes available.

\subsubsection{Air Handling Equipment}

Air handling equipment delivers the cooling and heating energies to the residence. This is an integral part of the micro-CHP system because it relates to the micro-CHP fluid flow design, energy use optimization, and cost analysis.

Traditionally, there are two types of heating systems: forced air and hydronic heating, as shown in Figure 4-11(a) and (b), respectively.

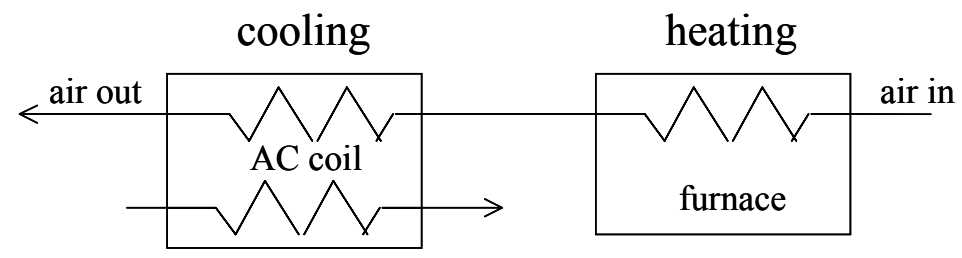

(a) The schematic of a common forced air heating and central AC cooling system 


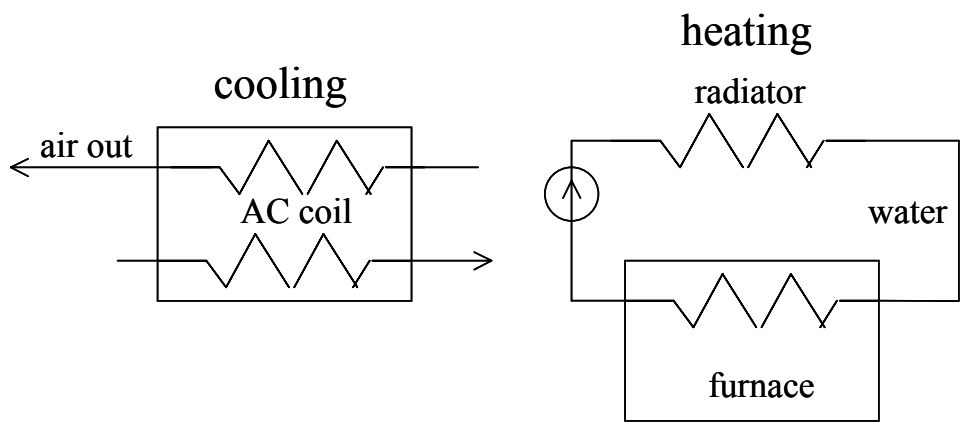

(b) The schematic of a separate hydronic heating and central AC cooling system

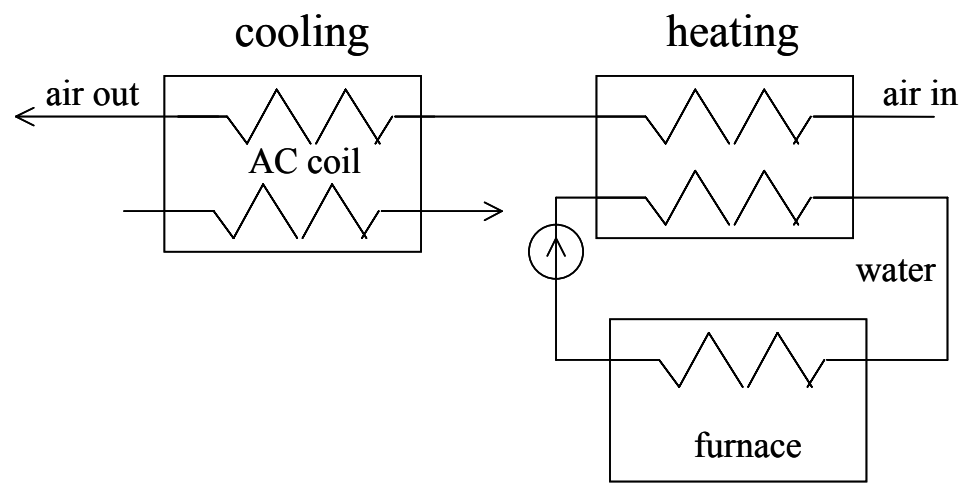

(c) The schematic of integrated hydronic heating / central AC cooling

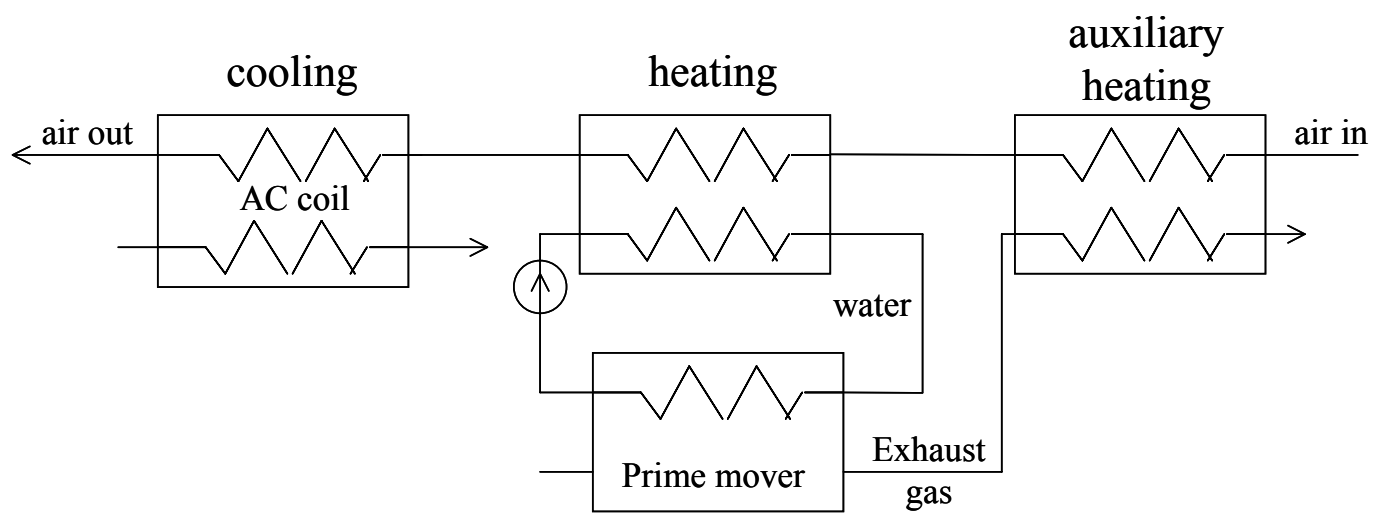

(d) The schematic of integrated hydronic heating / central AC cooling with micro-CHP

Figure 4-11 Air handling schematics for different heating / cooling systems

Hydronic heating systems have been proven to provide even and comfortable heating. Hydronic heating is mainly used in the northeast region while forced air heating is dominant in the rest of the US, as well as for most new constructions, even in the northeast. Forced air heating system, especially the old ones, has relatively larger fan noise and is more likely to cause uneven heating in the house traditionally. However, hydronic heating is more expensive than a forced air heating system, especially when a central air conditioner is used. For a combined forced air heating and central AC, the water distribution system is saved, and both heating and cooling use the air distribution system, as shown in Figure 4-11(a). There are two coils in the supply air stream: the cooling coil and the heating coil, which do not run simultaneously. Although there is a popular belief 
hydronic heating is more uniform, if designed and installed properly, the forced air heating system can also provide even heating.

One slight disadvantage is that the fan power needs to be higher due to the fact that the air passes through two coils in a combined hot air/central AC system. Proper arrangement of the coils may minimize this effect. There are concerns about being allergic to the dust in the air through the forced air system. This can be handled by installing high quality air filters, around $\$ 300$, as opposed to the common $\$ 10$ filter in the market.

A type of combined hydronic/forced air heating systems is available ${ }^{[12]}$, as shown in Figure 4-11(c). In this case, one single furnace can provide hot water and space cooling, thus saving a hot water heater. In terms of the air handling, it is the same as the forced air cooling / heating in Figure 4-11(a).

The air handling system above can serve as a prototype when used with micro-CHP, as shown in Figure 4-11(d). The cooling water of the prime mover can be used to generate hot water or space heating hot water, in place of the furnace in the previous case, Figure 4-11(c). The differential capital cost between Configuration (c) and (d) are the prime mover cost minus the furnace cost essentially.

An auxiliary heater has been added to preheat the air and utilize the exhaust gas leaving the prime mover in Figure 4-11(d). This will increase the overall energy efficiency. Of course, more capital cost will be incurred although a low temperature gas/gas heater can be inexpensive. The capital cost increase and the energy savings should be investigated.

Air handling equipment is used by both a conventional system and a micro-CHP system. When choosing a micro-CHP system, the air handling equipment will have little effect on the design and optimization of the micro-CHP significantly, assuming that the baseline system to be compared with the micro-CHP is the configuration in Figure 4-11(c).

In a residential house, humidity is not directly controlled. Rather, the humidity is removed when the humid air is in contact with the cooling coil of the AC system and vapor condenses. Therefore the moisture removal rate is related to the indoor air humidity and the coil temperature. In winter, the indoor air is usually dryer than required and humidification is typically achieved through a separate humidifier. If a desiccant system is included in the thermally activated technology (TAT) equipment, it is possible to humidify the air by utilizing the micro-CHP. 


\subsubsection{Energy Storage Equipment}

Building CHP loads are either electrical or thermal. Thus, CHP energy storage devices must be capable of storing and discharging electrical and/or thermal energy even though the storage process and media may be other than electrical or thermal. The following sections contain detailed descriptions of many of the candidate energy storage devices for CHP applications.

\subsubsection{Electrical Energy Storage Devices}

The Electrical Energy Storage (EES) technologies that are considered in this study are categorized as shown in Figure 4-12. Detailed descriptions of these technologies are included in the following sections.

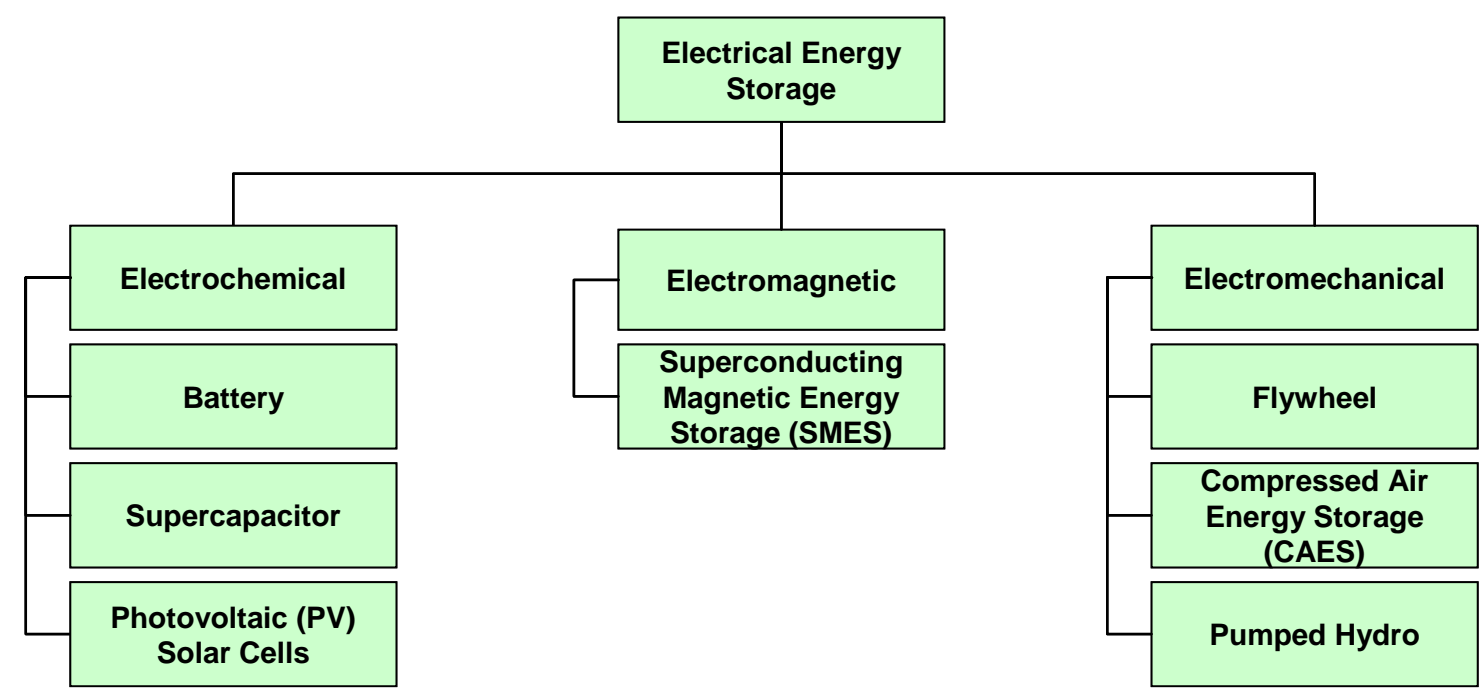

Figure 4-12 Electrical Energy Storage Technologies

\subsection{Electrochemical Energy Storage}

The electrochemical energy storage technologies that are evaluated in this study include batteries, and supercapacitors.

\subsection{Battery}

Electrochemical cells are devices in which chemical energy is converted to electrical energy through reduction-oxidation (redox) reactions involving the active materials that make up the cell. Batteries are a collection of electrochemical cells. The three key components of a battery system are identified below.

1. The anode or negative electrode that provides electrons to a load through an oxidation reaction.

2. The cathode or positive electrode that accepts electrons from the load and undergoes a reduction reaction. 
3. The electrolyte that is a charge and ion transfer medium (ionic conductor) placed between the anode and cathode.

The many present and emerging battery technologies are all based on various combinations of electrodes and electrolytes to optimize metrics such as operating voltage, load profiles, system weight, battery life and reliability, charge and discharge rates, and cost. There are three different types of electrochemical cells, as identified below.

1. Primary batteries are not recharged easily or effectively and are discarded once they have been discharged. These have typically been used for lower power applications like toys, lighting devices, portable electronic equipment, etc.

2. Secondary batteries are rechargeable devices where battery capacity is recovered by passing current (usually from a prime mover or the grid) in the opposite direction of the discharged current. These have been used in energy storage devices for uninterruptible power systems (UPS) where emergency no-fail devices are required, in hybrid electric vehicles, and portable electronic devices like cellular phones and laptop computers.

3. Reserve (primary) batteries are used for long-term storage under adverse environmental conditions with the goal of providing high power for a short period of time. These batteries have been used in missiles, torpedoes and other weapon systems.

The secondary battery is the best suited technology for electrical energy storage in micro-CHP applications. The following subsections provide a description of the various current and emerging secondary battery systems that could be used in CHP system architectures. Detailed technical information for many of the battery systems discussed herein is comprehensively covered by Linden and Reddy in Reference ${ }^{[57]}$.

\subsection{Super Capacitor}

A super or ultra capacitor differs from an ordinary capacitor in that it has extremely high capacitance and significantly increased energy density resulting from large electrode surface area and reduced equivalent series resistance (ESR). The capacitance of a super-capacitor is about three orders of magnitude higher than that of a conventional electrolytic capacitor in a comparable package size. The electrodes of super capacitors consist of microporous carbons, metal oxides, or both, with an aqueous or organic electrolyte. Currently, the energy density of these devices is $3-5 \mathrm{Wh} / \mathrm{kg}$ with a power density of 300-500 W/kg and high efficiency (90-95\%) charge / discharge.

Secondary batteries are the most common electrical energy storage device and are suitable for applications requiring stable discharging of a energy over a long duration. However, drawing a large amount of energy over a short duration from a battery is not always possible and may result in deterioration of the battery. Other limitations of batteries include a relatively short shelf life and a limited number of charge and discharge cycles. Accordingly, super capacitors have undergone development as an energy storage device that has excellent shelf and cycle life, providing an alternative to pulse batteries. Super capacitors complement some of the battery's shortcomings as well as those of ordinary capacitors. The most common applications for super capacitors are improved power quality, high power ride-through, and pulse power applications. 


\subsection{Electromagnetic Energy Storage}

The only electromagnetic energy storage technology that is evaluated in this study is known as Superconducting Magnetic Energy Storage (SMES), a description of which is included in the following section.

\subsection{Superconducting Magnetic Energy Storage (SMES)}

A large amount of power can be stored in the magnetic field created by the flow of dc current in a coil of superconducting material. This material is typically cryogenically cooled today in order to achieve a superconducting state. The stored power can be discharged instantaneously and rectified for use. Recharging can be accomplished within minutes. A schematic of an SMES system is shown Figure 4-13.

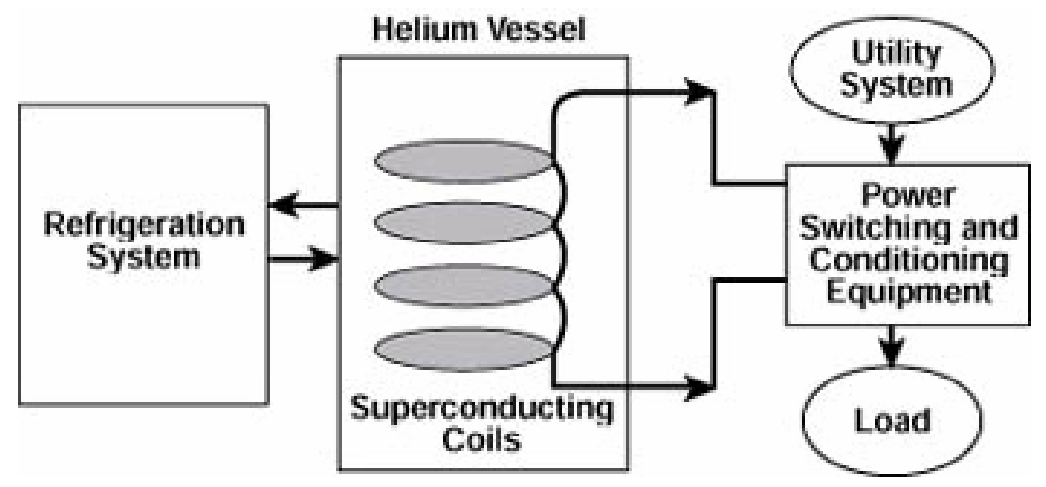

Figure 4-13 Superconducting Magnetic Energy Storage Schematic

\subsection{Electromechanical Energy Storage}

The electromechanical energy storage technologies that are evaluated in this study include flywheels, Compressed Air Energy Storage (CAES) and pumped hydro. Note that CAES and pumped hydro have potential to be employed as either electrical or thermal energy storage devices. These technologies are described here as electrical energy storage devices since the only current applications involve recovering the stored energy as electrical energy. Note also that CAES and pumped hydro are categorized as electromechanical energy storage devices since mechanical means are typically used in the energy charge and discharge processes.

\subsection{Flywheel}

A flywheel is a device that stores energy mechanically in the inertia of a rotating mass. The flywheel storage device consists of a rotor wheel with a large rotational inertia, a bearing system for suspending the rotor, and a mechanism for both storing and extracting energy. A flywheel can be used as a means for electrical storage by integrating an electric motor-generator into the flywheel system. When electric power is supplied to the system the motor-generator is operated as a motor, converting electrical energy to kinetic energy by accelerating the flywheel. To recover the kinetic energy stored in the flywheel, the motor-generator is operated as a generator and electrical power is produced as the flywheel is decelerated. The integration of a flywheel and an electric motorgenerator is typically described as an electromechanical battery. 


\subsection{Compressed Air Energy Storage (CAES)}

Compressed air energy storage systems store energy by compressing air in a reservoir using a compressor powered by off peak, low cost electric energy. During charging, the plant's generator operates as a motor. When discharging, the compressed air is expanded in a combusting turbine that is connected to a generator. Natural gas is used as the fuel during plant discharge, in the same fashion as a conventional turbine plant. However, during discharge, the combustion turbine in a CAES plant uses all of its mechanical energy to generate electricity, making the process more efficient.

\subsection{Pumped Hydro}

In pumped hydro storage, a body of water is stored at relatively high elevation, representing stored potential energy. Electrical energy is produced by releasing the water from this reservoir, causing it to flow through hydroturbines and into a lower reservoir. The water is then pumped back up to recharge the upper reservoir. Generation and pumping can be accomplished either by single-unit, reversible pump-turbines, or by separate pumps and turbines. Mode changes between pumping and generating can occur within a period of minutes and up to 40 or more times daily. Pumped hydro storage was first introduced in the early 1900s in the Swiss Alps and has been operating in the United States since the late 1920s. Typically, dams are used to construct the upper and lower reservoirs. Within the last 10 years, advanced pumped storage technology has been developed to improve speed hydraulically and mechanically for ultra fast loading and ramping, allowing frequent and rapid $(<15 \mathrm{sec})$ changes among the pumping, generating and stand-by spinning modes. 


\subsubsection{Thermal Energy Storage}

The Thermal Energy Storage (TES) technologies that are considered in this study are categorized as shown in Figure 4-14. Detailed descriptions of these technologies are included in the following sections.

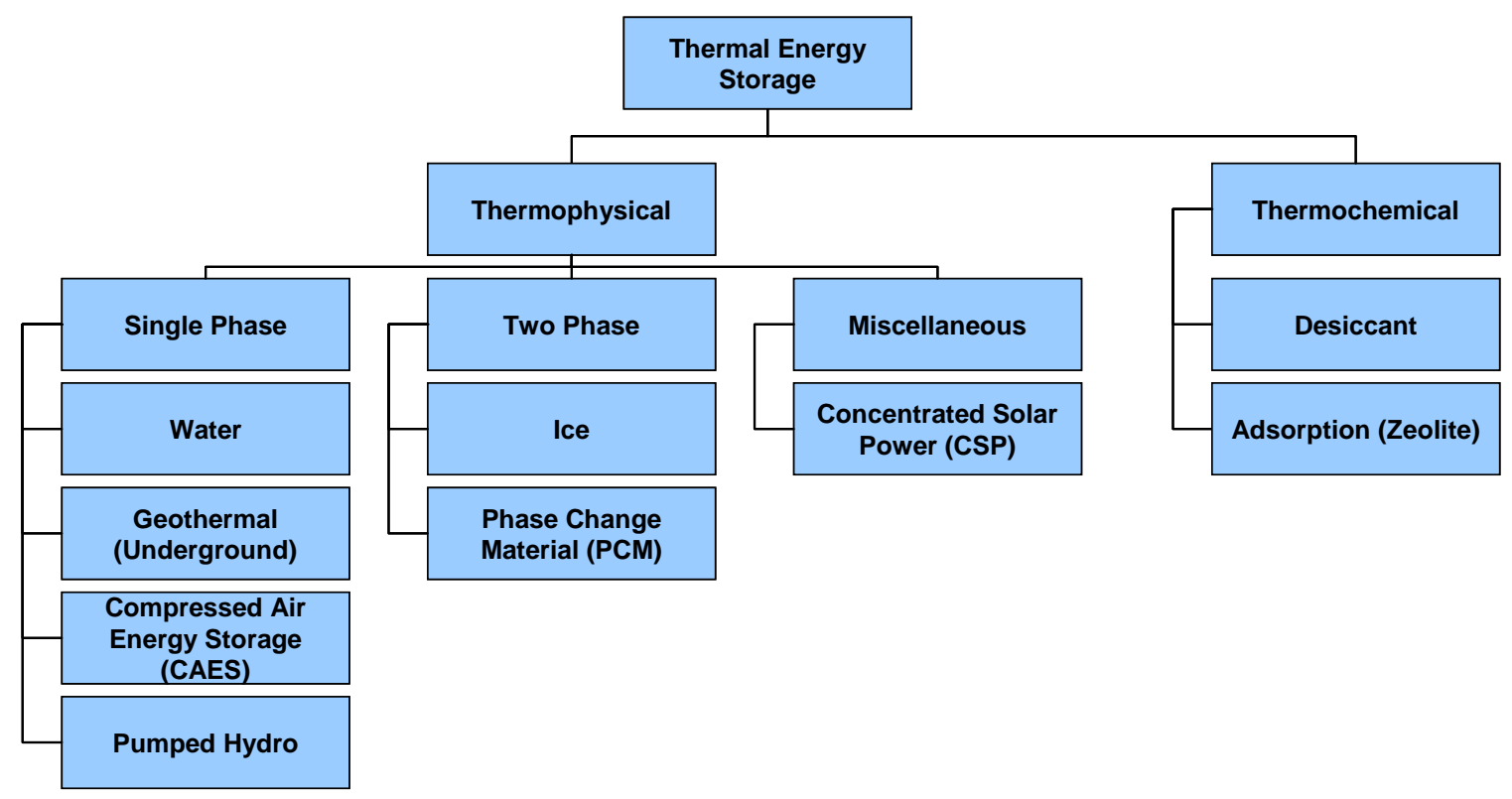

Figure 4-14 Thermal Energy Storage Device Categories

\subsection{Thermophysical Energy Storage}

The thermophysical energy storage technologies that are considered in this study are divided into single phase thermal processes, two phase thermal processes, and a miscellaneous category. The single phase TES devices include chilled water, geothermal, CAES, and pumped hydro. The two phase TES devices include ice storage and Phase Change Materials (PCMs). The only miscellaneous TES device is Concentrated Solar Power (CSP). These thermophysical energy storage technologies are described in detail in the following sections.

\subsection{Chilled Water}

Chilled water storage uses the sensible heat capacity of water $\left(1 \mathrm{Btu} / \mathrm{lbm}-{ }^{\circ} \mathrm{F}\right)$ to store thermal energy. Tank volume depends on the temperature difference between the water supplied from storage and the water returning from the load, and the degree of separation between warm and cold water in the storage tank. While most conventional non-storage HVAC systems operate on temperature differentials of 10 to $12^{\circ} \mathrm{F}$, chilled water systems generally need a differential of at least $16^{\circ} \mathrm{F}$ to keep the storage tank size reasonable.

Chilled water is generally stored at 39 to $42^{\circ} \mathrm{F}$, a temperature range that is directly compatible with most conventional water chillers and distribution systems. Return temperatures of 50 to $60^{\circ} \mathrm{F}$ or higher are desirable to maximize the tank temperature difference and minimize tank volume. 
Tank volume is also affected by the separation maintained between the stored cold water and the warm return water. Natural stratification has emerged as the preferred approach because of its low cost and good performance. Colder water remains at the bottom of the tank and warmer, lighter water remains at the top. Specially designed diffusers transfer water into and out of the storage tank at a low velocity to minimize mixing.

\subsection{Geothermal Heat Pump}

Geothermal energy storage uses the heat capacity of the soil matrix in an aquifer to store thermal energy. A schematic illustrating the operation of a geothermal energy storage system is shown in Figure 4-15. During the summer, cool water is pumped from one well location and used to cool the building. The heated water leaving the building is returned to the ground at another well location. Energy from this hot water stream is stored in the soil matrix. During the winter the cycle is reversed. Water is pumped from the heated ground to provide heating to the building. The cooled water leaving the building is returned to the ground at the cold well. This method enables thermal energy from the hot months during the summer to be stored to provide heating during the winter.

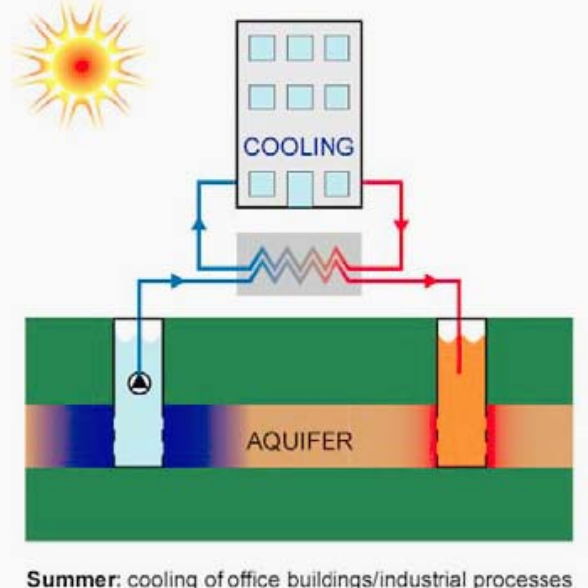

Figure 4-15 Schematic of Geothermal Energy Storage and Recovery

\subsection{Ice Thermal Storage}

Ice thermal storage takes advantage of the high latent heat of fusion of water (144 Btu/lbm). Storage volume is generally in the range of 2.4 to 3.3 cubic feet per ton-hour, depending on the specific ice storage technology. Thermal energy is stored in ice at $32^{\circ} \mathrm{F}$, the freezing point of water. The equipment must provide charging fluid at temperatures of 15 to $26^{\circ} \mathrm{F}$, below the normal operating range of conventional air-conditioning equipment. Depending on the storage technology, special ice-making equipment is used or standard chillers are selected for low temperature duty. The heat transfer fluid may be the refrigerant itself or a secondary coolant such as glycol with water or some other antifreeze solution. The low temperature of ice can also provide lower temperature air for cooling. The lower-temperature chilled water supply available from ice storage allows a higher temperature rise at the load, up to $25^{\circ} \mathrm{F}$. 
The following ice thermal storage technologies have been used.

- Ice Harvesting

- External melt ice-on-coil

- Internal melt ice-on-coil

- Encapsulated ice

- Ice Slurry

The most common commercial technology today is internal melt ice-on-coil. External melt and iceharvesting systems are more common in industrial applications and can also be applied in commercial buildings. Encapsulated ice systems are also suitable for many commercial applications.

\subsection{Phase Change Material (PCM)}

Thermal energy can be stored in the form of latent heat of fusion. The heat of fusion is the energy required to convert a fluid from the liquid phase to the solid phase. This energy can then be released by melting the solid phase and converting the material back to liquid form. The phase change process allows a large amount of energy to be stored in a constant, or nearly constant temperature reservoir. The amount of energy stored in the material as it changes phase and the temperature at which the phase change takes place are properties of the specific material.

Phase change materials that are well suited for thermal energy storage in CHP and HVAC applications will have a high latent heat of fusion per unit volume and phase change temperatures that are consistent with source and sink temperatures.

Ice is the most common example of a phase change material. Ice has a heat of fusion that is larger than other available phase change materials. However, pure ice can only change phase at $32^{\circ} \mathrm{F}$. This temperature is well below the source and sink temperatures in most HVAC and CHP systems. As a result ice storage systems require additional chiller equipment to make ice.

A number of alternate phase change materials are available. The two primary classes of phase change materials are inorganic hydrated salts, and organic materials. The latent heats of these materials are typically less than ice, however these materials have been engineered to change phase at any of a wide range of possible temperatures.

Hydrated salts are compounds made up of combinations of salt and water that are combined in such a way to provide the desired melting point. Hydrated slats change phase at a single temperature. Organics are typically highly refined paraffin or fatty acids. These organic materials typically change phase over a narrow temperature range.

Each of these materials is available with phase change temperatures that are appropriate for HVAC and CHP applications. The selection of phase change materials is driven by the following selection criterion: high latent heat of fusion, high thermal conductivity, small volume changes with phase, non-corrosive, and the stability of material properties over time. 


\subsubsection{Other Equipment}

\subsubsection{Backup Power System Market}

Backup power system has been a fast-growing market in the US for the past few years. In 2003, the industrial backup power revenue increase was around $85 \%$ and the residential market growth is around $15-20 \%$, with 2002 as the basis year.

Some of the growth was attributed to the large-scale power blackout in August 2003 and even Y2K a few years ago. Business owners such as the telecom companies tend to think that the cost of backup power is low compared to the loss of work. Construction and rental end users also drive the market, which is mainly portable power equipment. In the year 2003, the portable power market has a $7-10 \%$ growth rate.

For residential users, weather-related power outage remains one of the greatest drivers. It has been observed that home genset sales tend to spike after severe weather. In 2003, 89\% of the sales of the residential units were for standby or backup application, while there was only $6 \%$ for continuous operation and 5\% for peaking. New homes that include a genset comprise one of the market segments with the greatest growth rate.

\subsection{Current State of Technology}

Based on how the generator is integrated, there are portable power units and stationary generator set. Portable power generators typically use manual start and manual transfer of power, while the stationary power gensets, which are supposed to provide power as soon as possible when the grid is down, are started automatically whenever needed. Stationary systems are generally more fuel efficient than the portable devices ${ }^{[90]}$. Even without sound attenuation equipment, the stationary power gensets are designed to have a lower noise than portable ones. Certain stationary gensets have the option of adding sound attenuation devices.

The advantages of the portable devices compared to the stationary ones are that, for the same power, the costs of the portable devices as well as the transfer switch for it are lower than the stationary. Also the portable power genset generally does not need permit while the stationary does.

\subsection{Future Trend and Development}

About $80 \%$ of the revenue of current total generators is from diesel engine units ${ }^{[124]}$ and the rest is natural gas-fired. The number of natural gas-fired units is expected to grow, because of the fact that there is a well-established natural gas infrastructure. This is particularly attractive to the residential customers, who may not like the idea of storing liquid fuel in the basement or utility room. Dual-fuel genset, with better flexibility and the capability to increase the power output using diesel, are expected to get more market presence ${ }^{[85]}$.

The backup power growth rate is expected to stay rather constant for the next few years ${ }^{[84]}$. However, some hurdles do exist. First the backup power system cost is rather high. For a Guardian $15 \mathrm{~kW}$ stationary power, the equipment capital cost is around $\$ 3200$ and the installed cost is about double the equipment capital cost. Since backup power is used only a few hours per year, which is 
considered a luxury feature, it may be difficult for the backup power system to enter the majority of households. Second, the US economic downturn in recent years affects the industrial/commercial market as well, which is the major backup power market. Finally, the emissions metrics of the standby power system, which are typically higher than large scale power plants, needs to be improved. Some EPA emission regulations, especially the Tier IV standards, will affect portable gensets of all sizes.

\subsection{The Effect on Micro-CHP}

Micro-CHP can be designed for different purposes. If the major purpose is to provide backup power, the prime mover capacity needs to be large enough to cover the house electric peak load, around 10 $\mathrm{kW}$ for a single family house. If the purpose is to save utility and equipment cost, it should run in a thermally-led mode because thermally-led operation fully utilizes the waste heat of power generation. In addition, the prime mover capacity should be around 1-2 $\mathrm{kW}$ because too large a prime mover generates more electricity than can be used by the house. As a result, the utilization ratio is low and the capacity is high.

It is desirable for a household to have both backup power and utility savings. One solution is to have both the backup power generation and the micro-CHP. Indeed, micro-CHP and backup power are not in head-to-head competition but are complementary. If both systems exist, only one set of interconnection device is needed.

In this study of micro-CHP assessment, backup power generation can be included in both the baseline configuration and the micro-CHP systems.

\subsection{Technology Assessment}

After identifying the candidate micro-CHP devices, each technology is evaluated based on various performance and cost metrics. This evaluation is not intended to provide a definitive figure of merit for each technology, but rather to provide a simple means of differentiating the various technologies. The results of this process provides a first order filter that is used to identify the technologies that have the greatest potential for achieving high value impact as energy storage devices in micro-CHP systems.

\subsubsection{Prime Mover Technology Evaluation}

A prime mover in a micro-CHP system generates electricity and the waste heat of the prime mover is used to drive the thermally activated equipments. The various prime mover technologies described in Section 4.1.1 are evaluated using the metrics and weighting factors shown in Table 4-2. The weighting factors shown in this table are assigned subjectively and are intended to provide a relative measure of the importance of each metric with respect to application in a CHP system.

Table 4-2 Micro-CHP Prime Mover Evaluation Metrics And Weighting Factors

\begin{tabular}{|l|c|}
\hline \multicolumn{1}{|c|}{ Evaluation Metric } & Weighting Factor \\
\hline Efficiency & 0.5 \\
\hline Life & 0.5 \\
\hline
\end{tabular}




\begin{tabular}{|l|c|}
\hline \multicolumn{1}{|c|}{ Evaluation Metric } & Weighting Factor \\
\hline Low capital cost & 2.0 \\
\hline Technology maturity & 0.1 \\
\hline Scalable for residential & 0.5 \\
\hline Customer acceptance & 0.1 \\
\hline Low noise & 0.5 \\
\hline Environmental friendly & 0.1 \\
\hline Fast response & 0.5 \\
\hline Large operating range & 0.5 \\
\hline Easily couples with TAT & 0.2 \\
\hline Source energy availability & 0.1 \\
\hline Source energy flexibility & 0.1 \\
\hline Maintenance cost & 0.5 \\
\hline Fuel cost & 0.5 \\
\hline Waste heat temperature & 0.5 \\
\hline
\end{tabular}

Scores ranging from 0.1 (lowest score) to 2 (highest score) are assigned to each prime mover technology for each metric, based on both quantitative and qualitative assessments, relative to application in a CHP system. The raw scores for each prime mover are shown in Table 4-3. The weighted scores are shown in Figure 4-16. It can be seen that the reciprocating engines and the Stirling engines have higher scores, suggesting that they are more appropriate for the micro-CHP.

One of the advantages of this evaluation method is that if the metrics change, e.g., for governmental administration the environment is more important, the weighting factor for that item can be increased. The ranking of the technologies would be different and could be assessed easily. 
Table 4-3 Raw scores for micro-CHP prime mover evaluation

\begin{tabular}{|c|c|c|c|c|c|c|c|c|c|c|c|c|c|c|c|c|}
\hline Weight & 0.5 & 0.5 & 2 & 0.1 & 0.5 & 0.1 & 0.5 & 0.1 & 0.5 & 0.5 & 0.2 & 0.1 & 0.1 & 0.5 & 0.5 & 0.5 \\
\hline System & Efficiency & Life & $\begin{array}{c}\text { Low } \\
\text { capital } \\
\text { cost }\end{array}$ & $\begin{array}{c}\text { Technology } \\
\text { maturity }\end{array}$ & $\begin{array}{l}\text { Scalable for } \\
\text { residential }\end{array}$ & $\begin{array}{c}\text { Customer } \\
\text { acceptance }\end{array}$ & $\begin{array}{l}\text { Low } \\
\text { noise }\end{array}$ & $\begin{array}{c}\text { Environm } \\
\text { ental } \\
\text { friendly }\end{array}$ & $\begin{array}{c}\text { Fast } \\
\text { response }\end{array}$ & $\begin{array}{c}\text { Large } \\
\text { operating } \\
\text { range }\end{array}$ & \begin{tabular}{|c} 
Easily \\
couples \\
with TAT
\end{tabular} & $\begin{array}{c}\text { Source } \\
\text { energy } \\
\text { availability }\end{array}$ & $\begin{array}{c}\text { Source } \\
\text { energy } \\
\text { flexibility }\end{array}$ & $\begin{array}{l}\text { Maintena } \\
\text { nce cost }\end{array}$ & Fuel cost & $\begin{array}{l}\text { Waste heat } \\
\text { temperature }\end{array}$ \\
\hline Photovoltaic & 1 & 4 & 1 & 3 & 5 & 3 & 5 & 4 & 5 & 5 & 1 & 2 & 1 & 4 & 5 & 1 \\
\hline Wind turbine & 3 & 5 & 2 & 4 & 4 & 2 & 3 & 5 & 3 & 2 & 1 & 1 & 1 & 4 & 5 & 1 \\
\hline Solar thermal engine & 2 & 4 & 1 & 3 & 2 & 2 & 5 & 4 & 2 & 3 & 4 & 2 & 1 & 3 & 5 & 4 \\
\hline Reciprocating engine & 3 & 2 & 5 & 5 & 5 & 5 & 1 & 2 & 5 & 4 & 3 & 5 & 3 & 2 & 2 & 3 \\
\hline Rotary engine & 3 & 2 & 4 & 4 & 5 & 3 & 1 & 2 & 5 & 4 & 3 & 5 & 3 & 2 & 2 & 3 \\
\hline Microturbine & 2 & 3 & 4 & 3 & 2 & 3 & 3 & 3 & 3 & 4 & 4 & 5 & 3 & 3 & 2 & 4 \\
\hline Steam turbine & 2 & 3 & 2 & 5 & 1 & 2 & 3 & 4 & 2 & 2 & 4 & 5 & 4 & 1 & 1 & 3 \\
\hline Therm elec power gen. & 1 & 4 & 1 & 2 & 2 & 3 & 5 & 2 & 5 & 5 & 4 & 5 & 3 & 4 & 1 & 5 \\
\hline Stirling engine & 3 & 4 & 3 & 3 & 5 & 3 & 5 & 4 & 2 & 3 & 4 & 5 & 4 & 4 & 2 & 5 \\
\hline PAFC & 4 & 4 & 1 & 4 & 3 & 4 & 5 & 4 & 4 & 5 & 5 & 5 & 2 & 4 & 3 & 3 \\
\hline MCFC & 5 & 2 & 1 & 2 & 4 & 4 & 5 & 2 & 4 & 3 & 5 & 5 & 2 & 1 & 3 & 5 \\
\hline SOFC & 5 & 3 & 1 & 2 & 4 & 4 & 5 & 4 & 4 & 3 & 4 & 5 & 2 & 4 & 3 & 5 \\
\hline PEMFC & 4 & 4 & 1 & 3 & 5 & 4 & 5 & 4 & 5 & 5 & 4 & 5 & 2 & 4 & 3 & 2 \\
\hline
\end{tabular}

Table 4-4 Raw scores for micro-CHP thermally activated technology evaluation

\begin{tabular}{|c|c|c|c|c|c|c|c|c|c|c|c|c|c|c|c|}
\hline Weight & 0.1 & 0.5 & 0.5 & 2 & 0.1 & 0.5 & 0.5 & 0.1 & 0.5 & 0.1 & 0.5 & 0.2 & 0.1 & 0.1 & 0.5 \\
\hline System & $\begin{array}{c}\text { Ratio of } \\
\text { waste } \\
\text { heat }\end{array}$ & $\begin{array}{c}\text { Efficiency } \\
\text { or COP }\end{array}$ & $\begin{array}{l}\text { Long } \\
\text { life }\end{array}$ & $\begin{array}{c}\text { Low } \\
\text { capital } \\
\text { cost }\end{array}$ & $\begin{array}{c}\text { Tech- } \\
\text { nology } \\
\text { maturity }\end{array}$ & $\begin{array}{l}\text { Scalable } \\
\text { for } \\
\text { residential }\end{array}$ & $\begin{array}{l}\text { Low } \\
\text { noise }\end{array}$ & $\begin{array}{c}\text { Environ- } \\
\text { mental } \\
\text { friendly }\end{array}$ & $\begin{array}{c}\text { Fast } \\
\text { response }\end{array}$ & \begin{tabular}{|c|}
$\begin{array}{c}\text { Large input } \\
\text { temperature } \\
\text { range }\end{array}$ \\
\end{tabular} & \begin{tabular}{|c|} 
Large \\
operating \\
range
\end{tabular} & $\begin{array}{l}\text { Easily } \\
\text { couples } \\
\text { with }\end{array}$ & $\begin{array}{l}\text { Customer } \\
\text { acceptance }\end{array}$ & \begin{tabular}{|c|} 
Source \\
energy \\
flexibility
\end{tabular} & $\begin{array}{r}\text { Maintena } \\
\text { nce cost }\end{array}$ \\
\hline LiBr Absorption & 3 & 3 & 4 & 3 & 5 & 4 & 4 & 4 & 2 & 5 & 4 & 5 & 4 & 5 & 2 \\
\hline Ammonia Abs. cycle & 3 & 3 & 4 & 1 & 5 & 4 & 4 & 3 & 2 & 5 & 4 & 5 & 4 & 5 & 3 \\
\hline Silica gel aDsorption & 4 & 3 & 5 & 1 & 4 & 2 & 4 & 4 & 3 & 3 & 4 & 5 & 4 & 5 & 1 \\
\hline Carbon methanol aDso & 4 & 3 & 4 & 2 & 2 & 4 & 4 & 4 & 3 & 3 & 4 & 5 & 4 & 5 & 2 \\
\hline Gas engine Chiller & 3 & 5 & 4 & 4 & 5 & 5 & 3 & 3 & 5 & 3 & 4 & 3 & 5 & 3 & 4 \\
\hline ORC & 2 & 2 & 4 & 2 & 5 & 2 & 3 & 3 & 3 & 2 & 2 & 2 & 2 & 4 & 2 \\
\hline Steam turbine & 1 & 2 & 4 & 2 & 5 & 2 & 3 & 4 & 3 & 1 & 2 & 1 & 2 & 3 & 2 \\
\hline Therm elec power gen. & 2 & 1 & 4 & 1 & 2 & 3 & 5 & 5 & 5 & 2 & 4 & 5 & 4 & 5 & 5 \\
\hline Water heater & 5 & 5 & 4 & 5 & 5 & 5 & 4 & 5 & 5 & 5 & 5 & 5 & 5 & 5 & 5 \\
\hline Solid desiccant & 3 & 3 & 4 & 3 & 5 & 4 & 4 & 4 & 4 & 3 & 4 & 3 & 5 & 4 & 4 \\
\hline Liquid desiccant & 4 & 3 & 4 & 3 & 5 & 4 & 4 & 2 & 3 & 3 & 4 & 4 & 3 & 5 & 3 \\
\hline Cromer cycle & 3 & 4 & 4 & 2 & 3 & 4 & 4 & 3 & 4 & 3 & 4 & 4 & 5 & 5 & 3 \\
\hline
\end{tabular}




\section{MicroCHP Prime Mover Technology Assessment}

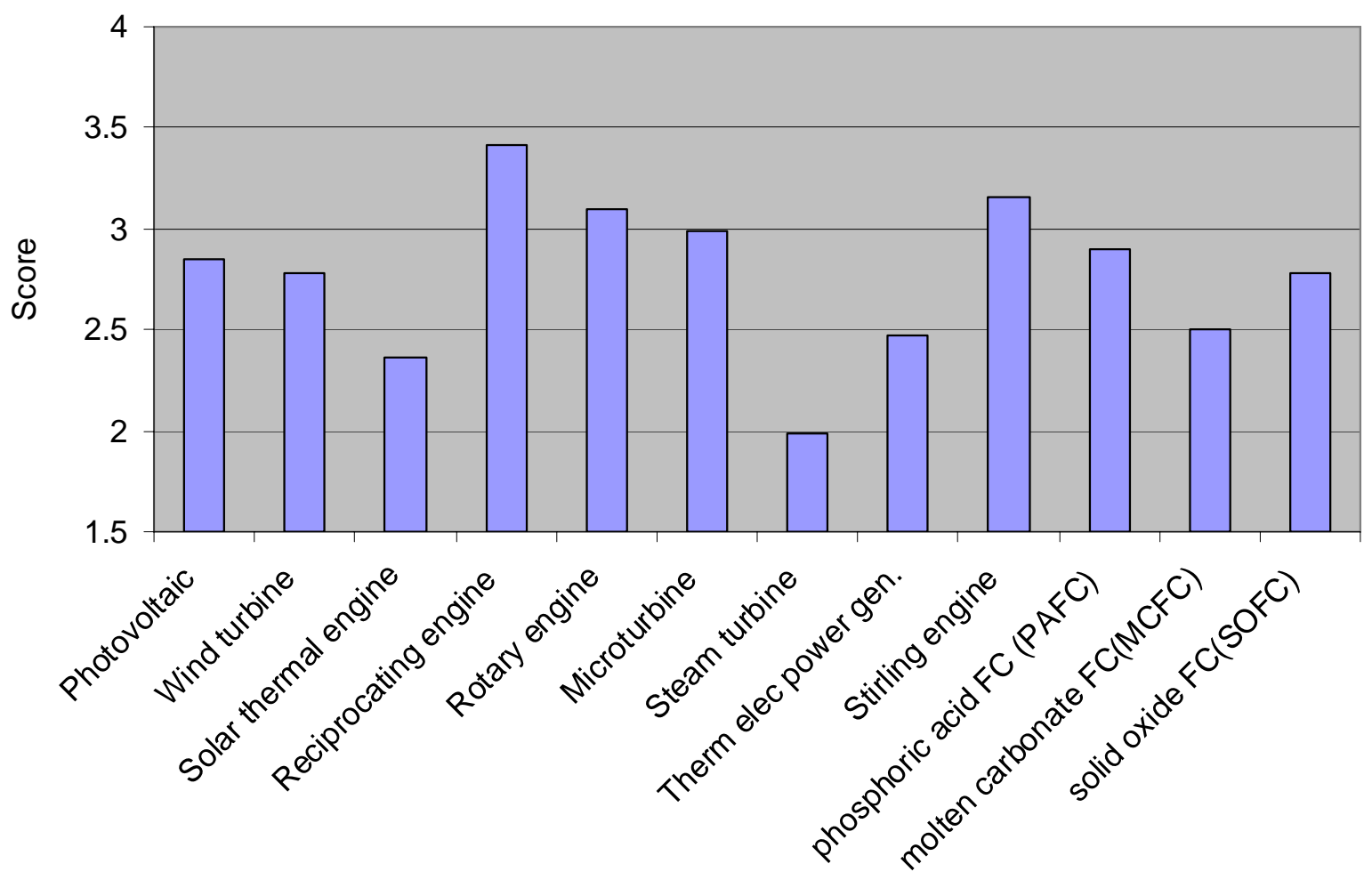

Figure 4-16 The weighted scores for evaluation of different prime movers

\subsubsection{Thermally Activated Technology Evaluation}

Thermally activated technology (TAT) usually denotes heat driven cooling (absorption and adsorption cooling), dehumidification (solid and liquid desiccant systems), bottoming power generation (organic Rankine cycle) or waste heat recovery equipments. The raw scores for each TAT are shown in Table 4-4. The various TAT equipment described in Section 4.1.3 are evaluated using the metrics and weighting factors shown in Table 4-5. The weighting factors shown in this table are assigned subjectively and are intended to provide a relative measure of the importance of each metric with respect to application in a CHP system.

Table 4-5 Micro-CHP TAT Evaluation Metrics And Weighting Factors

\begin{tabular}{|l|c|}
\hline \multicolumn{1}{|c|}{ Evaluation Metric } & Weighting Factor \\
\hline Ratio of waste heat utilization & 0.1 \\
\hline Efficiency or COP & 0.5 \\
\hline Long life & 0.5 \\
\hline Low capital cost & 2 \\
\hline Technology maturity & 0.1 \\
\hline
\end{tabular}




\begin{tabular}{|l|c|}
\hline \multicolumn{1}{|c|}{ Evaluation Metric } & Weighting Factor \\
\hline Scalable for residential & 0.5 \\
\hline Low noise & 0.5 \\
\hline Environmental friendly & 0.1 \\
\hline Fast response & 0.5 \\
\hline Large input temperature range & 0.1 \\
\hline Large operating range & 0.5 \\
\hline Easily couples with prime movers & 0.2 \\
\hline Customer acceptance & 0.1 \\
\hline Source energy flexibility & 0.1 \\
\hline Maintenance cost & 0.5 \\
\hline
\end{tabular}

Similar to the prime mover evaluation, the scores for each technology are assigned for each metric. The weighted scores are shown in Figure 4-17. It can be seen that the water heater has the highest score. The second is the gas engine chiller. Strictly speaking, a gas engine chiller, which contains a gas engine and a vapor compression chiller, is not a single piece of TAT equipment. However, it is evaluated here for the purpose of comparison to other equipment such as an absorption chiller that provides the same function.

\section{MicroCHP Thermally Activiated Technologies Assessment}

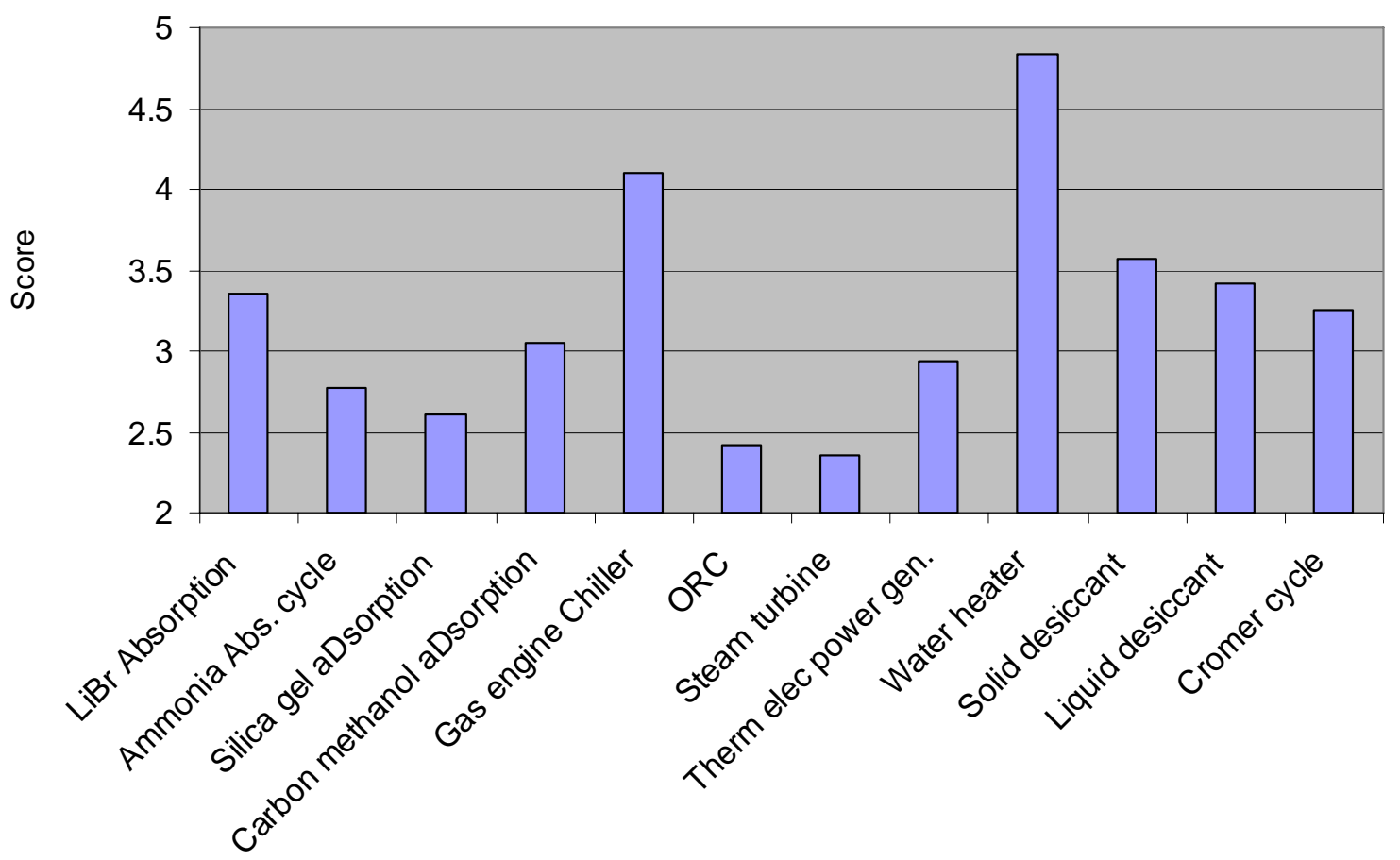

Figure 4-17 The weighted scores for evaluation of different thermally activated technologies 


\section{$5 \quad$ System Synthesis and Analysis}

The overall objective of the system synthesis and analysis effort is to characterize a range of micro-CHP systems that satisfy the customer requirements. These characteristics consist of performance, economics, emissions, reliability, nuisances, operation. The first three in particular are correlated and strongly depend on the system configuration (architecture), design and operation. In order to quantify the economics and performance and to quantify the value of each micro-CHP system, analysis tools are needed. Such tools must have the following characteristics:

1. Building load and climate models for representative building types and climate zones in North America.

2. Thermodynamic performance models of the micro-CHP systems, their constituent subsystems and alternate conventional (non-CHP) systems to produce detailed energy utilization profiles.

3. Electricity and natural gas rate models for the desired markets to derive projections of operating costs.

4. Capital cost data and models to produce complete life cycle cost evaluations for the energy conversion equipment.

5. Emission models to evaluate the emission from a micro-CHP system, as well as that of conventional systems.

\subsection{System Configuration and Operation}

While different candidate technologies have been identified and analyzed in Chapter 4 that can potentially be used in a micro-CHP system, the synthesis of system solutions, i.e., their configuration or architecture and their operation strategy to meet the customer needs requires careful study.

The micro-CHP system configuration consists of a combination of the following main subsystems.

- A prime mover to generate electricity that partially meets household electrical load.

- A heat recovery device to recover the waste heat from the prime mover to meet hot water and heating loads.

- An electrical power interface with the grid to meet electrical loads and ensure power quality.

- A process air subsystem to handle air circulation to the house.

- A supplementary burner to provide additional energy for space heating and hot water, if the waste heat is not sufficient.

- A thermally activated chiller such as an absorption or adsorption chiller to meet the cooling load.

- A vapor compression lag chiller to meet cooling loads, if thermally activated chiller is not available. 
In its simplest embodiment, a micro-CHP system includes a prime mover to produce power and a heat exchanger to recover the heat. However, a large number of possible configurations exist, due to the specificities of the several prime mover technologies in terms of capacity, power and power conversion (DC/AC), efficiency, turn-down operation or waste heat grade. More over, the operation of a system, which aims to optimize the functional requirements of the product such as maximizing system economic value is another level of complexity for a particular system. In order to address the complex design task of such micro-CHP systems, the advanced modeling tools developed at UTRC have been deployed in this study.

An array of customer needs has been identified, which ranges from simple secured heating to fully integrated solution for thermally activated cooling, heating and power. Based on these needs, seventeen systems with different combinations of prime movers and thermally activated technologies and different operation strategies are delineated, as discussed in Section 5.2.2.2. Thermodynamic and economic performance of each system is studied under a variety of conditions, including building location, size, system capacity and control schemes. Desired micro-CHP configurations as well as operation strategies are then obtained.

\subsection{System Architecture Analysis}

In this section, micro-CHP systems with different architectures are analyzed. The detailed system configuration and the control strategy are modeled with the necessary level of thermodynamic details. Economics data wherever needed, are obtained or estimated based on expert opinions. The overall methodology in analyzing the micro-CHP is introduced first below.

\subsubsection{The General Procedure of the Micro-CHP System Analysis}

The general procedure of the micro-CHP system analysis is:

1) The user chooses the building location, size, structure and material etc. in the building simulation tool, which is the Energy-10 in this study;

2) Energy-10 exports the hourly thermal and electric load as well as weather data;

3) The user chooses a micro-CHP system to be modeled, including the prime mover type, capacity, micro-CHP operation mode, vintage and whether using net metering, etc.

4) Check whether the micro-CHP system can meet the building loads.

The performance, economics and emission characteristics of the micro-CHP systems are compared to the performance of conventional house HVAC equipments. The operating and life cycle costs of the conventional system are used as a baseline to calculate the payback period, cash flow, and emissions. The conventional building subsystems consist of the following. 
- Vapor compression chiller to meet all cooling loads

- Gas water heater to meet hot water and heating loads

- Electricity from the grid to meet all electric loads

The metrics used to compare the performance of the different micro-CHP systems are the payback period with respect to investment and baseline system definition, cash flow, and emissions compared to a conventional, non-CHP system, as well as favorable features such as automatic switching at power outage or provision of additional backup power for lighting and appliances.

\subsubsection{Description of Micro-CHP Modeling Tool}

Since 2003, the United Technologies Research Center (UTRC) has been developing proprietary tools to model the performance and economics of CHP systems. The micro-CHP modeling tool is similar to other CHP modeling tools developed at UTRC, such as the energy storage CHP Tool and Desiccant CHP Tool with several unique features such as:

- the building simulation tool: Energy-10 instead of DOE-2

- the thermodynamic and economic simulation tool: Matlab.

- an emission module to address the environmental impact

The tool consists of four major parts:

1. Building loads and climate models

2. Thermodynamic models that capture the performance characteristics of all the relevant micro-CHP systems and subsystems.

3. Economic models that cover detailed utility rate information as well as operating and life cycle cost calculations.

4. Emission models

Each of these four parts is described in more detail below. The CHP modeling tool architecture is designed for flexibility such that different in-house, legacy or commercial models could be used for each main part without the need to modify the tool architecture. In the current embodiment, the micro-CHP modeling tool kernel is based on Matlab and interfaces with Energy-10 simulation environment for building modeling. The thermodynamic modeling tool has been developed using Matlab and interfaced with Excel. The economic and emission models, including information on utility rates are based in Matlab.

\subsubsection{Residential Load Models}

A few building simulation packages (such as EnergyPlus, Energy-10, DOE-2 and eQuest) have been evaluated to identify which one is suitable for the micro-CHP analysis. The eQuest package uses DOE-2 as its computing engine. Energy-10 and eQuest are favored for their better interface and hourly load capability. A quantitative comparison is made between Energy-10 and eQuest. It is found that eQuest produces much larger heating loads than Energy-10, as shown in Figure 5-1. One of the possible reasons for the difference is that Energy-10 and eQuest handle the load differently. For example, Energy-10 enables the user 
to create a load schedule while eQuest does not. Considering that Energy-10 is designed to meet the national survey data (EIA's National Building Energy Consumption Survey and Residential Energy Consumption Survey), Energy-10 is chosen as the building load simulator.

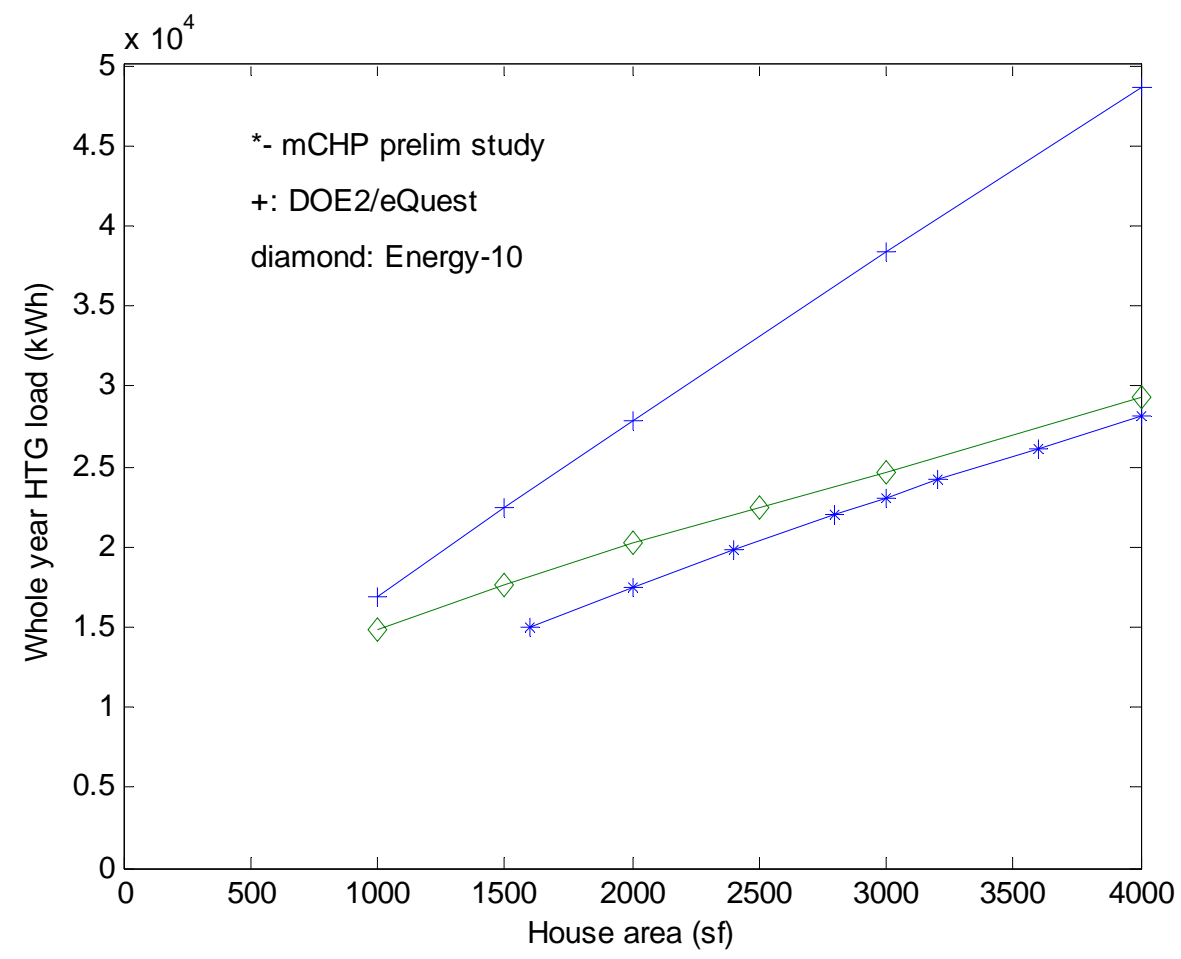

Figure 5-1 Annual total heating load from Energy-10 and eQuest

The major inputs to run the building analysis in Energy-10 include house location, size, number of floors and zones, equipment sizing, operating time and indoor set temperature, etc. If the user does not supply a specific input parameter, Energy-10 will use the default. More detailed information can be found in ${ }^{[79]}$.

The major output parameters are the ambient wet and dry bulb temperature, space heating and cooling load, hot water load, electric load for fan, HVAC and the total electric load, etc. The load data are retrievable in a text file and are used in the thermodynamic modeling.

\subsubsection{Thermodynamic Models}

The approach for performance analysis is based on suitable reduced order steady state and part load component and subsystem models compatible with the evaluation framework outlined in section 5.2 above.

\subsection{Objectives of Thermodynamic Modeling}

Compared to conventional systems, micro-CHP systems provide means to the customer to reduce the overall utility bill, to supply backup power capability and to reduce emissions. 
The system thermodynamic performance is modeled to determine the micro-CHP system power generation, fuel consumption, emissions as well as those for the conventional systems. These benefits are a strong function of the micro-CHP configuration, design and operation (i.e., control strategies). The selection of optimal operation strategies goes hand in hand with the proper sizing of the CHP system.

\subsection{System Control and Operation Strategy}

\section{Extra load handling:}

A micro-CHP system produces electricity and heat, which may not always be equal to the required electric and heating loads in the house. If the generation amount by the micro-CHP is smaller than the house load requirements, the house needs to purchase electricity from the grid and/or burn more fuel using a burner. If the generation from the micro-CHP unit is more than the required house loads, means must be available to handle the surplus such as sending the electricity back to the grid or dissipate the extra heat to the environment.

Having smaller micro-CHP capacity will reduce the likelihood for generating extra load. However, if the system is too much undersized, the micro-CHP benefit will degrade. On the other hand, there are always times when the generation amount is larger than the need. Therefore, equipment or methods to handle extra load should be taken into consideration in the micro-CHP system design.

To handle the extra electric load, either net metering or an electric resistant heater can be used. Net metering enables the customer to send extra power back to the grid and requires minimum additional equipment and less sophisticated control. The benefit is that customers can generate electricity when they do not need it such as at midnight, to compensate for the consumption in peak usage hours. However, most states in the US only allow net metering for a limited number of applications such as renewable electric generation. If the house owner becomes a net power producer, the extra power sent to the grid can be credited at a much lower price than the purchase price from the grid or not at all. Therefore, it is not generally financially beneficial to send too much power to the grid. Also residential scale power generation, when connected to the grid, may degrade the grid reliability and, hence, utility profit. Therefore, net metering may not be an option for many states. In that case, a resistance heater can be used to convert the extra electric load back to heat for space heating or hot water heating. The disadvantage is that customers need to pay for the heat and related control devices.

Excess heating capacity in the form of flue gas can be easily discharged to the ambient. However, if the heat energy is, for example, contained in the jacket water of the heat recovery system used to keep the prime mover running, the excess heat load has to be released by another method. An energy storage device, such as a hot water tank, can be used, which may be full at certain time, unless it is sufficiently large. An alternative approach is to use a heat exchanger to dissipate the heat into the ambient air.

Electrically led operation vs. thermally-led operation: 
Generally, disposing extra electricity in the form of heat without heat recovery will reduce the system energy efficiency. The system efficiency of a micro-CHP system denotes the overall energy utilization of the micro-CHP. The system electric efficiency is defined as the system electric output versus the incremental fuel input compared to a conventional system. Such definitions are used in this study since they clearly show the effective output and the corresponding expenses of the system. More detailed definitions are in Appendix 8.1. To avoid wasting the heat energy, it is desired to run the micro-CHP system in thermally-led operation mode.

Thermally-led operation means matching the house thermal load with micro-CHP heat generation and under-sizing the electrical power generation capacity. Because all the electricity generated by the micro-CHP is consumed by the house electric equipment, the power generation efficiency can be close to $100 \%$, only discounted by loss such as mechanical-electrical conversion or DC-AC inverter. Figure 5-2 shows the energy flow in conventional and thermally-led micro-CHP systems.

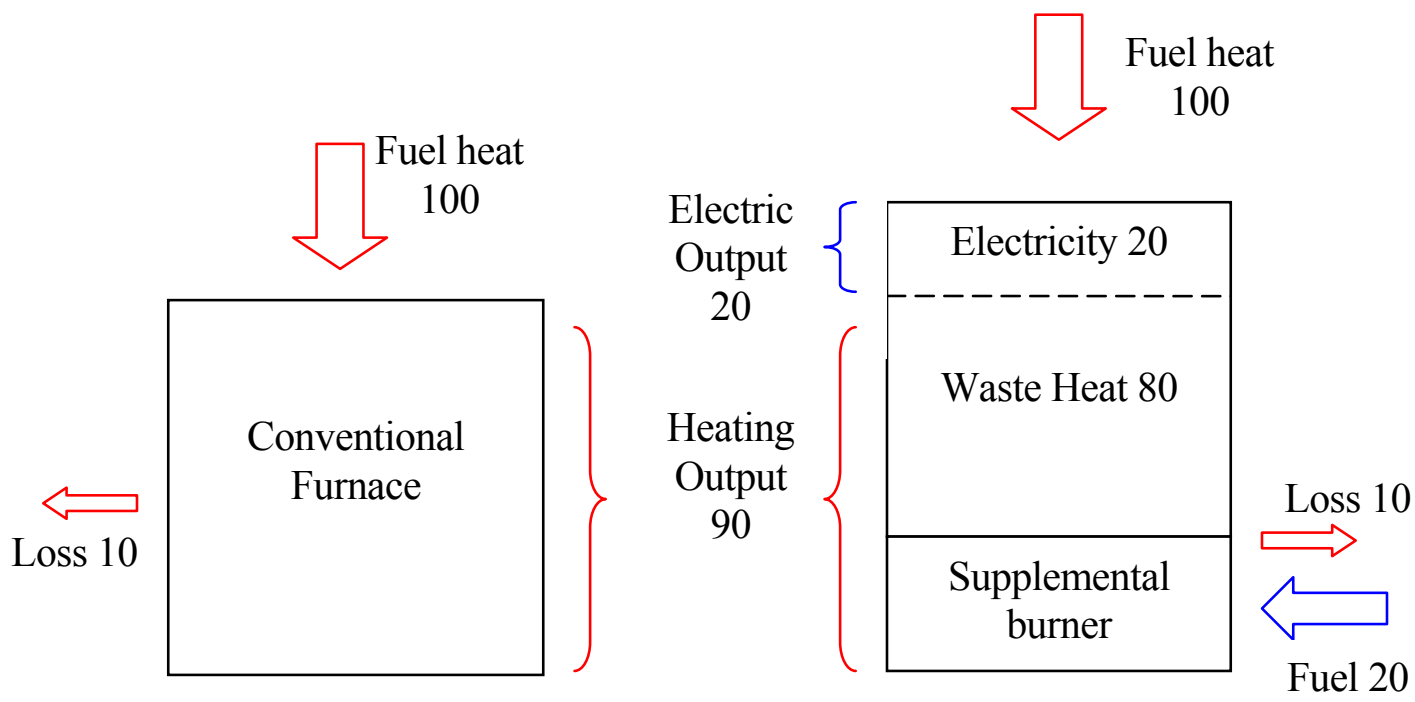

System energy efficiency $\eta=90 / 100$

System energy efficiency $\eta=(90+20) /(100+20)$

Equivalent electric efficiency $\eta=20 / 20=100 \%$

Conventional System

Thermally-led micro-CHP System

Figure 5-2 Energy efficiency of conventional and thermally-led micro-CHP systems

Usually the electricity generation does not meet the house electric load. If the electricity generation is lower than the house electric load, electricity will be drawn from the grid. 
Otherwise, extra electricity needs to be handled, e.g., using an electric resistance heater, which is not a waste but just part of the contribution for heating.

In contrast to the thermally-led operation, electrically led operation matches the house electrical power load with micro-CHP electrical power generation, up to the micro-CHP prime mover capacity. Grid electricity will be purchased if the house electrical load is higher than the prime mover capacity. In electrically led mode, thermal load usually does not match the house thermal load. If the heat generation from the micro-CHP is higher than the house load, excess heat energy will be disposed to the environment. Otherwise, a backup burner will be needed to make up for the additionally required thermal loads.

Thermally-led operation has higher overall energy utilization potential than electrically led operation because there is generally no energy wasting in this mode. This of course depends on the specific prime mover and instantaneous electrical to thermal load ratios $(\mathrm{E} / \mathrm{T})$ for the house. Another issue with electrically led mode in load following operation is that the prime mover has to respond very quickly since the house electric loads usually undergo abrupt changes, such as startup of the refrigerator compressor. Certain prime movers such as solid oxide fuel cells or Stirling engines, may not respond as well as the internal combustion reciprocating engines. Thermally-led operation, however, is not perfect in that the thermal load in summer is small without space heating load. Hot water load is the major thermal load, which is much smaller than the space heating load. Therefore, the micro-CHP system may not be running for most of the summer.

Whether the system should run in thermally-led or electrically led mode depends on the instantaneous thermal and electric load profiles, house size, location, utility rates and equipment efficiency, etc. It is possible to use a hybrid running mode, for example, running thermally-led in winter and electric led when the electric load and electricity price are high in summer.

\section{Variable Output vs. Bang-Bang Control}

Traditional equipment such as a furnace uses an on-off cycle, or Bang-Bang control, to produce the desired amount of load when the load is not equal to the design capacity. Today many manufacturers provide variable output equipment, e.g., a variable speed fan or a twostage burner in the furnace. The variable output equipments meet the load in a smoother way and tend to be more efficient.

In micro-CHP where there is a load matching issue between thermal and electric loads, Bang-Bang control and variable output may have more complications. For example, in the Bang-Bang control mode, the furnace will either provide full capacity or none at a certain time. The electricity generation will also follow this pattern since the heat comes as a byproduct of the prime mover or vice-versa. The chances that the prime mover will provide heat and electricity to the house simultaneously will be smaller in the Bang-Bang control mode. Also, the electricity, whenever it is generated, will be at full capacity for prime 
movers like IC engine. Without net-metering, this operation mode will result in inefficient use of electricity.

\subsection{System Configurations}

Control options mentioned in the previous sections may change the micro-CHP energy savings and value proposition. System modeling will consider these different control schemes for the selection of the optimal set of system configurations.

Seventeen system configurations have been studied with different control combinations, as listed below:

Table 5-1 Micro-CHP system configurations that have been modeled

\begin{tabular}{|c|c|l|}
\hline Configuration & $\begin{array}{c}\text { System } \\
\text { No }\end{array}$ & \\
\hline \multirow{3}{*}{ Baseline } & 1 & Basic micro-CHP + Net metering \\
\cline { 2 - 4 } & 2 & Basic micro-CHP + Electric heater \\
\cline { 2 - 4 } & 3 & Basic micro-CHP + Electric heater (Bang-Bang control mode) \\
\hline \multirow{4}{*}{$\begin{array}{c}\text { Electrically } \\
\text { led }\end{array}$} & 4 & Basic micro-CHP + Electric heater (Electrically led) \\
\cline { 2 - 4 } & 5 & Basic micro-CHP + Electric heater (Electrically led in cooling hours) \\
\cline { 2 - 4 } & 6 & Basic micro-CHP + Electric heater (Electrically led in cooling hours + Bang-Bang control) \\
\cline { 2 - 4 } & 7 & Basic micro-CHP + Electric heater (Hybrid control: to maximize prime mover capacity) \\
\hline \multirow{3}{*}{ Heat pump } & 8 & Basic micro-CHP + Net metering (Electrically led in cooling hours) \\
\cline { 2 - 4 } & 9 & Basic micro-CHP with heat pump (Electrically led in cooling hours) \\
\cline { 2 - 4 } Direct drive & 10 & Basic micro-CHP with heat pump (Electrically led in cooling hours + Bang-Bang control) \\
\cline { 2 - 4 } & 11 & Basic micro-CHP with heat pump + Net metering (Electrically led in cooling hours) \\
\cline { 2 - 4 } & 12 & Basic micro-CHP + Direct drive VCC + Electric heater (VCC led in cooling hours, thermally led other times) \\
\cline { 2 - 4 } Thermal \\
cooling & 14 & Basic micro-CHP + Direct drive VCC + Electric heater (VCC led in cooling hours, electrically led other times) \\
\cline { 2 - 4 } & 15 & Prime mover + Hot water + Space heating + Electric heater + Absorption chiller \\
\hline
\end{tabular}

*Basic micro-CHP consists of prime mover + space heating + hot water heating + VCC chiller

Systems 1 to 3 are baseline micro-CHP systems that include a basic micro-CHP architecture plus net metering or an electric heater. A basic micro-CHP system consists of a prime mover, a vapor compression chiller, and a waste heat recovery device, which is similar to a furnace that provides both space heating and hot water heating. The baseline micro-CHP operates in thermally-led mode.

Systems 4 through 8 operate in electrically led mode or hybrid led mode, either using an electric heater or net metering. Systems 9, 10 and 11 have a heat pump that generates the cooling load in summer. In winter, the heating load is provided by the waste heat from the prime mover and by the heat from the heat pump. If the ambient temperature is lower than a certain point, the heat pump will not run the refrigeration cycle. The heat is generated with the built-in electric heater instead.

Systems 12,13 and 14 are basic micro-CHP systems mechanically driving a vapor compression cycle (VCC) chiller directly. It is similar to a basic micro-CHP that electrically drives the VCC chiller. The difference is that in Systems 12 through14, there is no need to 
convert mechanical energy to electricity, thus these are slightly more efficient. A potential problem is that to drive the VCC chiller, the prime mover capacity has to be large enough, thus increasing the capital cost of the prime mover.

Systems 15 and 16 contain thermally-led cooling or dehumidification equipment. Having thermally activated cooling or dehumidification generates a higher thermal demand in summer, which is advantageous for thermally-led micro-CHP systems.

\subsection{Model Structure}

One objective of the thermodynamic modeling is to determine the fuel needed by the microCHP system and the electricity to be purchased from the grid for each micro-CHP system configuration with specific building electrical, heating, cooling and hot water loads.

The thermodynamic modeling procedure is as follows (using thermally-led System 2 in Table 5-1 as an example):

1) Determine the building loads from Energy-10;

2) Choose the system to run, including the control schemes;

3) Find out the total heat needed to meet the thermal load, given the micro-CHP system heat recovery efficiency;

4) Calculate electricity generation capacity with the efficiency of the chosen prime mover;

5) If the building electricity load is higher than the prime mover capacity, the control will set the operation to the prime mover capacity;

6) If necessary; purchase additional electricity from the grid,

7) Calculate the waste heat generated by the prime mover, including the heat from the electric heater. If needed, adjust the total thermal load demand;

8) If the waste heat is lower than the total thermal load demand, supplement the shortfall with a burner.

9) Total amount of fuel for the prime mover and the burner is calculated.

The heat energy that can be recovered from the prime mover and the electricity generated depend on the part load factor and vary with the ambient temperature.

Equipment specifications used in the modeling are shown below: 
Table 5-2 Specifications of equipment used in the modeling

\begin{tabular}{|c|c|}
\hline \multicolumn{2}{|c|}{ Equipment Specs } \\
\hline Equipment & Efficiency/COP \\
\hline Furnace & $93 \%$ \\
\hline Gas water heater & $65 \%$ \\
\hline $\begin{array}{c}\text { Liquid desiccant } \\
\text { regeneration heat/latent heat }\end{array}$ & $135 \%$ \\
\hline Electric heater & $100 \%$ \\
\hline VCC chiller & 3 \\
\hline Absorption chiller & 0.6 \\
\hline Heat pump COP & 3 \\
\hline
\end{tabular}

The prime movers in this analysis include Stirling engines, internal combustion reciprocating engines, fuel cells, thermoelectric power generators and Rankine cycle engines. The default efficiency and the cost for each prime mover can be seen in Table 5-3.

\subsubsection{Economic Models}

The economic analysis is carried out once the thermodynamic simulation is completed. The thermodynamic model output provides the year-total electricity and fuel amount to be purchased. The micro-CHP analysis tool contains three main modules relative to the economics of a CHP system.

- Calculation of prices and costs for installed equipment

- Calculation of operating costs, including gas and electricity bills

- Calculation of economic metrics, including mortgage and payback for the customer

The economic evaluation is mainly based on the payback compared to a system that does not have any integrated CHP, i.e., the entire electric load is met by the grid. Heating and hot water are provided by a furnace and a gas hot water heater, respectively. The cooling is provided by an electrically driven conventional vapor compression chiller (VCC). Because micro-CHP prime movers generally have the capability to provide backup power, a backup power system with the same capacity as the micro-CHP prime mover is added onto the conventional system for fair comparison.

The installed cost of a micro-CHP system is modeled as the combined cost of several components. The operating costs are based on the electricity and gas bills. The equipment maintenance cost is not considered here, which is expected to be minimal for residential applications. The fuel and electricity bills are based on energy consumed multiplied by the respective unit price plus any monthly flat fee, which is an option for most US residential markets.

The economic metrics used for this report are payback and mortgage of the investment at different interest and mortgage terms. It should be noted that the payback could be quite different whether the user choose a standby power system in the baseline or not. The payback for customer is calculated as follows. 
where,

$$
\text { Payback }=\frac{\Delta(\text { Equipment Price })}{\Delta(\text { operating } \cos t)}
$$

$\Delta($ Equipment Price $)=$ difference in the price of equipment (CHP vs. conventional) $\Delta($ operating cost $)=$ annual difference in the total operating cost, i.e., utility cost + maintenance cost

\subsection{System Cost Models}

This section describes details of the equipment cost and underlying assumptions for the conventional and micro-CHP systems. A conventional system is defined to include the following equipment:

- Space heating equipment, mainly a furnace

- A hot water heater

- A VCC chiller

- A backup power generator

A micro-CHP system consists of:

- A prime mover

- Space heating equipment

- A hot water storage tank

- A vapor compression chiller or thermally activated chiller

- An electric heater or net metering device

- An induction motor, if present

- Necessary control devices

Conventional Systems:

The cost of each component in the conventional systems includes the equipment cost, installation labor cost and parts installation cost. The equipment cost of the space heating, or furnace, is based on Carrier 58MVP high efficient furnace cost with a capacity of 100,000 $\mathrm{BTU} / \mathrm{hr}$. The hot water heater cost is assumed to be a linear function of the capacity, matching the typical gas water heater cost on the market, i.e., around $\$ 780$ for a 100 -gallon heater. The VCC chiller cost is based on the information from Porter Pipe \& Supply Co. Detailed installation, labor, and parts costs for space heating, hot water, and chiller are estimated based on expert engineering experience ${ }^{[161]}$.

Backup power capacity in a conventional system is sized to be the same as the prime mover capacity in a micro-CHP system. Equipment cost is regressed based on Guardian stationary systems $(>6 \mathrm{~kW})$ and Coleman Powermate portable systems $(\leq 6 \mathrm{~kW})$. The installation cost is assumed to be 1.1 times of the equipment cost plus $\$ 100$ for the control parts needed in installing the backup power system. 
Micro-CHP Systems:

- A prime mover

- Space heating equipment

- A hot water storage tank

- A vapor compression chiller/heat pump or thermally activated chiller

- An electric heater or net metering device

- An induction motor, if present

The prime mover cost varies with the prime mover type and size. The Stirling engine and internal combustion reciprocating engine are commercial products and the costs for these two types of prime mover are regressed as a function of the prime mover electrical power capacity. The Rankine cycle engine and fuel cell micro-CHP systems are based on prediction ${ }^{[124]}$. The thermoelectric cost is based on the devices that are used for purposes other than micro-CHP since thermoelectric micro-CHP systems are not available yet. For reference, the nominal efficiencies of different prime movers are also listed in table 5-3 indicating currently achievable efficiency.

Table 5-3 Prime mover power generation efficiency and unit cost

\begin{tabular}{|c|c|c|}
\hline Prime mover & Efficiency & $\begin{array}{c}\text { Capital cost } \\
\mathbf{( \$ / k W )}\end{array}$ \\
\hline Stirling & $16 \%$ & $\$ 1604 / \mathrm{kW}$ \\
\hline Rankine & $10 \%$ & $\$ 1638 / \mathrm{kW}$ \\
\hline Thermoelectric & $5 \%$ & $\$ 3000 / \mathrm{kW}$ \\
\hline Fuel Cell & $30 \%$ & $\$ 3000 / \mathrm{kW}$ \\
\hline IC & $27 \%$ & $\$ 1604 / \mathrm{kW}$ \\
\hline
\end{tabular}

The space heating installed cost in a micro-CHP is similar to that in a conventional system because micro-CHP can essentially be treated as a conventional heating system plus a prime mover. A slight difference is that the space heating in a micro-CHP system requires an auxiliary burner, two water pumps and corresponding piping, with the total miscellaneous additional cost of \$220 approximately.

For hot water heating, micro-CHP system provides heat for water heating, thus saving the cost of $\$ 967$ for installing a separate flue gas pipe, as in a typical conventional system. It is assumed that the hot water tank in a micro-CHP system has the same equipment cost as that of a gas water heater in a conventional system.

If the chiller in the micro-CHP is a VCC type, the installation parts and labor costs are the same as in a conventional system. If the chiller is thermally activated, the parts and installation costs are roughly $20 \%$ higher than that of the VCC chiller, according to expert engineering estimates ${ }^{[161]}$. If a heat pump is used, the capacity of the heat pump is sized based on cooling. The heat pump cost is assumed to be 1.1 times of the cost of VCC cooling only unit that has the same cooling capacity as the heat pump ${ }^{[161]}$. 
The net metering system cost is assumed to be $\$ 200$, which usually includes a 2 -way meter and a interconnect switch. If net metering is not used, an electric heater is needed to consume any extra electricity generated by the prime mover. The electric heater needs to adjust the capacity smoothly and continuously. Two heaters may be needed. If the system is calling for heat, it can be utilized in the house. If heat is not needed, the power still needs to be dumped and this would have to be outside of the house to a separate resistance. Such a heater usually is much more expansive than a fixed capacity electric coil. To save the cost, the electric heater is made up of a $1 \mathrm{~kW}$ variable output coil plus zero to a few $\mathrm{kW}$ fixed capacity coils, depending on the capacity of the prime mover. In that case, the electric heater can have output from zero to the total electric heater capacity continuously while keeping the cost relatively low. The cost is around $\$ 57$ for a fixed $1 \mathrm{~kW}$ electric heater and $\$ 347$ for a $0 \sim 1 \mathrm{~kW}$ variable output electric heater.

The induction motor that is proposed in the current micro-CHP application is not available commercially. It is assumed that the incremental cost is $\$ 300$ to account for additional hardware and the more complicated control.

If a system is for a residential new construction (RNC), the cost may be different from that in an add-on or replacement (AOR). For example, in a new construction, the flue gas pipe needs to be installed but is not necessarily needed for AOR. The distribution and installation cost for conventional equipment such as furnace or hot water is usually higher than that for a new installation. It is not clear how much additional cost will be for a micro-CHP system due to the fact that the market has generally not seen any such systems yet. This study will therefore focus on the RNC market.

\subsection{Utility Cost}

To calculate the utility cost, the amount of electricity purchased from the grid and the fuel consumptions is first calculated for the micro-CHP and the conventional systems. The electricity and natural gas rates for the city that the house is located are obtained from the utility rate database in the modeling tool. The rate information is up to date as of October 2004 for the seventeen cities in this study.

The utility rate model includes a fixed monthly cost as well as a variable portion. The variable portion usually can be lumped into a certain amount of dollars per kilowatt of electricity or per cubic foot natural gas. For some cities, the rate is different when the energy consumption is above a certain level of usage. This difference has been captured in the modeling. With the hourly energy consumption from the thermodynamic modeling and the utility rates, the monthly electric and gas costs are obtained.

\subsubsection{Emission Models}

In a conventional system, the electricity is generated in a utility power plant and gas is burned in a house furnace or hot water heater. When a micro-CHP system is used, the amount of electricity needed by a house is reduced due to the self power generation using micro-CHP. Although the fuel consumption for a house may increase when using micro- 
CHP systems, the fuel burning process in most micro-CHP prime movers is clean, especially in the external combustion engines. In addition, the overall energy efficiency of micro-CHP increases compared to a conventional system, leading to even less pollutant emission.

The generation rate is available for $\mathrm{CO}_{2}$ and toxic pollutants such as $\mathrm{SO}_{\mathrm{X}}$ or $\mathrm{NO}_{\mathrm{X}}$ that are generated in a fossil power plant and in a residential furnace or hot water heater.

Table 5-4 Emission rate in a utility power plant and in a residential house (EPA statistics)

\begin{tabular}{|c|c|c|}
\hline & $\begin{array}{c}\text { Electricity generated in a utility } \\
\text { power plant }[\mathrm{kg} / \mathrm{kWe}]\end{array}$ & $\begin{array}{c}\text { Heat in a residential house } \\
{[\mathrm{kg} / \mathrm{kW} \text { heat }]}\end{array}$ \\
\hline $\mathrm{CO}_{2}$ & 0.632 & 0.182 \\
\hline $\mathrm{SOx}$ & 0.00274 & $1.43 \times 10^{-4}$ \\
\hline $\mathrm{NOx}$ & 0.00135 & $9.11 \times 10^{-7}$ \\
\hline
\end{tabular}

Although the emission rate for electric generation and for heat generation in the table above are not comparable directly, the total emission generated to meet the electric and thermal loads can be calculated with above data for either using traditional energy equipment, i.e., grid power and boiler/furnace, or using a micro-CHP. The comparison result may show whether a micro-CHP brings any environmental benefit. The benefit of micro-CHP systems in terms of the emission is discussed in Section Error! Reference source not found.

\subsubsection{Analysis Results}

Extensive modeling studies have been performed to understand the factors affecting microCHP system economics. This section presents a selection of key trade studies that illustrates the impact of the critical parameters (see sections 6.1-6.2) on product and customer requirements. These results constitute the basis for the system configuration selection and for the critical parameters selection discussed in section 6.1-6.2.

The basic micro-CHP consists of a prime mover, a space heater, a hot water heater, a backup power unit and of a VCC chiller (if applicable). For a fair comparison, the conventional system should have the same backup power capacity and cooling capacity than the microCHP system.

Based on the data and recommendation in section 3, New York, Newark (New Jersey), and Detroit were selected in the system simulation. In addition, San-Francisco and Salt Lake City are also added to the list to cover a broad representation of the market with high heating load from the West and the mountain regions. Consistent with the recommendation to focus on high-end users first, a $3,000 \mathrm{ft}^{2}$ house size is selected, which is above the average US house size $\left(2320 \mathrm{ft}^{2}\right)$ in the locations considered.

The following variants are considered in the simulation:

Location: $\quad$ New York, San Francisco, Salt Lake City, Newark, and Detroit House area: $\quad 3,000 \mathrm{ft}^{2}$ 
PM options: $\quad$ Reciprocating engine, Stirling, Rankine, TE, FC

CHP heating: $\quad$ Domestic hot water and space heating

A total of seventeen systems listed in Table 5-1 have been analyzed.

In the modeling tool, the prime movers (PM) differ by their efficiency and price. Table 5-5 provides a comparison of the prime mover technologies considered in this analysis.

Table 5-5 Comparison of Prime Mover Technologies with multiple sources in Chapter 9 Color code: green - good, yellow - medium, red - not acceptable

\begin{tabular}{|c|c|c|c|c|c|c|}
\hline $\begin{array}{l}\text { Evaluation } \\
\text { Criteria }\end{array}$ & Stirling & Rankine & IC & MT & TE & Fuel Cell \\
\hline Cost & $\$ 1604 / \mathrm{kW}$ & $\$ 1638 / \mathrm{kW}$ & \begin{tabular}{|l|}
$\$ 1604 / \mathrm{kW}$ \\
$+\$ 1500(\mathrm{~S}+\mathrm{E})$ \\
\end{tabular} & $\begin{array}{l}\$ 700-1100 / \mathrm{kW} \\
+30-50 \% \text { inst. }\end{array}$ & $\sim \$ 3000 / \mathrm{kW}$ & $>\$ 3000 / \mathrm{kW}$ \\
\hline Reliability & $\begin{array}{l}10 \text { years without } \\
\text { stopping }\end{array}$ & \begin{tabular}{|l} 
Expect to be \\
good due to \\
simplicity
\end{tabular} & $\begin{array}{l}\text { Needs regular } \\
\text { maintenance }\end{array}$ & $\begin{array}{l}\text { Needs regular } \\
\text { maintenance }\end{array}$ & $\begin{array}{l}\text { Expected to } \\
\text { be good (no } \\
\text { moving parts) }\end{array}$ & $\begin{array}{l}\text { Some parts } \\
\text { not reliable }\end{array}$ \\
\hline Life & Very long & \begin{tabular}{|l|} 
Large \\
Rankine: 30 \\
years
\end{tabular} & $>40,000$ hours & $\sim 10$ years & $\begin{array}{l}\text { Expected to } \\
\text { be long }\end{array}$ & $\begin{array}{l}\text { Expect not } \\
\text { as long as } \\
\text { other PMs }\end{array}$ \\
\hline $\begin{array}{l}\text { Technology } \\
\text { maturity }\end{array}$ & $\begin{array}{l}\text { Commercialized, } \\
\text { but still in } \\
\text { development }\end{array}$ & \begin{tabular}{|l|} 
No \\
commercial \\
units
\end{tabular} & $\begin{array}{l}>100 \text { year } \\
\text { history }\end{array}$ & Commercialized & $\begin{array}{l}\text { Some } \\
\text { commercial } \\
\text { units }\end{array}$ & $\begin{array}{l}\text { In } \\
\text { developmen }\end{array}$ \\
\hline Noise & Low noise & $\begin{array}{l}\text { Expected to } \\
\text { be low }\end{array}$ & $\begin{array}{l}\text { Low noise } \\
\text { with sound } \\
\text { attenuation }\end{array}$ & $\begin{array}{l}\text { Low noise with } \\
\text { sound } \\
\text { attenuation }\end{array}$ & Low noise & Low noise \\
\hline Efficiency* & $12-30 \%$ & $10 \%$ & $25-45 \%$ & \begin{tabular}{|l|}
$20-30 \%$ \\
$(\sim 60 \mathrm{~kW})$ \\
$10-12 \%(\sim 1 \mathrm{~kW})$ \\
\end{tabular} & $5-10 \%$ & $32-55 \%$ \\
\hline Fuel flexibility & $\begin{array}{l}\text { Can use all kinds } \\
\text { of fuel }\end{array}$ & \begin{tabular}{|l|} 
Can use all \\
kinds of fuel
\end{tabular} & $\begin{array}{l}\text { Limited by } \\
\text { design }\end{array}$ & $\begin{array}{l}\text { Limited by } \\
\text { design }\end{array}$ & $\begin{array}{l}\text { Can use all } \\
\text { kinds of fuel }\end{array}$ & $\begin{array}{l}\text { Limited by } \\
\text { design }\end{array}$ \\
\hline Emissions & Similar to furnace & \begin{tabular}{|l|} 
Similar to \\
furnace
\end{tabular} & \begin{tabular}{|l|} 
Controls \\
required for \\
NOx and $\mathrm{CO}$ \\
\end{tabular} & $\begin{array}{l}\text { Low, }<9-50 \\
\text { ppm NOx }\end{array}$ & $\begin{array}{l}\text { Similar to } \\
\text { furnace }\end{array}$ & Very low \\
\hline Maintenance & Moderate & Moderate & Frequent & $\begin{array}{l}\text { Moderate } \\
\text { expected }\end{array}$ & Little & Moderate \\
\hline $\begin{array}{l}\text { Furnace } \\
\text { integration }\end{array}$ & Easy to integrate & \begin{tabular}{|l} 
Easy to \\
integrate
\end{tabular} & $\begin{array}{l}\text { Harder to } \\
\text { integrate }\end{array}$ & $\begin{array}{l}\text { Harder to } \\
\text { integrate }\end{array}$ & \begin{tabular}{|l}
$\begin{array}{l}\text { Easy to } \\
\text { integrate }\end{array}$ \\
\end{tabular} & $\begin{array}{l}\text { Harder to } \\
\text { integrate }\end{array}$ \\
\hline Responsiveness & $\begin{array}{l}\text { On the order of } \\
\text { minutes }\end{array}$ & $\begin{array}{l}\text { On the order } \\
\text { of minutes }\end{array}$ & $\begin{array}{l}\text { On the order } \\
\text { of seconds }\end{array}$ & $\begin{array}{l}\text { On the order of } \\
\text { seconds }\end{array}$ & $\begin{array}{l}\text { On the order } \\
\text { of minutes }\end{array}$ & $\begin{array}{l}\text { Minutes to } \\
\text { hours for } \\
\text { startup }\end{array}$ \\
\hline
\end{tabular}




\section{Commercialization Strategy}

The micro-CHP system performance and economics have been analyzed within the possible design space in terms of building and equipment variations. This chapter will discuss the full product platform, modular system, and component selection that support commercialization of residential CHP systems.

\subsection{Equipment Commonality}

The performance and economics of micro-CHP systems depend on several factors, such as the equipment size and climate as well as building energy consumption characteristics. Different micro-CHP systems may be desired for different houses and regions. From a manufacturing standpoint, it is desirable to narrow the various configurations down to a few distinct products that can serve as broad and diverse a market as possible. Modular design is also preferred to reduce the manufacturing cost and make service and/or replacement easier. In this section, the desired solutions for different market segments are investigated. Common and shared components or subsystems are identified on a functional basis. This approach will serve as the basis for a product platform strategy.

\subsubsection{System Solutions for Various Regions and Market Segments}

The climate conditions vary significantly across the United States. This variance can be illustrated by the annual heating and cooling degree days as shown in Figure 3-4. Dwellings in the northern climates have a significant heating need that can exceed 8,000 annual degree days combined with a moderate cooling need, typically below 1,000 annual Fahrenheit degree days. For the definition of degree days, please refer to Appendix 8.1. Dwellings located in the southern states typically have heating needs that are less than 3,000 degree days but can have annual cooling loads exceeding 2,000 degree days. This variation between the regions demonstrates that there is not likely one micro-CHP system design concept that will be economically feasible for all regions. It is, however, desirable that there be a commonality on the component and subsystem levels in order to achieve the most effective manufacturing and supply chain management.

A more complete picture of U.S. climate characteristics is provided by Fairey ${ }^{[82]}$ in a study of actual heat pump performance for several U.S. locations, as shown in Figure 6-1. The study provides a good baseline to perform a first order analysis of the economics of a CHP system. The analysis is performed for a heat pump with a SEER of 12 and a HSPF of 7.8. The best-in-class heat pump performance is represented by a SEER of 17.5 (45\% greater than the Fairey study) and a HSPF of 9.6 (23\% greater than the Fairey study). This data can be used as a baseline to compare potential CHP solutions with heat pumps. (Note that the values of HSPF and SEER can be converted to an equivalent COP by dividing by 3.413.)

Within each region it is also important to understand population and housing demographics in order to assess the viability of a relevant market for micro-CHP systems. Market size is strongly influenced by the population of larger homes, age distribution of existing homes, rate of new construction, specific needs of potential customers such as perceived value of 
secure heat and secure power, occupancy habits and other factors. From these demographics and additional regional economic factors such as utility rates and rate structures, it is possible to define and estimate the size of several market segments within each region. These segments will have varying needs of cogeneration performance ranging from self powered HVAC appliances that provide security during extended grid loss events to fully capable CHP system that are capable of providing heating, cooling, hot water and electricity independent of the grid.

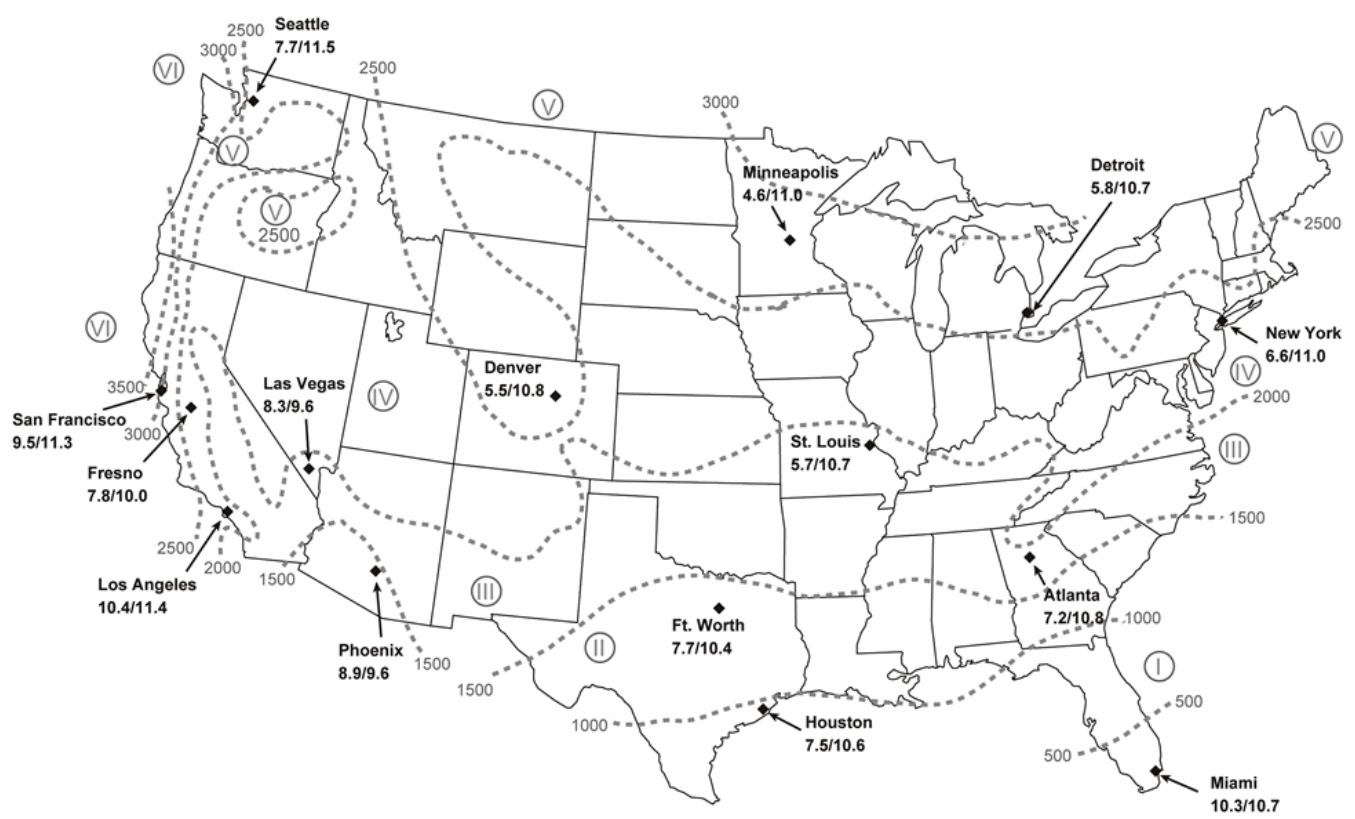

Legend:

Heat pump heating operating efficiency / cooling operating efficiency (Btu/Wh).

Labeled HSPF = 7.8, SEER = 12.0 (Btu/Wh).

Dotted lines and roman numerals in gray are ARI climate zones.

Boundary values are estimated zone full load heating hours.

Figure 6-1 ARI climate zones showing results of simulations in representative climates ${ }^{[82]}$

To segment the market, it is necessary to identify not only climate variations but also specific needs of the customers. The customer needs can range from a secure and reliable heating system that will operate even during an extended grid outage to a fully integrated cogeneration system that would allow normal functionality of the home independent from the electrical grid. Between these extremes it is also possible to identify a basic cogeneration approach in which the home heating system is designed to optimize operating economics by utilizing high grade heat from fuel combustion to generate electrical power to meet part of the house electrical demand while using lower grade heat to meet household heating demand. This system concept is similar to the cogeneration systems currently being marketed in Europe, for which the main drivers are a combination of environmental and economic benefits. 


\subsubsection{System Solutions for Northern U.S. Regions}

The typical design solution for a conventional residential HVAC system in northern U.S. climates consists of a ducted hot air furnace and central air conditioning, typically installed in the basement of the house. Natural gas is the dominant fuel in this market. Domestic hot water is typically provided by a gas-fired hot water heater. In existing homes in the New England region and in new construction of higher end homes, it is also common to find hydronic hot water baseboard heating systems in combination with ducted central air conditioning.

Heat pumps are uncommon in northern U.S. climates due to the relatively cold winters, the unfavorable cost ratio between electric energy and natural gas, and the threefold difference between the heating and cooling design loads. A typical 3,000 $\mathrm{ft}^{2}$ two-story northern residence has a heating design load of around 100,000 Btu/hr $(29 \mathrm{~kW})$ and a cooling design load of about 3 tons $(10.5 \mathrm{~kW})$.

There are several important considerations for micro-CHP solutions intended for northern U.S. climates. Among these are the relatively high expenditures associated with residential heating and cooling, the large imbalance between the heating and cooling loads, and the need for reliable heating equipment. Since northern parts of the country experience sub- freezing temperatures for extended periods, reliable heating is critical not only for comfort but also for the prevention of damage that may be caused by frozen water pipes due to loss of power or a failure of the heating system. The need for secure and reliable heating is especially critical for many retired people who live in northern states but travel south over the winter months, leaving their homes unoccupied for extended periods.

\subsubsection{Micro-Cogen: Power and heat generation}

In addition to providing secure heating for the home, it would be desirable and beneficial to incorporate a larger capacity prime mover that could provide emergency electrical power during grid outages for other critical residential loads such as freezers, well \& sump pumps, limited lighting, and medical devices. This emergency power could be made available automatically by inter-connecting the electrical power produced by the prime mover with the residential electrical system. Such a configuration also opens the possibility for limited cogeneration whereby the electrical power produced by the prime mover during normal heating operation can be used to power residential electrical loads, thus offsetting grid electricity consumption.

The fundamental requirement of a co-generating furnace is to provide reliable heat and power during both grid-connected and grid independent modes of operation. The system should be designed to meet the full residential thermal loads and a selected group of essential residential electrical loads. In order to maximize the co-generation benefit, the system should be configured not only to provide space heating but also to provide full capacity for domestic hot water heating. In addition, the system should be capable of reducing total energy costs by generating electricity at a lower cost than the electric utility. The cogeneration capability can be achieved either via direct connection to the residential electrical 
system or through discrete transfer switches that transfer loads between the co-generation system and the utility grid.

The target customers for this product are people that value availability of a reliable heating source, desire standby electrical power supply during grid outage, and/or seek an overall reduction in utility bills. Typical customers include those living in areas subject to severe weather conditions that result in frequent power outage, people having home businesses, people living in areas with unreliable transmission and/or distribution grid, elderly customers who need the assurance of reliable space heating and electric power, persons with illnesses that make them more vulnerable when left without space heating and electric power, and people who leave their homes unattended for extended periods of time during the colder months. This type of product will also be an economical option for regions with expensive electric power and reasonable fuel costs.

In addition to grid independent operation, a co-generating furnace should satisfy all the critical requirements for a conventional gas-fired condensing furnace in terms of performance, size, noise, reliability, installation, and operation. The system should also be able to operate without intervention even during extended periods of grid power loss.

\subsection{Product Requirements}

To be successful in the market place, a co-generating furnace must satisfy the following requirements.

1. During a grid-independent operation, the system shall provide full heating capacity.

2. In case of failure of the power generation unit the system shall be capable of producing about $50 \%$ of the full heating capacity as long as it is connected to the grid.

3. The system can operate independently of the external power grid. During gridindependent operation, the only power required by the system shall be supplied internally by an integrated battery and electric generator.

4. The system shall be capable of providing full heating capacity for domestic hot water.

5. The system shall be capable of providing emergency electric power even when there is no thermal load. As a result, the overall system efficiency will be reduced since there is no heat recovery.

6. The life cycle cost of the system, including the benefits associated with local electricity production, shall be comparable to that of an equivalent gas-fired furnace integrated with a permanently installed autonomous backup power generation system.

\subsection{System Design}

The proposed configuration for a co-generating furnace consists of a power generation system integrated with a modified variable speed condensing gas furnace. A simple schematic of such a system is shown in Figure 6-2 and a pictorial representation is shown in Figure 6-3. The power generation system consists of a prime mover, a heat recovery system, and an electrical conditioning system. The prime mover uses the fuel heat to generate power, 
the waste heat of which is used for space heating, domestic hot water (DHW) or space cooling through a heat recovery system. Electricity is supplied from the prime mover to the house electric equipment, including the pump or fans in the micro-CHP system, if any, through an electrical conditioning system. Potential prime mover (PM) candidates include a Stirling engine generator, a Rankine cycle engine generator, and an internal combustion (IC) engine generator. A TEG is not currently an economically attractive alternative for the cogenerating furnace because at higher power levels, since its cost becomes significantly greater than other available options. In addition, the low efficiency of the TEG would result in low duty cycle operation, low electricity generation, and minimal economic benefit.

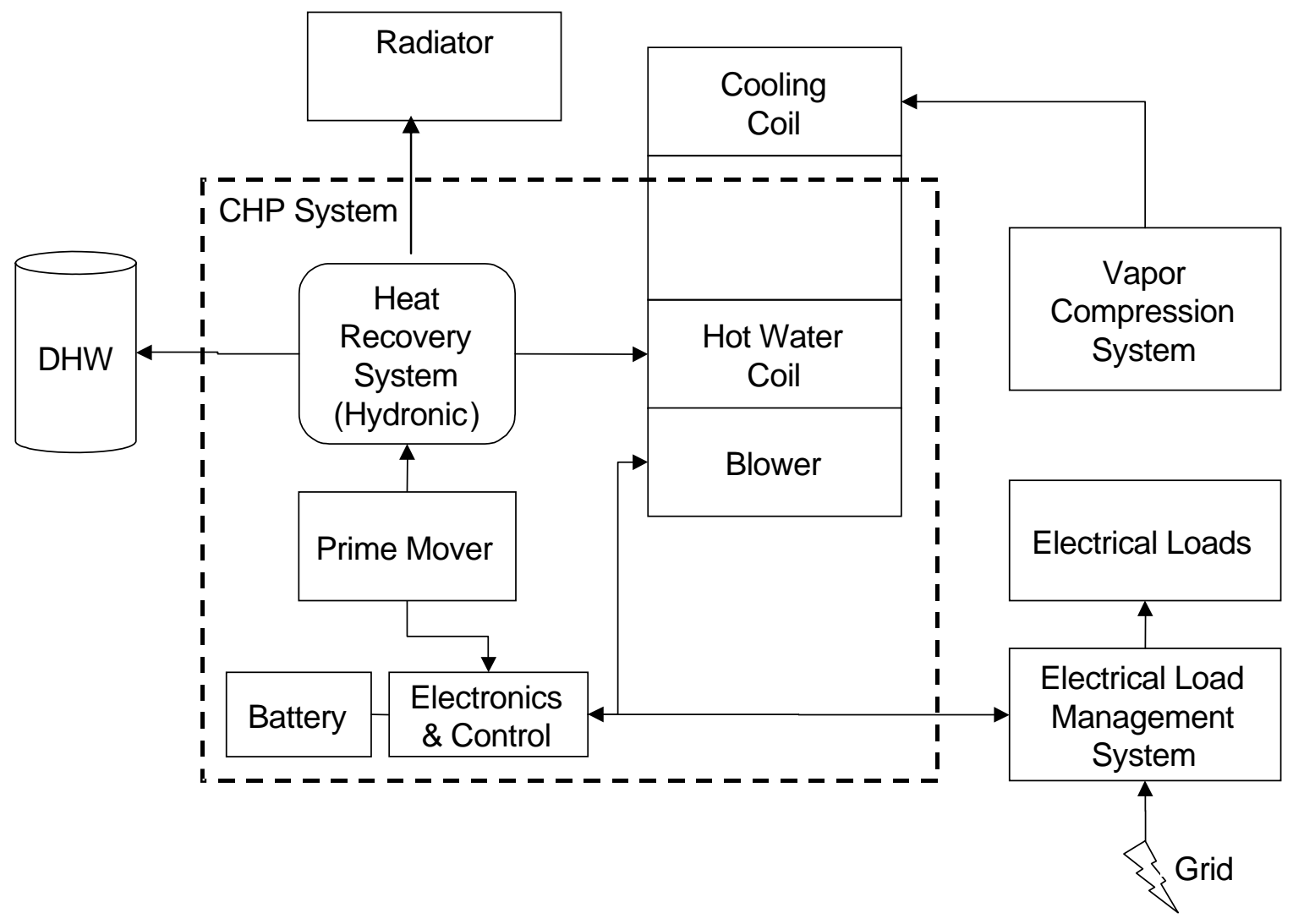

Figure 6-2 Co-generating furnace schematic 


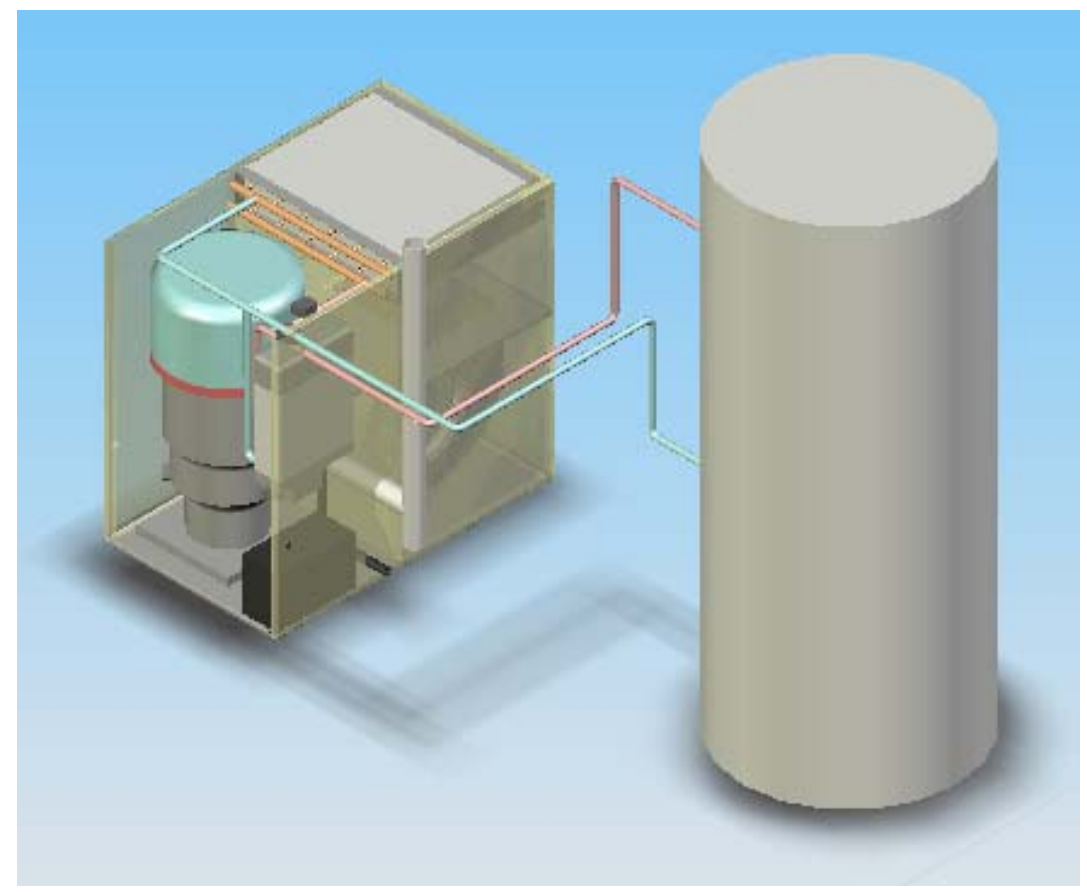

Figure 6-3 Pictorial representation of integrated Stirling based co-generating furnace concept

During grid-connected operation, the prime mover operates in a thermally-led mode. Thus, all the heat produced in the power generation process is used to satisfy the thermal loads of the house. Additional thermal capacity is provided via a supplemental burner that is integrated with the prime mover or located in the downstream exhaust air. Part of the electricity generated by the prime mover is used by the furnace blower and controls while the remainder is directed to the house electrical loads to offset power drawn from the external electrical grid. This can be accomplished either through a direct grid interconnection or through automatic transfer switches in a way that is transparent to the customer.

When electricity generation by the prime mover is greater than the house electrical load, excess electricity can be converted to heat using a resistance electric heater or fed back to the utility grid through a meter that runs in either direction (net metering). Note that net metering provides the potential for additional economic benefit but is only feasible in locations where it is allowed by regulations and where a mutually acceptable agreement can be reached with the local utility company.

When a grid power outage is detected, the system automatically starts and operates in an electrically-led mode to meet the electrical demands of the furnace and selected essential household loads. The heat that is produced by the power generation process will be used to the maximum extent possible to meet the thermal loads of the house. When the heat produced is less than what is required, the supplemental burner will provide additional heat. When the heat produced is greater than what is required, the excess heat will be rejected to an outdoor radiator unit. 


\subsubsection{Micro-Trigen: Power, Heat and Cooling Generation}

The fundamental requirement for a tri-generation micro-CHP system is to provide full services and comfort for the dwelling occupants with or without external supply of power while utilizing electricity and fuel in the most efficient manner through heat recovery and other integrated system solutions. To this end, it is required that the system can provide all essential electrical power to the building and that both heating and cooling requirements are satisfied under all conditions.

The target customers are people with premium homes located outside the utility's distribution lines or in areas with unreliable electric grid service. If these products can be provided at a reasonably low cost, this market could expand to other areas that have a favorable difference in costs between electricity and fuel.

\subsection{Product Requirement}

The differences between a base load co-generating system and a Trigen system are:

- All the house electric loads, including the air conditioner, can be satisfied when the utility grid is down including capacity for transient current inrush.

- Heat pump is used as much as possible to increase the winter heating efficiency.

- Vapor Compression Cooling (VCC) provides cooling.

\subsection{System Design}

Due to high first cost, this type of system will, at least initially, mainly be sold to off-grid customers in remote locations or areas with very unreliable power supply networks. The best solution for this application is likely to be one of the following two cases: 1) Combination of a basic thermally-led cogeneration system for base load and low power operation and a larger generator that would provide peak power when needed; 2) Prime mover sized so as to provide enough power and heat for all operations. In this proposed system, the prime mover capacity is large enough so that the entire house electric load, including the air conditioner, can be provided by the PM when the grid is down.

A VCC heat pump is part of the system, which provides heat in the winter months in combination with the exhaust heat from the prime mover. When a heat pump is used, the overall energy utilization is improved.

In the summer months, the VCC provides cooling. The VCC heat pump needs to be designed with variable speed compression to avoid cycling and high inrush currents. If there is not enough thermal load, the PM can produce power as needed by the VCC or other house load and dump extra heat to an outside heat dump that can be a radiator, a thermal storage device or a pool. 


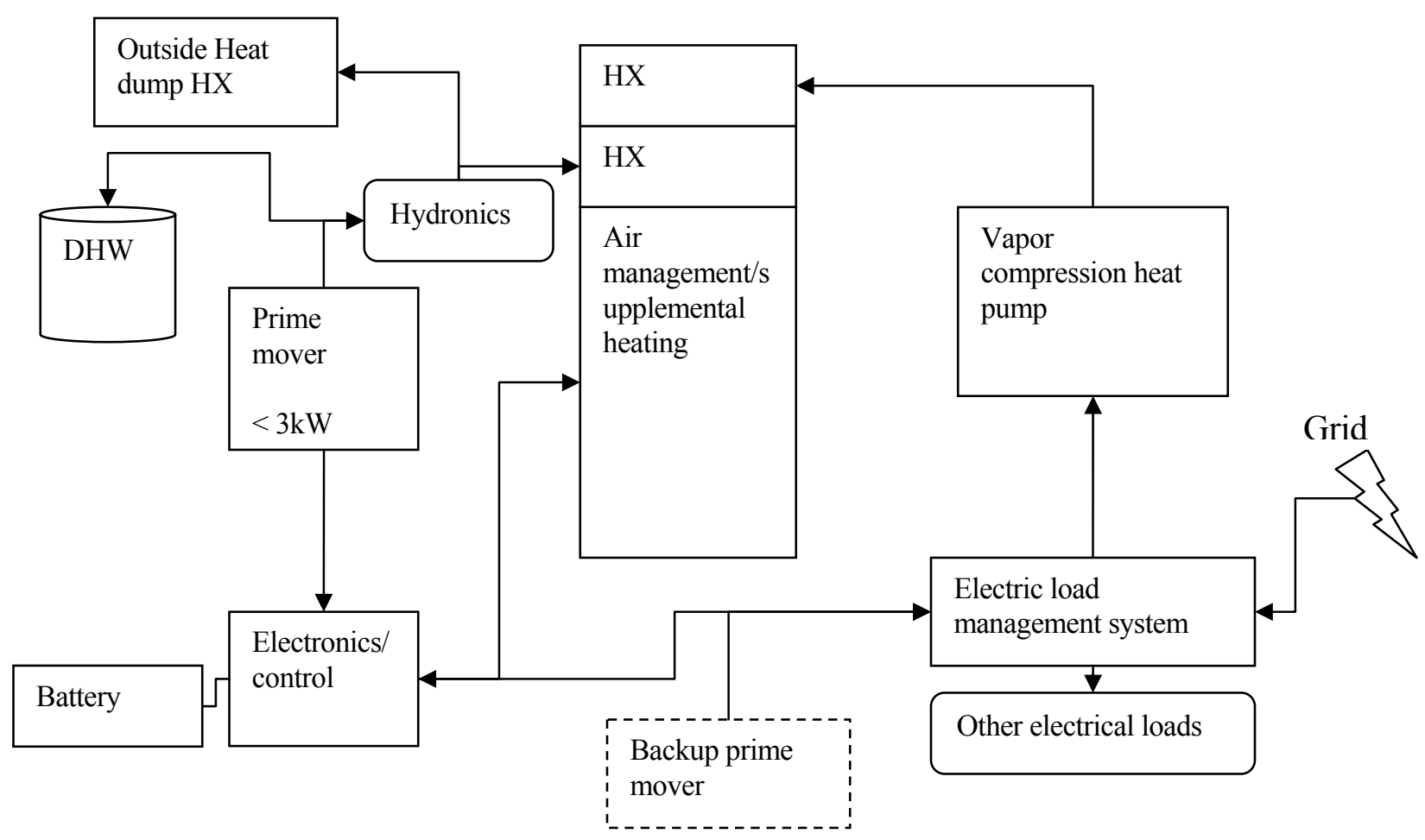

Figure 6-4 Tri-generating furnace for northern climates

\subsubsection{System Solutions for Southern Regions}

Residential solutions for combined power and cooling are not as attractive as combined heat and power solutions due to the low efficiency of thermally activated cooling technologies.

A typical 3,000 $\mathrm{ft}^{2}, 2$-story building has a typical design heating load of 50,000 Btu/h (15 $\mathrm{kW})$ while the design cooling load is about 5 ton $(15 \mathrm{~kW})$. A common solution to meet these loads are electric heat pumps that have a seasonal efficiency in heating mode, HSPF ranging from 7 to $10 \mathrm{BTU} / \mathrm{Wh}$ and a Seasonal SEER for cooling of about $10 \mathrm{BTU} / \mathrm{Wh}$.

The system efficiency can be very high in heating mode if a vapor compression heat pump is combined with a prime mover that can be modulated. With this solution, it is possible to recover most of the heat from the prime mover while the electric energy is used to power electric loads in the HVAC system and potentially other electric loads in the house.

In the cooling mode, it is much more difficult to make use of the waste heat from the prime mover. Current residential size absorption chillers have a COP of less than 0.7 . When coupled with a prime mover with an efficiency of $25 \%$ the system will generate much more electricity than typically needed for a residential application given that the entire cooling load shall be met with the thermally activated chiller. In order to make the system more viable the cooling needs are to be provided by both a vapor compression heat pump and a thermally activated system that utilizes the waste heat from the prime mover. 
The design heating load is very infrequent while the cooling load can be high for extended periods of time. Overall this makes the application of residential cooling, heat and power systems questionable with current technology.

\subsubsection{Co-generation Solution for Southern Climates}

The fundamental requirement for a base load co-generation system is to provide reliable heating and power without dependency of power from the grid and to utilize fuel and electricity in the most cost effective way. The system must satisfy the building load, including the electrical load from the chiller.

The target customers are people who value reliable heating and are willing to pay a premium for the security of having secure climate control of their house during power outages. In addition, the target customers should be willing to invest in a system that would reduce the cost of extensive operation in a grid-independent mode during the heating season.

In milder climates, it is not feasible to compete with the electric grid even during the heating season due to the high seasonal efficiency of a heat pump and the prevailing ratio between fuel cost and electric energy cost. The average COP for a high-end heat pump is around 3. This implies that the ratio between electric rates and fuel cost has to be over three to enable any possibility of positive cash flow, if the heating is mainly provided from waste heat recovery in the micro-CHP.

\subsection{Product requirement}

Given the system solutions in the previous subsection, a list of requirements is determined for better system design and development.

1. General requirement

- The system can run independently of the utility grid, i.e., the power is supplied by a PM included in the system, which is sized based on chiller capacity ( $16 \mathrm{~kW}$ cooling/COP $4 \sim 5 \rightarrow 4 \sim 3.2 \mathrm{~kW}$ ).

- The system can run with grid power without penalty compared to a conventional system.

- The system can provide a few $\mathrm{kW}$ of emergency electric power if no cooling/heating equipment is running, or provide reduced power if the cooling/heating equipment is running.

- System has the best payback or cash flow and is within acceptable range.

- The PM automatically adjusts the load based on the total electric load requirements.

2. Summer load requirement:

- The cooling load (as depicted in the Energy-10 tool) is met both at the design point $(99.5 \%$ of the times) and at part load.

- Hot water load is met.

3. Winter load requirement: 
- The heating load (as depicted in the Energy-10 tool) is met both at the design point $(99.5 \%$ of the times) and at part load.

- Hot water load is met.

\subsection{System solution}

Basic co-generation can be provided through heat recovery of the waste heat from the prime mover. This can include both space heating and domestic hot water. It is also required to add a heat dump device (radiator) to enable operation in an electric led mode during power outages.

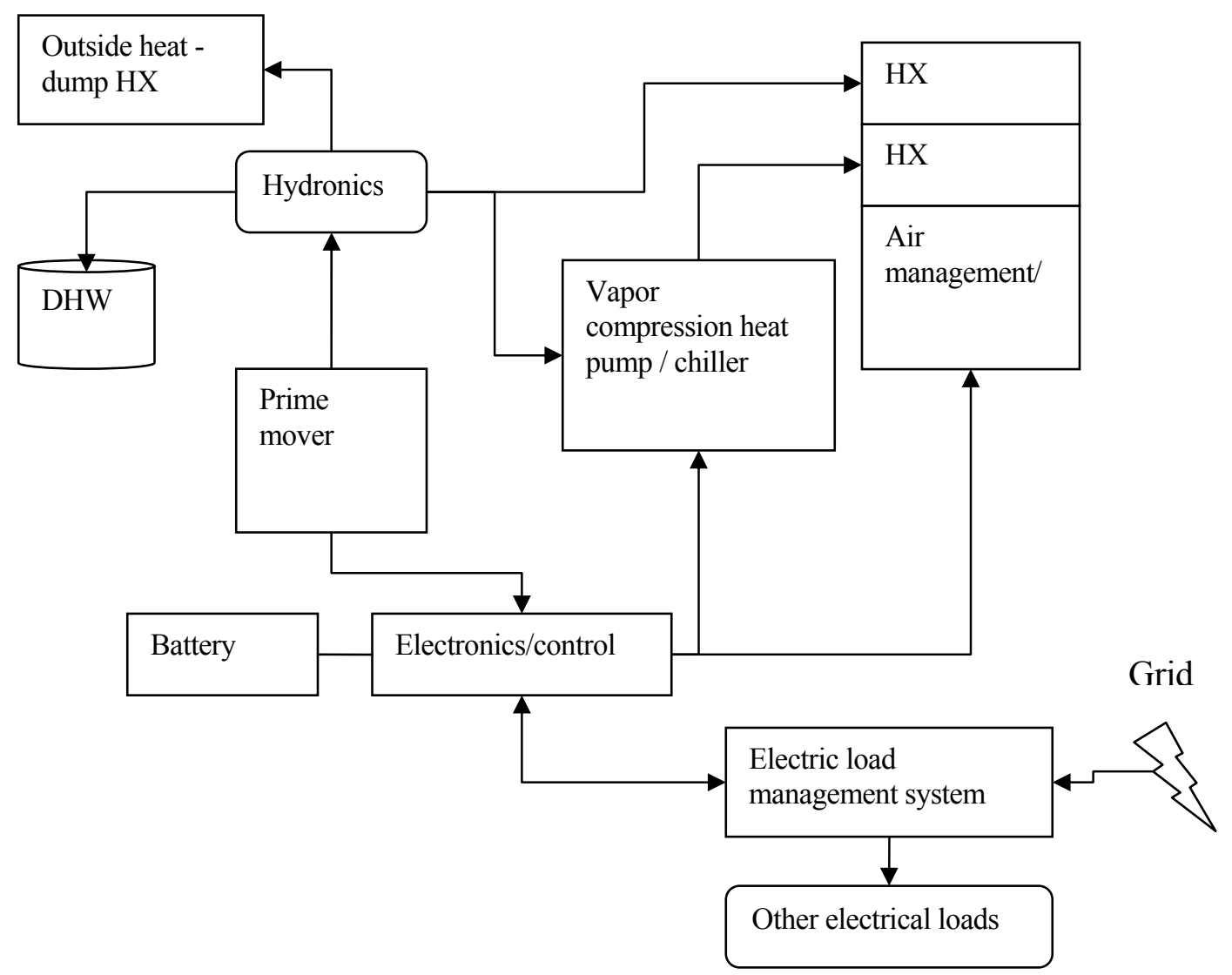

Figure 6-5 Basic co-generation system for southern climates

\subsubsection{Tri-generation Solution for Southern Climates}

The fundamental requirement of a Tri-generating system is to provide full comfort for the occupants of the dwelling with or without external supply of power while utilizing electricity and fuel at the most efficient way through heat recovery and integrated system solutions. To this end, it is required that the system has the capacity to satisfy all essential electrical power, heating and cooling requirements of the building at all conditions. 
The target customers are people with premium homes located in remote areas relative to the utility's transmission lines or in areas with unreliable electric grid. If the products can be provided at lower costs, this market could expand to other areas that have a favorable difference in cost between electricity and fuel.

\subsection{Product Requirement}

1. General requirement

- The system can run independently from the utility grid, i.e., the power is supplied by a PM included in the system.

- The system can run with grid power with no efficiency penalty compared to conventional system.

- The system can provide electric power for all loads in the home including transient inrush current.

- The system should be designed to minimize operating cost and/or energy usage.

- The PM can automatically adjust the load based on the total electric total load requirements.

2. Summer load requirement:

- The cooling load (as depicted in the Energy-10 tool) is met both at the design point $(99.5 \%$ of the times) and at partial load.

- Hot water load is met.

3. Winter load requirement:

- The heating load (as depicted in the Energy-10 tool) is met both at the design point $(99.5 \%$ of the times) and at partial load.

- Hot water load is met.

\subsection{System Solution}

Solution: A high efficiency prime mover combined with a VCC heat pump, heat recovery and an absorption chiller integrated as shown in Figure 6-6.

The PM capacity matches the power needed by VCC and other electric loads during cooling mode; PM electricity is used for VCC chiller. PM waste heat is used first for hot water and by a heat activated chiller. The input/output is optimized at any time depending on the load, equipment size and efficiency.

During heating hours, PM electricity is used for running a heat pump. The PM waste heat is used first for hot water and for space heating. The input/output is optimized at any time depending on the load, equipment size and efficiency.

It is possible that the PM reaches its maximum capacity while more electricity is needed. In such case, the cooling shortfall is provided by the absorption chiller (cooling hours) or the heating shortfall is provided by the backup burner (heating hours). If there is no grid connection, the PM capacity determines the maximum power to draw. 


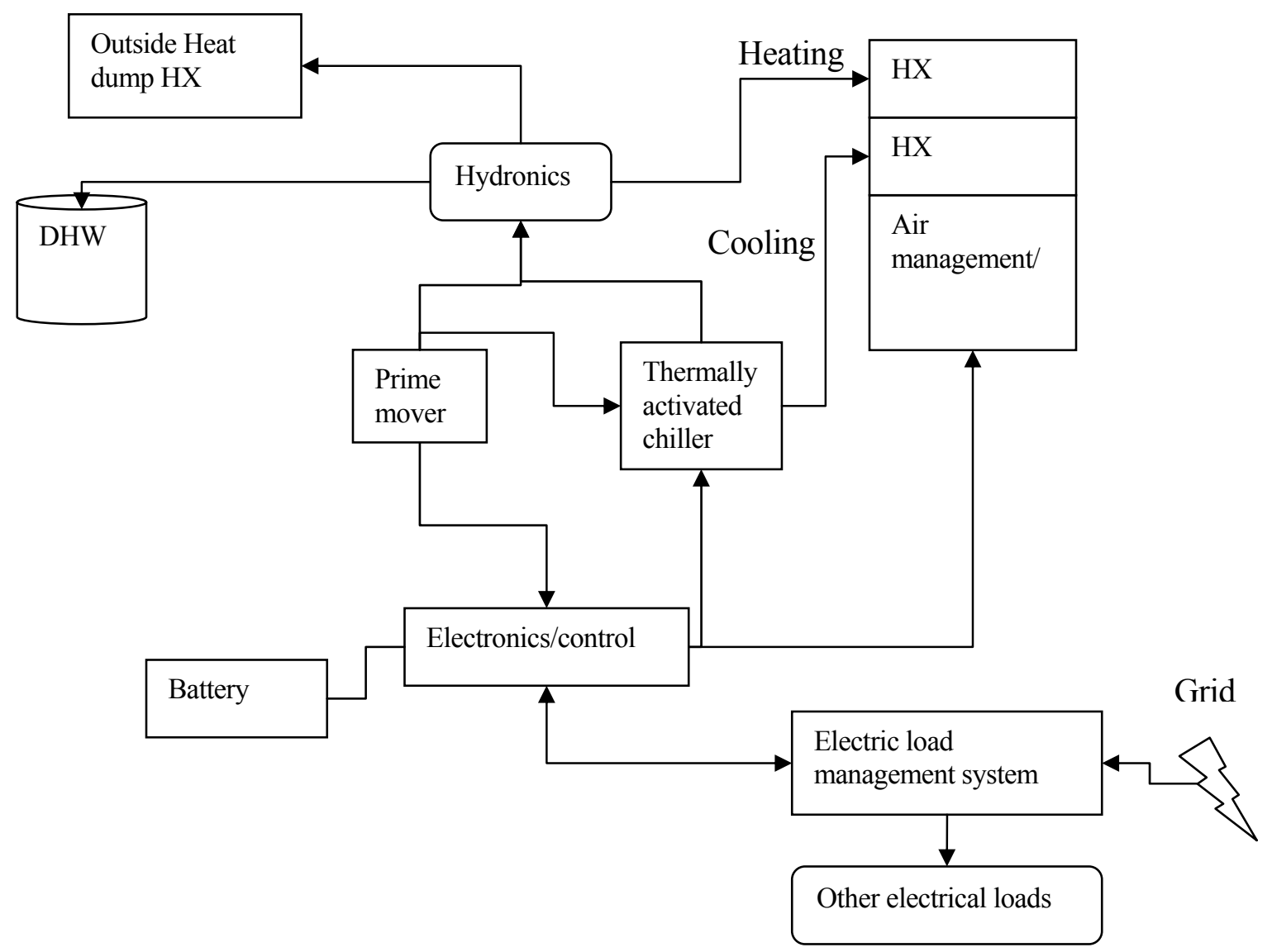

Figure 6-6 Tri-generation solution for southern climate system solution

\subsubsection{Two Versions of Micro-CHP Development}

The analysis results summarized in Section 5.2.3 and the description of the market segments and their needs in Sections 6.1.2 and 6.1.3 suggest that each segment has specific requirements with specific system solutions. From the manufacturer perspective, it is undesirable to develop many versions of similar products in order to maximize market acceptance and to minimize the technical and market risks. It is therefore necessary to group similar versions into a single platform with priority to the largest market segment.

In this context, the system solutions for Northern U.S. regions are:

N1 - Micro-Cogen

N2 - Micro-Trigen

The system solutions for Southern regions are:

S1 - Base Load Co-Generation for Southern Climates

S2 - Tri-generation Solution for Southern Climates 
The N1, N2 and S1 are similar in terms of the exhaust heat utilization and surplus power capability. It is thus preferable to group similar versions such as N1, N2 and S1 into a single platform. The S2 are more distinctive compared to other options and, therefore, are kept as independent versions.

With this in mind, it recommended, that the micro-CHP product development includes two products, micro-Cogen and micro-Trigen. Each of above corresponds to a particular version of micro-CHP product series, as shown in Figure 6-7.

- Version 1: Furnace combined with hot water, essential electrical power, or MicroCogen, which provides integrated space heating and hot water. PM capacity is 2-5 $\mathrm{kW}$ to provide power to essential home electrical circuits during both normal and backup power operation.

- Version 2: Micro-Cogen combined with thermally activated cooling (TAC), essential electrical power, or Micro-Trigen, which provides integrated space heating, space cooling, and hot water. It has a $2-5 \mathrm{~kW}$ prime mover to provide power to essential home electrical circuits during both normal and backup power operation.

The Micro-Cogen (Version 1) is a good starting point for micro-CHP research \& development, since it might be accepted more readily by potential manufacturers and customers, assuming that the cost is within a reasonable range. Adding cooling capability to micro-CHP (Version 2) is a long-term goal in anticipation of future development of cost effective TEG units. The effort will require collaboration of teams of cooling component designers, system integrators, design for manufacturability (DFM) and cost analysts, and a utility or commercialization partner. 


\section{Micro-trigen: Secured Heating +} Essential Electrical Power

- Provides integrated space heating, space cooling, and hot water

- 2 kW PM provides power to essential home electrical circuits during both normal and backup power operation

\section{Micro-cogen: Secured Heating \&} Cooling + Essential Electrical Power

- Provides integrated space heating and hot water

- 2 kW PM provides power to essential home electrical circuits during both normal and backup power operation

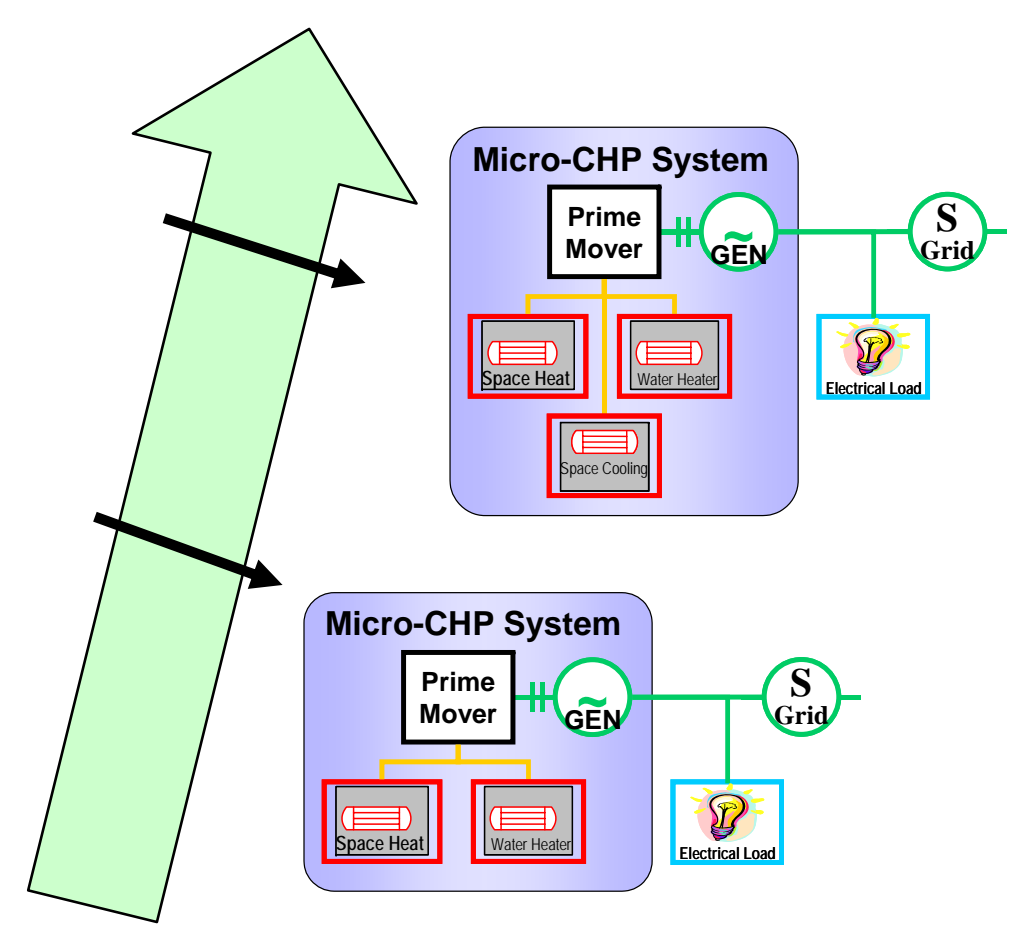

Figure 6-7 Staged Micro-CHP product development plan 


\subsubsection{Common System Components}

The previously described systems share a significant numbers of components that will make it possible to take a platform approach to residential combined heat and power. The micro-CHP systems defined previously include the following major common components /sub-systems:

- $\quad$ Prime mover

- Heat recovery subsystem

- Power interface

- Process air subsystem

- Supplementary burner

The following components/subsystems are a major consideration for the micro-Cogen and microTrigen with regard to both cost and function:

- Dump radiator (for micro-Cogen and micro-Trigen)

- Hot water tank (for micro-Cogen and micro-Trigen)

- TAT chiller (for micro-Trigen)

\subsection{System Development Incentives}

Since micro-CHP products recover the exhaust heat produced during the power generation and convert it to cooling or heating, these systems can always reduce energy consumption when operated correctly following the principles outlined in this report. Compared with the conventional system with back-up power functionality, various micro-CHP products may have instant payback or acceptable payback at optimistic OEM prices and margins in specific regions with favorable utility spark spread.

Capital cost directly affects payback and market size which in turn affects capital cost. Micro-CHP is expected to remain an expensive technology in the early stage of its commercialization. For a new and expensive technology, the market usually will not automatically emerge without external incentives. As the market emerges and the volume increases, production cost reductions will slowly transition micro-CHP to mass-production, which will in turn translate into cost reduction.

In the initial stage, financial incentives are likely to be very helpful for the house owners to consider micro-CHP systems as a viable alternative to traditional residential cooling, heating and power systems because of the high capital cost of the micro-CHP systems. For a micro-Cogen or microTrigen unit, these incentives can be in the form of government rebates or tax credits to the installer or house owner based on a demonstrated level of improvement in energy efficiency, a reduction in overall energy consumption, or economic benefits. Other financial incentives could include guaranteed financing, lease arrangements, or low interest rate loans, provided by either the public or private sector.

Manufacturers and/or research institutes also require incentives to pursue development programs that result in enhanced reliability, improved efficiency and lower cost, making micro-CHP systems 
more attractive to the market. In addition, further investigation is required to define optimum control schemes that will maximize energy savings and improve the economic value proposition. Such development incentives could be in the form of tax credits, government contracts, or research grants. The potential energy savings brought by micro-CHP systems justify such investment of public funding. 


\section{$7 \quad$ Conclusions and Recommendations}

In the context of growing concern over scarcity of energy resources, over increasing pressure to mitigate environmental impact, and in order to comply with the need for more secure comfort for home-owners, integrated micro-CHP system solutions represent an opportunity to answer all these requirements at once.

Recent indicators show the emergence of Combined cooling Heating and Power (CHP) suitable for residential applications (i.e., micro-CHP), which produce less than $10 \mathrm{kWe}$. More than 12,000 micro-CHP systems have been sold worldwide, 4,500 in 2003. The sales in 2004 were estimated to be around 7,500 units, almost exclusively thermally-led combined heating and power systems. Although sales volume is still lagging by 1-2 years relative to earlier market projections, the trends are consistent with these predictions with market growth of over 35\% per year, and a worldwide market of hundreds of thousands units in a five year horizon. The market needs are strongly segmented by geographical regions, the main markets being in Europe (73.5\% in 2004) and in Japan (26.4\% in 2004). The market in North-America is almost non-existent today, with only $0.1 \%$ of the world-wide sales. Early market acceptance requires several key conditions to converge: high energy consumption, high energy expenditure, large spark-spread (i.e., difference between electricity and fuel costs), big-square footage homes, and high income. In hot climate regions the aforementioned characteristics do not converge at this point in time and, therefore, micro-CHP products which include cooling subsystems are not expected to become significant markets, at least in the early stage of the commercialization of micro-CHP products.

Current technology gaps including mainly reliability and system response time and low production volumes constitute important technical and financial hurdles, respectively, to the commercialization of micro-CHP products. With regard to the technical hurdles, the present analysis shows that in order to present a viable alternative to traditional systems for cooling, heating, and power, microCHP system must fulfill the following requirements:

- Provide the same comfort level as existing solutions at any time (e.g., including during power outages), safely, reliably, more efficiently, and by complying with existing emission and regulatory standards.

- Reached a technology readiness level where the major risks have been eliminated.

All the above conditions need to be fulfilled while meeting the customer economic acceptance criteria. For power generation, Thermoelectric Generators (TEG) is suited for very low power, Internal Combustion (IC) engine and Stirling generators for mid to high power systems. High first cost and low technology readiness level make fuel cell less attractive at present, although their efficiency are unequaled and could make them a game changer at some point in time. For heating, traditional heat exchangers coupled with combustion and prime movers waste heat are used and are fully mature technology. For cooling, LiBr absorption chillers are currently the best suited and should be preferred over vapor compression systems as they better utilize the waste heat from the prime movers than by just using the electricity produced by the PM to drive a compressor. 
A multiple stage development plan has been defined to address the risk mitigation. These stages include concept development and supplier engagement, component development, system integration, system demonstration, and field trials.

The proposed micro-CHP market strategic development roadmap is staged in order to increase the likelihood of success. The objective of the first stage is to gain early market acceptance. This strategic market and product development roadmap leverages product commonalities in order to better accommodate interchangeability of components and sub-systems such as prime movers.

- Version 1: Furnace + Hot water + Essential Electrical Power, or Micro-Cogen, which provides integrated space heating and hot water. It has a 2-5 $\mathrm{kW}$ PM to provide power to essential home electrical circuits during both normal and backup power operation. The suggested PM is a $2 \mathrm{kWel}$ Stirling engine.

- Version 2: Micro-Cogen + Thermally Activated Cooling (TAC) + Essential Electrical Power, or Micro-Trigen, which provides integrated space heating, space cooling, and hot water. It has a 2-5 kW PM to provide power to essential home electrical circuits during both normal and backup power operation. The suggested PM is a $2 \mathrm{kWe}$ Stirling engine and the TAC is a $14 \mathrm{~kW} \mathrm{LiBr}$ absorption chiller.

Paybacks are acceptable for the Micro-Cogen version. However, there is no clear economically viable path for a Micro-Trigen version with today's available technology.

With regard to the initial financial hurdle, this analysis suggests that the establishment of a microCHP market in the U.S. will occur in several steps, will require strategic alliances and partnerships between OEMs and suppliers, between OEMs, utility companies and distributors, and will initially need support, via incentives to home owners and to manufacturers, from federal/state government authorities, and/or utility companies It is important to recognize that the adaption of the public to Micro-CHP technology will take time. The idea of paying a premium to ensure house comfort and/or freeze protection while saving energy, reducing emissions and operating cost, will be gradually understood and accepted by the public as an important element in the complex comfortsafety-environment-cost equation. In the initial stage of micro-CHP commercialization, financial incentives to the home owners will help create the necessary conditions for sales volume that will catalyze the transition to mass-production and cost reduction. Incentives to the manufacturers will help improve product performance and efficiency, enhance reliability, and lower cost, thereby, making micro-CHP products more attractive.

Successful development of a micro-CHP system for residential applications has the potential to provide significant benefits to users, customers, manufacturers, and suppliers of such systems and in general, to the nation as a whole. The benefits to the ultimate user are a comfortable and healthy home environment at an affordable cost, potential utility savings, and a reliable supply of energy. Manufacturers, component suppliers, and system integrators will see growth of a new market segment for energy products. The benefits to the nation include significantly increased energy efficiency, reduced consumption of fossil fuels, reduced pollutant and $\mathrm{CO}_{2}$ emissions from power generation, enhanced security from power interruptions as well as enhanced economic activity and job creation. An integrated CHP energy system provides advantages over conventional power generation, since the energy is used more efficiently through means such as heat recovery. Foreign companies are readily selling products, mostly in Europe and it is urgent to react promptly to this 
offer that will soon emerge on the U.S. market otherwise. For all these reasons, UTC urges the U.S. Department of Energy to fund the Phase II Development Program in the nation's interest. 


\section{Appendix}

\subsection{Glossary:}

- CDD (Cooling Degree Day): used to estimate how hot the climate is and how much energy may be needed to keep buildings cool. CDDs are calculated by subtracting a balance temperature from the mean daily temperature, and summing only positive values over an entire year. The balance temperature used can vary, but is usually set at $65^{\circ} \mathrm{F}\left(18^{\circ} \mathrm{C}\right), 68^{\circ} \mathrm{F}$ $\left(20^{\circ} \mathrm{C}\right)$, or $70^{\circ} \mathrm{F}\left(21^{\circ} \mathrm{F}\right)$.

(Source: http://www.epa.gov/heatisland/resources/glossary.html)

- HDD (Heating Degree Day): used to estimate how cold the climate is and how much energy may be needed to keep buildings warm. HDDs are calculated by subtracting the mean daily temperature from a balance temperature, and summing up only positive values over an entire year. The balance temperature used can vary, but is usually set at $65^{\circ} \mathrm{F}\left(18^{\circ} \mathrm{C}\right), 68^{\circ} \mathrm{F}\left(20^{\circ} \mathrm{C}\right)$, or $70^{\circ} \mathrm{F}\left(21^{\circ} \mathrm{F}\right)$.

(Source: http://www.epa.gov/heatisland/resources/glossary.html)

- Electric efficiency of a prime mover: defined as the electric output divided by the fuel heat input to the prime mover.

- Equivalent electric efficiency of a CHP system: defined in this report as the system electric output divided by the differential fuel heat input compared to a conventional system. For example, if the heating load $Q_{h}$ is $9 \mathrm{~kW}$ for a building and the conventional system has a thermal efficiency $\eta_{t h}$ of $90 \%$, the system needs fuel heat input $Q_{f, c o n v}$ is:

$$
Q_{f, \text { conv }}=Q_{h} / \eta_{\text {th }}=9 / 0.9=10(\mathrm{~kW})
$$

If a CHP system is used in which the prime mover efficiency $\eta_{e l e}^{P M}$ of $10 \%$ and if the electric output $P$ is $\mathbf{2} \mathbf{k W}$, the fuel heat input $Q_{f, C H P}$ is

$$
Q_{f, C H P}=P / \eta_{\text {ele }}^{P M}=2 / 0.1=20(\mathrm{~kW})
$$

The waste heat from power generation $Q_{w h}$ is

$$
Q_{w h}=Q_{f, C H P}-P=20-2=18(k W)
$$

Since the heating load $Q_{h}$ is only $9 \mathrm{~kW}$, the rest, in the amount of

$$
Q_{\text {loss }}=Q_{w h}-Q_{h}=18-9=9(\mathrm{~kW})
$$

will be discharged or dissipated to the ambient. The differential fuel heat input in the CHP system compared to a conventional system is: 


$$
\Delta Q_{f}=Q_{f, C H P}-Q_{f, \text { conv }}=20-10=10(\mathrm{~kW})
$$

The equivalent electric efficiency $\eta_{\text {ele }}^{C H P}$ of the system is therefore

$$
\eta_{\text {ele }}^{\text {CHP }}=\frac{P}{\Delta Q_{f}}=\frac{2}{10}=0.2
$$

which is higher than actual prime mover efficiency $\eta_{e l e}^{P M}$ of $10 \%$ as a result of waste heat utilization.

- HSPF (Heating Seasonal Performance Factor): a measure of a heat pump's energy efficiency over one heating season. It represents the total heating output of a heat pump (including supplementary electric heat) during the normal heating season (in Btu) as compared to the total electricity consumed (in Watt-hours) during the same period. HSPF is based on tests performed in accordance with U.S. Department of Energy (DOE) test procedures found in 10 CFR 430 Appendix M to subpart B.

(Source: http://www.energystar.gov/index.cfm?c=airsrc_heat.pr_crit_as_heat_pumps)

- SEER (Seasonal Energy Efficiency Ratio): a measure of equipment energy efficiency over the cooling season. It represents the total cooling of a central air-conditioner or heat pump (in Btu) during the normal cooling season as compared to the total electric energy input (in watthours) consumed during the same period. SEER is based on tests performed in accordance with DOE test procedures found in 10 CFR 430 Appendix M to subpart B. (Source: http://www.energystar.gov/index.cfm?c=airsrc heat.pr_crit_as_heat_pumps)

- Spark spread: The difference between the price of electricity sold by a generator and the price of the fuel used to generate it, adjusted for equivalent units. The spark spread can be expressed in $\$ / M W h$ or $\$ / M M B m$ (or other applicable units). To express in $\$ / M W h$, the spread is calculated by multiplying the price of gas, for example (in $\$$ MMMBtu), by the heat rate (in Btu/KWh), dividing by 1,000, and then subtracting the electricity price (in \$/MWh) (Source: http://www.riskwaters.com/guides/engloss/eprmgloss.htm )

- System energy efficiency: a gross energy utilization ratio, defined in this report as the sum of all useful energy output in $\mathrm{kW}$, including electric and heating output, divided by the total system fuel heat. Fuel high heating value is used in this study, unless noted otherwise. Heating output is the total heat required for space heating, domestic hot water and thermally activated cooling. 


\section{$9 \quad$ References}

1. "A New Look at an Old Idea The Electromechanical Battery." Science and Technology Review, Apr. 1996: 13-19.

2. Advanced Locomotive Propulsion System-Technology Prospectus." Center for Electromechanics, The University of Texas at Austin. 19 Mar. 2004 http://www.utexas.edu/research/cem/programs/ALPS_TechProspect.html.

3. "An Introduction to Distributed Generation Interconnection" U.S. Department of Energy, State of Wisconsin Division of Energy, Alliant Energy, and Unison Solutions, June 2004 http://www.eere.energy.gov/de/pdfs/dist_gen_interconn.pdf

4. "Documents and Presentations." 2004. Beacon Power Corporation. 19 Mar. 2004 http://www.beaconpower.com/products/EnergyStorageSystems/AboutFlywheels/papers.htm

5. "Energy Conservation through Energy Storage." 18 Feb. 2003. International Energy Agency. 19 Mar. 2004 http://www.energy-storage.org/techniques/techniques.html.

6. "Innovative PCM's and Thermal Technology." 10 Nov. 2002. Rubitherm Phase Change Material. 19 Mar. 2004 http://www.rubitherm.de/.

7. "Integrated Energy Systems (IES) for Buildings: A Market Assessment." Resource Dynamics Corporation for U.S. DoE Energy Efficiency and Renewable Energy an Oak Ridge National Laboratory. Aug. 2002: 1-2 and 1-3.

8. "Integrated Energy Systems (IES) for Buildings: A Market Assessment." Resource Dynamics Corporation for U.S. DoE Energy Efficiency and Renewable Energy an Oak Ridge National Laboratory. Aug. 2002: 1-2 and 1-3.

9. "Investigation into Distributed Resources in Texas, 1999 Interconnection Guidelines for Distributed Generation in Texas", Project No. 20363, Public Utility Commission of Texas, Office of Policy Development, February 16, 1999, http://www.puc.state.tx.us/electric/projects/20363/guidlns.cfm

10. "Latent Heat Storage Unit in Heating Ventilating and Air Conditioning: A technical Evaluation.” Rubitherm Phase Change Material. 9 Oct. 2001.

11. "Markets Energize For New Energy Storage Techniques." Business Communications Company, Inc. May 2001 http://www.bccresearch.com/editors/RE-086.html.

12. "MicroPower Connect Interconnection Guideline - For inverter based micro-distributed resource (DR) systems connected to 600 volt or less distribution systems", MicroPower Connect (Canada), June 16, 2003 http://www.micropower-connect.org/

13. "News Release." 3 Oct. 2003. JEOL Ltd. 18 Mar. 2004 http://www.jeol.co.jp/english/newsroom/2003/031003.htm.

14. "Next Generation Microturbine: Market Analysis and Equipment Optimization." United Technologies Research Center for Oak Ridge National Laboratory. 19 Dec. 2003.

15. 'Next Generation Microturbine: Market Analysis and Equipment Optimization." United Technologies Research Center for Oak Ridge National Laboratory. 19 Dec. 2003. 
16. "PlusICETM Eutectic \& PCM Solutions." Environmental Process Systems Limited. 17 Mar. 2004 http://www.epsltd.co.uk.

17. "PlusICETM Thermal Energy Storage Design Guide." Environmental Process Systems Limited.

18. "Power Technologies 2003 Databook." 2003. U.S. DOE National Renewable Energy Laboratory. 19 Mar. 2004 http://www.nrel.gov/analysis/power_databook/hardcopy.asp.

19. "Power Technologies 2003 Databook." 2003. U.S. DOE National Renewable Energy Laboratory. 19 Mar. 2004 http://www.nrel.gov/analysis/power_databook/hardcopy.asp.

20. "Powering Future Vehicles with the Refuelable Zinc/Air Battery." Science and Technology Review, Oct. 1995: 7-13. 22 Mar. 2004 http://www.1lnl.gov/str/pdfs/10 95.1.pdf.

21. "Problems and Solutions." 2001. eVonyx, Inc. 17 Mar. 2004 http://www.evonyx.com/solutions.htm.

22. "Problems and Solutions." 2001. eVonyx, Inc. 17 Mar. 2004 http://www.evonyx.com/solutions.htm.

23. "RE Storage The Missing Link." 2002. Elsevier Advanced Technology. 17 Mar. 2004 http://www.re-focus.net/mar2002 4.html.

24. "RE Storage The Missing Link." 2002. Elsevier Advanced Technology. 17 Mar. 2004 http://www.re-focus.net/mar2002 4.html.

25. "Technologies \& Applications." 2003. Electricity Storage Association, Inc. 17 Mar. 2004 http://www.energystorage.org/tech/technologies comparisons.htm.

26. "The Market and Technical Potential for Combined Heat and Power in the Commercial/Institutional Sector.” Onsite Sycom Energy Corporation for U.S. DoE Energy Information Administration. Jan. 2000.

27. "The Market and Technical Potential for Combined Heat and Power in the Commercial/Institutional Sector.” Onsite Sycom Energy Corporation for U.S. DoE Energy Information Administration. Jan. 2000.

28. "The world's lightest 4-stroke outboard, the Honda BF2D, is a heavyweight performer" http://www.tackletour.com/reviewhondabf2d.html

29. "Thermal Energy Storage for Space Cooling." Federal Energy Management Program. Dec. 2000: 15 .

30. "Thermal Energy Storage Strategies for Commercial HVAC Systems.” May 1997. Pacific Gas and Electric Company. 19 Mar. 2004

http://www.pge.com/003_save_energy/003c_edu train/pec/info_resource/pdf/THRMSTOR. $\underline{\text { PDF. }}$

31. "Triathlonz Energy Powered by Zoxy." Zoxy Energy Systems AG. 17 Mar. 2004 http://212.227.185.174/en/seite.php?seite=/en/produkte/seite.htm.

32. "Triathlonz Energy Powered by Zoxy." Zoxy Energy Systems AG. 17 Mar. 2004 http://212.227.185.174/en/seite.php?seite=/en/produkte/seite.htm. 
33. A.C.S. Hayden, 'Choosing a Heating System That Saves Energy', Home Energy Magazine Online March/April 1996, http://hem.dis.anl.gov/eehem/96/960309.html

34. American Stirling Company, October 20, 2004, http://www.stirlingengine.com/FullPower.adp

35. American Stirling Company, October 20, 2004, http://www.stirlingengine.com/FullPower.adp

36. ASHRAE 2001 Fundamentals Handbook, Chapter 22

37. ASHRAE 2001 Fundamentals Handbook, Chapter 22

38. Atcitty, Stan, Satish Ranade, and Amber Gray-Fenner. "Summary of State-of-the-Art Power Conversion Systems for Energy Storage Applications." Sandia National Laboratory Report SAND98-2019. Sep. 1998.

39. B. Brooks, Distributed Generation Codes and Standards, 'Overview of Interconnection Issues', Proceedings of the Workshop on Interconnecting Distributed Energy December, 2001, Honolulu, Hawaii, http://www.state.hi.us/dbedt/ert/icw/brooks/brooks.html

40. B. Patel and J. Daley, 'Connected Backup Power Systems Help Smooth the Road to Distributed Generation', Energy \& Power Management, November 2000, http://energyusernews.com/CDA/ArticleInformation/features/BNP_Features_Item/0,2584, 14487,00.html

41. Beckard, Christer, Troman, Mark, \& Marsh, Andrew, Munters: Cool Company But Valuation Overheated, Merrill Lynch Global Securities Research and Economic Group, October 13, 2003, RC\#60128701

42. Beckard, Christer, Troman, Mark, \& Marsh, Andrew, Munters: Cool Company But Valuation Overheated, Merrill Lynch Global Securities Research and Economic Group, October 13, 2003, RC\#60128701

43. Biomass Combustion and Cofiring, October 20, 2004, http://www.ieabcc.nl/overview/powergeneration.html

44. Biomass Combustion and Cofiring, October 20, 2004, http://www.ieabcc.nl/overview/powergeneration.html

45. Bowler, Michael. "Flywheel Energy Systems: Current Status and Future Prospects." Magnetic Material Producers Association Joint Users Conference. 22-23 Sep. 1997.

46. Bradshaw, Dale T. "IEEE PES Meeting on Energy Storage.” Energy Research and Technology Applications. 19 Mar. 2004 http://www.electricitystorage.org/pubs/2000/summer2000/PHS-CAES.pdf.

47. C. Larsen and C. Cook, 'Connecting to the Grid - A Guide to Distributed Generation Interconnection Issues', Interstate Renewable Energy Council (IREC), Fourth Edition, 2004

48. California Distributed Energy Resource Guide, ' Interconnect Equipment', California Energy Commission (CEC), http://www.energy.ca.gov/distgen/interconnection/equipment.html 
49. California Distributed Energy Resource Guide, October 20, 2004 http://www.energy.ca.gov/distgen/equipment/stirling_engines/stirling engines.html

50. California Distributed Energy Resource Guide, October 20, 2004 http://www.energy.ca.gov/distgen/equipment/fuel_cells/fuel_cells.html

51. California Distributed Energy Resource Guide, October 20, 2004 http://www.energy.ca.gov/distgen/equipment/reciprocating_engines/reciprocating_engines.h $\underline{\mathrm{tml}}$

52. California Distributed Energy Resource Guide, October 20, 2004 http://www.energy.ca.gov/distgen/equipment/microturbines/microturbines.html

53. California Distributed Energy Resource Guide, October 20, 2004 http://www.energy.ca.gov/distgen/equipment/stirling engines/stirling engines.html

54. California Distributed Energy Resource Guide, October 20, 2004 http://www.energy.ca.gov/distgen/equipment/fuel_cells/fuel_cells.html

55. California Distributed Energy Resource Guide, October 20, 2004 http://www.energy.ca.gov/distgen/equipment/reciprocating_engines/reciprocating engines.h $\underline{\mathrm{tml}}$

56. California Distributed Energy Resource Guide, October 20, 2004 http://www.energy.ca.gov/distgen/equipment/microturbines/microturbines.html

57. Certification of Grid-Connected Distributed Energy Resources, Project Opportunity, EPRIPEAC, http://www.epri-peac.com/project_opportunities/cert_grid_conn.html

58. Charles J. Cromer and Arthur D. Hallstrom, Cromer Cycle Desiccant-based Combined System, Integrated Energy Systems Peer Review, May 2002, Nashville, Tennessee

59. Charles J. Cromer and Arthur D. Hallstrom, Cromer Cycle Desiccant-based Combined System, Integrated Energy Systems Peer Review, May 2002, Nashville, Tennessee

60. Cooling, Heating and Power Systems Evaluation Tasks for Energy Storage, Micro Grids and Desiccant Systems, Volume IV - Desiccant Systems Evaluation, March 2004, under Capstone Turbine Corporation Subcontract No. 4000009920 with Oak Ridge National Laboratory

61. Cooling, Heating and Power Systems Evaluation Tasks for Energy Storage, Micro Grids and Desiccant Systems, Volume IV - Desiccant Systems Evaluation, March 2004, under Capstone Turbine Corporation Subcontract No. 4000009920 with Oak Ridge National Laboratory

62. Cullen, R. "N.A. Industrial Battery Forecast." Battery Council International. May 2003.

63. D. Dempsey, Carrier, e-mail correspondence, June 20, 2005

64. D. Reicher, C. Curtis, and J. McNamara, 'Unraveling the Mystery of Grid Interconnection', Energy \& Power Management, http://www.energyusernews.com/CDA/ArticleInformation/features/BNP_Features_ Item/0 ,2584,106042,00.html 
65. D.T. Allen and W.Ch. Mallon, 'Further Development of "Self-Powered Boilers", IEEE 18th International Conference on Thermoelectrics, 1990, pp 80-83

66. Distributed Generation: System Interfaces', An Arthur D. Little White Paper, 1999 http://www.encorp.com/dwnld/pdf/whitepaper/ADLittleWhitePaperDGSystemInterfaces.pdf

67. DOE 2001 Residential Energy Consumption Survey (RECS) http://www.eia.doe.gov/emeu/recs/contents.html

68. DOE document, October 20, 2004, http://www.eere.energy.gov/buildings/appliance_standards/residential/pdfs/05.pdf

69. DOE document, October 20, 2004, http://www.eere.energy.gov/buildings/appliance_standards/residential/pdfs/05.pdf

70. Douglas Crane, Potential Thermoelectric Applications in Diesel Vehicles, DEER Conference, Newport, RI, August 25, 2003

71. Douglas Crane, Potential Thermoelectric Applications in Diesel Vehicles, DEER Conference, Newport, RI, August 25, 2003

72. DSIRE - Database of State Incentives for Renewable Energy, http://www.dsireusa.org/index.cfm

73. Emerging Technologies and Practices: 2004 ACEEE, October 20, 2004, http://www.aceee.org/pubs/a042_plb.pdf

74. Emerging Technologies and Practices: 2004 ACEEE, October 20, 2004, http://www.aceee.org/pubs/a042 p1b.pdf

75. Energy Information Administration, Electric Power Monthly, August 2004

76. Energy Information Administration, Natural Gas Monthly, July 2004

77. Energy Information Administration, Natural Gas Annual, 2002 Single Cooling, Heating and Power Performance Metric and Energy Savings Assessment.

78. Energy Information Administration, Natural Gas Monthly, July 2004

79. Energy-10 Developer's home page: http://www.nrel.gov/buildings/energy10/

80. Enibe, S. O., Iloeje, O. C., COSSOR - a transient simulation program for a solid absorption solar refrigerator, Renewable Energy, 2000, 19: 413-434

81. Enibe, S. O., Iloeje, O. C., COSSOR - a transient simulation program for a solid absorption solar refrigerator, Renewable Energy, 2000, 19: 413-434

82. Fairey, P., D.S. Parker, B. Wilcox and M. Lombardi, "Climate Impacts on Heating Seasonal Performance Factor (HSPF) and Seasonal Energy Efficiency Ratio (SEER) for Air Source Heat Pumps." ASHRAE Transactions, American Society of Heating, Refrigerating and Air Conditioning Engineers, Inc., Atlanta, GA, June 2004. http://www.fsec.ucf.edu/bldg/pubs/hspf/

83. Federal Energy Regulatory Commission (FREC), 'Commission Issues Standard Rule For Small Generator Interconnection, FERC Press Release, May 12, 2005 
84. Frost \& Sullivan report, North American Generator Set Market Update, \#A818-14, 2004

85. Frost \& Sullivan report, North American Generator Set Markets - Total Market Update, \#A818-14, 2003

86. Frost \& Sullivan, European Micro CHP Systems Market, A3890-14, 2001

87. GBU Adsorption Chiller, NAK, October 20, 2004 http:/www.gbunet.de/outgoing/nakprospect-e.pdf

88. GBU Adsorption Chiller, NAK, October 20, 2004 http://www.gbunet.de/outgoing/nakprospect-e.pdf

89. GeneratorJoe, Comparison of categories between portable and stationary genertors for home standby use, October 20, 2004, http://www.generatorjoe.net/page.asp?id=60

90. GeneratorJoe, Comparison of categories between portable and stationary genertors for home standby use, October 20, 2004, http://www.generatorjoe.net/page.asp?id=60

91. Global Thermoelectric, October 20, 2004, http://www.globalte.com/reasons.html

92. Guardian standby power quote from NexTag, October 20, 2004, http://www.nextag.com/serv/main/buyer/outpdir.jsp?nxtg=25a542 348F53AC278F9259\&se $\underline{\text { arch }=\text { guardian }+ \text { generator } \& \text { node }=2700400}$

93. Guardian standby power quote from NexTag, October 20, 2004, http:/www.nextag.com/serv/main/buyer/outpdir.jsp?nxtg=25a542 348F53AC278F9259\&se arch $=$ guardian + generator $\&$ node $=2700400$

94. Herbst, J.D., R.F. Thelen, and W.A. Walls. "High Speed Ground Transportation Association (HSGTA) Conference 2000.” Phiadelphia, PA. 10-13 May 2000.

95. HIJU Inc, October 20, 2004, http://www.adsorptionchiller.bigstep.com/homepage.html

96. HIJU Inc, October 20, 2004, http://www.adsorptionchiller.bigstep.com/homepage.html

97. Hi-Z technology, October 20, 2004, http://www.hi-z.com/websit07.htm

98. Hi-Z technology, October 20, 2004, http://www.hi-z.com/websit07.htm

99. Honda Eu1000i (1.8hp, $1 \mathrm{~kW}$ portable) produces $59 \mathrm{~dB}$ at 7 meters away http://www.hondapowerequipment.com/gensup.asp

100. http://comptune.com/tincan.htm, September 5, 2004

101. http://comptune.com/tincan.htm, September 5, 2004

102. http://electron9.phys.utk.edu/phys136d/modules/m3/images/twopstill.gif, October 20, 2004

103. http://electron9.phys.utk.edu/phys136d/modules/m3/images/twopstill.gif, October 20, 2004

104. Huang, J. and E. Franconi. "Commercial Heating and Cooling Loads Component Analysis." Building Technologies Department, Environmental Energy Technologies Division, Lawrence Berkeley National Laboratory. Nov. 1999.

105. Huang, J. and E. Franconi. "Commercial Heating and Cooling Loads Component Analysis." Building Technologies Department, Environmental Energy Technologies Division, Lawrence Berkeley National Laboratory. Nov. 1999. 
106. IEEE (The Institute of Electrical and Electronics Engineers), Standards Coordinating Committee 21 web site, http://grouper.ieee.org/groups/scc21/index.html

107. IEEE Standard 1547, IEEE Standard for Interconnecting Distributed Resources with Electric Power Systems, Standards Coordinating Committee 21, The Institute of Electrical and Electronics Engineers, (IEEE), 1547-2003, 28 July 2003

108. J.D. Churchill, 'Multiple Service Load Solid State Switching for Controlled Cogeneration System', U.S. Patent 5,536,976, Gas Research Institute, July 16, 1996

109. J.M. Daley 'Distributed Generation Interconnection Equipment Suitable for its intended Service', http://www.energetics.com/MADRI/pdfs/062305 daley.pdf, 2005

110. Kessling, Laevemann, and Peltzer. "Energy Storage In Open Cycle Liquid Desiccant Cooling Systems.” International Journal of Refrigeration, Vol 21 No 2 1998: 150-156.

111. Khufhair, A. and M. Farid. "A Review on Energy Conservation in Building Applications with Thermal Energy Storage by Latent Heat Using Phase Change Materials.” Energy Conversion \& Management, 45 (2004): 263-275.

112. Lazarewicz, Matt. "A Description of the Beacon Power High Energy and High Power Composite Flywheel Energy Storage Systems." White Paper, Beacon Power Corp.

113. Linden, D. and T.B. Reddy. Handbook of Batteries. New York: McGraw-Hill, 2002, Third Edition.

114. M. Davis (Chair), 'Edison Electric Institute - Distributed Resources Task Force Interconnection Study', Edison Electric Institute, June 2000

115. MacCracken, Mark M. “Application Series: Supplementing DG with Thermal Energy Storage.” DG Monitor Nov./Dec. 2003: 3.

116. MacCracken, Mark M. "Thermal Energy Storage Myths.” ASHRAE Journal Sep. 2003: 36-43.

117. Mohan, N., T.M. Undeland, and W.P. Robbins. Power Electronics: Converters, Applications and Design. New York: Prentice Hall, 1997.

118. Morrison, David G. and Lisa Eccles. "HEV Battery Research Rolls On.” Electronic Design. 8 Jan. 2001. Penton Media, Inc. 17 Mar. 2004 http://www.elecdesign.com/Articles/Index.cfm?ArticleID=4332.

119. Natural Gas Applications in Business \& Industry, 'Interconnect Standards Are Key to Distributed Generation', http://www.energysolutionscenter.org/resources/PDFs/GT_S03_Interconnect_Standards.pdf

120. NFPA 70 (National Fire Protection Association), National Electrical Code, 2002 Edition

121. Oak Ridge National Lab, Large Commercial Chillers, October 20, 2004, http://www.ornl.gov/sci/btc/apps/lgcmlch.html

122. Oak Ridge National Lab, Large Commercial Chillers, October 20, 2004, http://www.ornl.gov/sci/btc/apps/lgcmlch.html 
123. Onsite Energy Corporation, 'Assessment of On-Site Power Opportunities in the Industrial Sector', Prepared for: Oak Ridge National Laboratory, March 2001 http://www.nemw.org/uschpa/MktAssessIndustrialMar01.pdf

124. Platts Research \& Consulting, Micro-CHP: Coming to a Home near You?, MCS-04-1AMCHP, June 2004

125. R.Z. Wang, M. Li, Y.X. Xu, J. Y. Wu. An energy efficient hybrid system of solar powered water heater and adsorption ice maker. Solar Energy, 2000, 68(2):189-195.

126. R.Z. Wang, M. Li, Y.X. Xu, J. Y. Wu. An energy efficient hybrid system of solar powered water heater and adsorption ice maker. Solar Energy, 2000, 68(2):189-195.

127. Rix, D.H., Some aspects of the outline design specification of a $0.5 \mathrm{~kW}$ Stirling engine for domestic scale co-generation, Proc Instn Mech Engrs Vol 210, pp 25-33, 1996

128. Rojas, Alex. 'Flywheel Energy Matrix systems - Today’s Technology Tomorrow's Energy Solution." White Paper, Beacon Power Corp.

129. S.E. Adams III, P.J. Gregory, M.L. Marleau and J. Whitham, "Utility Management of Distributed Energy Resources” Draft Version, April 10, 1997

130. Schoenung, S. M., "Characteristics and Technologies for Long- vs. Short-Term Energy Storage A Study by the DOE Energy Systems Program.” Sandia National Laboratory Report 2001-0765. Mar. 2001.

131. Shelter Products Northwest, Inc, October 20, 2004 http://www.spnwsupply.com/L4-systems/hydronicforcedair.html

132. Shelter Products Northwest, Inc, October 20, 2004 http://www.spnwsupply.com/L4-systems/hydronicforcedair.html

133. Smarterway Inc., October 20, 2004, http://www.smarterwayinc.com/

134. Smarterway Inc., October 20, 2004, http:/www.smarterwayinc.com/

135. Stanton, W., J. Saliba, S. Piela. "Flywheel Energy Storage System Beta Site Testing." White Paper, Beacon Power Corp. 1999.

136. Stirling Energy Systems, http://www.stirlingenergy.com/solar_overview.htm, October 20, 2004

137. Stirling Energy Systems, http://www.stirlingenergy.com/solar overview.htm, October 20, 2004

138. T. Ackermann, 'Distributed Resources in a Re-Regulated Market Environment', Doctoral Thesis, Royal Institute of Technology, Stockholm, Sweden, May 2004

139. T. Basso and R. DeBlasio, 'IEEE 1547 Series of Standards: Interconnection Issues' Preprint, National Renewable Energy Laboratory, NREL/JA-560-34882, September 2003

140. T. Basso, 'IEEE 1547 Interconnection Standards', IEEE Std 1547 (2003), IEEE PES Meeting June 9, 2004, http://www.nrel.gov/eis/pdfs/interconnection_standards.pdf

141. T. Bronson, 'Grid Interconnection / Utility Tariffs: Issues and Solutions, Distributed Energy Center, GTI, presented at FEMP DER WORKSHOP, Chicago, June 25, 2002 
142. T.J. Starrs, 'Net Metering - New Opportunities for Home Power', Solstice, 1996, http://www.crest.org/repp_pubs/pdf/issuebr2.pdf

143. Takuma microturbine introduction, October 20, 2004, http://www.takuma.co.jp/microturbine-e.html

144. Takuma microturbine introduction, October 20, 2004, http://www.takuma.co.jp/microturbine-e.html

145. Taylor, P., P. Butler, et. al. "A Summary of the State of the Art of SMES, FES, and CAES Systems.” Sandia National Laboratory Report SAND99-1854. Jul. 1999.

146. Taylor, P., P. Butler, et. al. "A Summary of the State of the Art of SMES, FES, and CAES Systems.” Sandia National Laboratory Report SAND99-1854. Jul. 1999.

147. The SolarServer, October 20, 2004 http://www.solarserver.de/solarmagazin/artikel_april2001-e.htm

148. The SolarServer, October 20, 2004 http://www.solarserver.de/solarmagazin/artikel april2001-e.htm

149. The United States Department of Energy, Office of Energy Efficiency and Renewable Energy, 'The Micro-CHP Technologies Roadmap - Meeting 21st Century Residential Energy Needs', Based on the Results of the Micro-CHP Technologies Roadmap Workshop, June 11-12, 2003, Greenbelt, Maryland, December 2003, http://www.eere.energy.gov/de/pdfs/micro_chp_roadmap.pdf

150. U.S. Department of Energy, Office of Energy Efficiency and Renewable Energy, Office of Fossil Energy, ' Strategic Plan for Distributed Energy Resources, September 2000 http://www.eere.energy.gov/de/pdfs/de_program_plan.pdf

151. UL 1741, The Second Edition of the Standard for Inverters, Converters, and Controllers for Use in Independent Power Systems, Underwriters Laboratories, November 1, 2002

152. UL 1741, Underwriters Laboratories, Inc., Tests conducted, http://www.ul.com/dge/inverters/tests.html

153. UL 1995 Heating and Cooling Equipment, Underwriters Laboratories, Third Edition, February 18, 2005

154. Underwriters Laboratories - Streamlining Interconnection, U.S. Department of Energy Distributed Energy \& Electric Reliability - Fact Sheet, January 2003 http://www.nrel.gov/docs/fy04osti/35051.pdf

155. Underwriters Laboratories, Inc., Submittal Process, http://www.ul.com/services/submittal.html

156. United States Combined Heat \& Power Association, 'Combined Heat and Power (CHP) -A Vision for the Future of CHP in the U.S. in 2020', Based On Discussions at the CHP Vision Workshop, Washington, D.C., September 1999

157. US Department of Energy, Energy Efficiency and Renewable Energy, October 20, 2004 http://www.eere.energy.gov/de/technologies/det thermal_tech_proj_chiller.shtml 
158. US Department of Energy, Energy Efficiency and Renewable Energy, October 20, 2004 http://www.eere.energy.gov/de/technologies/det thermal tech_proj_chiller.shtml

159. US Energy Information Administration, October 20, 2004 http://www.eia.doe.gov/cneaf/solar.renewables/page/solarthermal/solarthermal.html

160. US Energy Information Administration, October 20, 2004 http://www.eia.doe.gov/cneaf/solar.renewables/page/solarthermal/solarthermal.html

161. UTC Internal Correspondences

162. R. van der Woude et al, "INTERMEDIATE RESULTS OF THE ENATECH MICRO COGENERATION SYSTEM FIELD TRIALS", Presented at the International Stirling Forum 2004 Osnabruck, Germany May 5-7, 2004 